FY 2006

\title{
DEVELOPMENT OF A NOVEL BI-DIRECTIONAL ISOLATED MULTIPLE-INPUT DC-DC CONVERTER
}

Prepared by:

Oak Ridge National Laboratory

Mitch Olszewski, Program Manager

Submitted to:

Energy Efficiency and Renewable Energy

FreedomCAR and Vehicle Technologies

Vehicle Systems Team

Susan A. Rogers, Technology Development Manager

October 2005 


\author{
OAK RIDGE \\ NATIONAL LABORATORY \\ MANAGED BY UT-BATTELLE \\ FOR THE DEPARTMENT OF ENERGY
}

\author{
DEVELOPMENT OF A \\ NOVEL BI-DIRECTIONAL ISOLATED \\ MULTIPLE-INPUT DC-DC CONVERTER \\ Hui Li \\ Florida State University
}

Publication Date: October 2005

Prepared by

Center for Advanced Power System

Electrical and Computer Engineering Department

Florida State University

Tallahassee, Florida 32310

for

OAK RIDGE NATIONAL LABORATORY

Oak Ridge, Tennessee 37831 managed by

UT-BATTELLE, LLC

for the

U.S. DEPARTMENT OF ENERGY

Under contract DE-AC05-00OR22725 


\section{DOCUMENT AVAILABILITY}

Reports produced after January 1, 1996, are generally available free via the U.S. Department of Energy (DOE) Information Bridge:

Web site: http://www.osti.gov/bridge

Reports produced before January 1, 1996, may be purchased by members of the public from the following source:

National Technical Information Service

5285 Port Royal Road

Springfield, VA 22161

Telephone: 703-605-6000 (1-800-553-6847)

TDD: $703-487-4639$

Fax: 703-605-6900

E-mail: info@ntis.fedworld.gov

Web site: $\mathrm{http}: / /$ www.ntis.gov/support/ordernowabout.htm

Reports are available to DOE employees, DOE contractors, Energy Technology Data Exchange (ETDE) representatives, and International Nuclear Information System (INIS) representatives from the following source:

Office of Scientific and Technical Information

P.O. Box 62

Oak Ridge, TN 37831

Telephone: $865-576-8401$

Fax: 865-576-5728

E-mail: reports@adonis.osti.gov

Web site: http://www.osti.gov/contact.html

This report was prepared as an account of work sponsored by an agency of the United States Government. Neither the United States government nor any agency thereof, nor any of their employees, makes any warranty, express or implied, or assumes any legal liability or responsibility for the accuracy, completeness, or usefulness of any information, apparatus, product, or process disclosed, or represents that its use would not infringe privately owned rights. Reference herein to any specific commercial product, process, or service by trade name, trademark, manufacturer, or otherwise, does not necessarily constitute or imply its endorsement, recommendation, or favoring by the United States Government or any agency thereof. The views and opinions of authors expressed herein do not necessarily state or reflect those of the United States Government or any agency thereof. 


\section{TABLE CONTENTS}

LIST OF FIGURES iv

LIST OF TABLES. vi

ACRONYMS vii

1. INTRODUCTION

1.1 BACKGROUND

2. POWER STAGE TOPOLOGY SELECTION

2.1 MULTIPLE-INPUT DC-DC CONVERTER TOPOLOGIES REVIEW .................. 3

2.2 PROPOSED TWO-INPUT DC-DC CONVERTER …………………………........... 4

3. OPERATION PRINCIPLE

3.1 INTRODUCTION

3.2 SOFT-SWITCHING OPERATION IN BOOST MODE .......................................... 7

3.3 SOFT-SWITCHING OPERATION IN BUCK MODE ........................................... 12

4. STEADY-STATE ANALYSIS AND DESIGN GUIDELINES

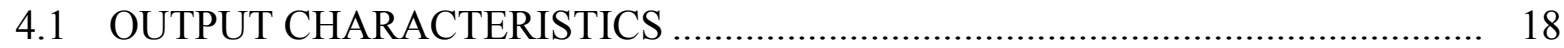

4.2 SOFT-SWITCHING CONDITIONS.......................................................... 22

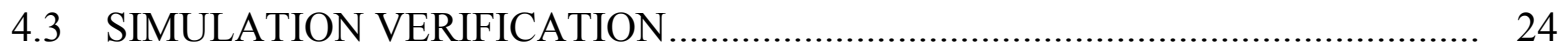

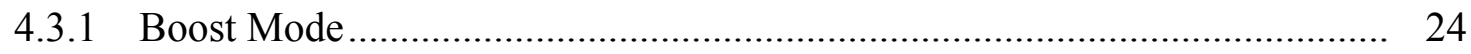

4.3.2 Buck Mode ............................................................................................ 25

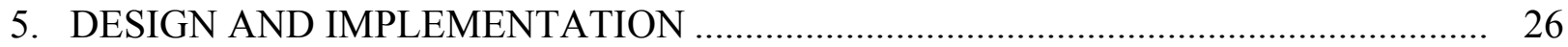

5.1 MAGENTIC-COMPONENT DESIGN

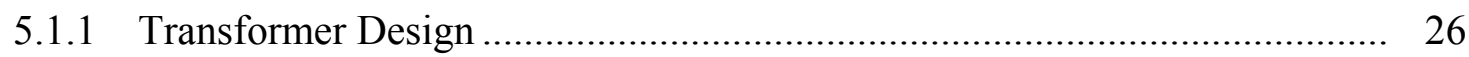

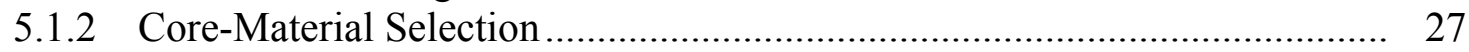

5.1.3 Turns-Ratio Selection ........................................................................ 28

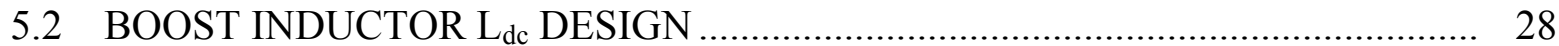

5.3 LEAKAGE-INDUCTANCE DESIGN ………...................................................... 28

5.4 CAPACITOR SELECTION

5.4.1 Resonant Capacitor Selection .............................................................. 29

5.4.2 DC Capacitor Selection........................................................................ 29

5.5 POWER SWITCHES

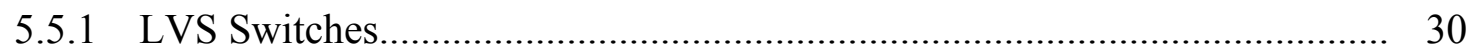

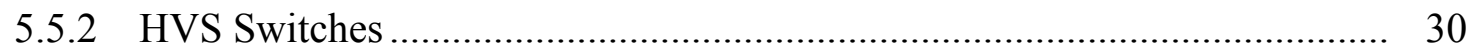

5.6 AUXILIARY POWER SUPPLY AND GATE-DRIVE CIRCUITS ........................ 31

5.7 POWER-STAGE LAYOUT DESIGN ……….................................................. 32 


\section{TABLE CONTENTS (cont'd)}

Page

6. EXPERIMENTAL RESULTS

6.1 EXPERIMENTAL SETUP.

6.2 EXPERIMENTAL RESULTS

6.2.1 With Phase-Shift Degree.................................................................... 34

6.2.2 No Phase-Shift Degree......................................................................... 35

6.2.3 Additional Experimental Results ....................................................... 36

APPENDIX A: MATHCAD DESIGN FILE ........................................................... 39

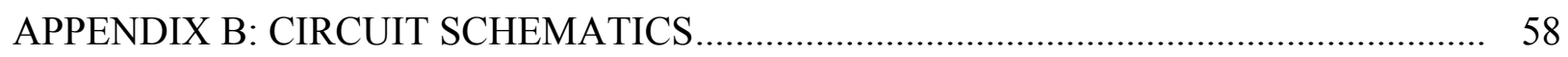

APPENDIX C: PHOTO OF PTOROTYPE ............................................................... 65

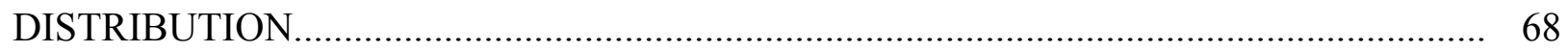




\section{LIST OF FIGURES}

Figure

Page

1.1 Block diagram of a FC-BU system

1.2 Block diagram of a FC-BU-UC system using a multiple-input

dc-dc converter......

1.3 System diagram

2.1 Reported uni-directional multiple-input dc-dc converters by using multi-winding transformer ....

Reported non-isolated bi-directional multiple-input dc-dc converters

2.3 Proposed two-input ZVS isolated bi-directional dc-dc converter

3.1 Circuit model of a three-winding transformer including " $\Delta$ " type and "Y" type model

Primary-referred equivalent circuit based on " $\mathrm{Y}$ " transformer model....

3.3 Waveforms and switching timing of a boost mode

3.4

3.5

Communication step diagrams during a switching cycle in boost mode.

Waveforms and switching timing of buck mode

4.1 Idealized voltages and current waveforms of a transformer on the condition that $\mathrm{v}_{1}=\mathrm{v}_{2}=\mathrm{v}_{5}=\mathrm{v}_{6}<\mathrm{v}_{3}=\mathrm{v}_{4}$.

4.2 Three-dimensional plot of output power and voltage as a function of control variables $\phi_{13}$ and $\phi_{53}$

The relation between output characteristics and control variables $\phi_{13}$ and $\phi_{53}$

Simulated waveforms of boost mode

6.2 Measured waveform under boost-mode operation with $\mathrm{V}_{\text {in } 1}=8 \mathrm{~V}, \mathrm{~V}_{\text {in2 }}=5 \mathrm{~V}$, $\mathrm{I}_{1}=52 \mathrm{~A}, \mathrm{I}_{2}=24 \mathrm{~A}, \phi_{13}=0.15 \pi, \phi_{53}=0.1 \pi, \mathrm{L}_{\mathrm{r} 12}=\mathrm{L}_{\mathrm{r} 34}=0.4 \mu \mathrm{H}, \mathrm{V}_{\text {out }}=123 \mathrm{~V}$, and $\mathrm{P}_{\text {out }}=420 \mathrm{~W}$

6.3 Calculated-current waveform under boost-mode operation with $\mathrm{V}_{\text {in1 }}=8 \mathrm{~V}$, $\mathrm{V}_{\text {in2 }}=5 \mathrm{~V}, \phi_{13}=0.15 \pi, \phi_{53}=0.1 \pi, \mathrm{L}_{\mathrm{r} 12}=\mathrm{L}_{\mathrm{r} 34}=0.4 \mu \mathrm{H}$, and $\mathrm{V}_{\text {out }}=123 \mathrm{~V}$......

6.4 Measured waveform under boost-mode operation with $\mathrm{V}_{\mathrm{in} 1}=5 \mathrm{~V}, \mathrm{~V}_{\mathrm{in} 2}=5 \mathrm{~V}$, $\mathrm{I}_{1}=27 \mathrm{~A}, \mathrm{I}_{2}=27 \mathrm{~A}, \phi_{13}=0.13 \pi, \phi_{53}=0.13 \pi, \mathrm{L}_{\mathrm{r} 12}=\mathrm{L}_{\mathrm{r} 34}=0.4 \mu \mathrm{H}, \mathrm{V}_{\text {out }}=90 \mathrm{~V}$, and $\mathrm{P}_{\text {out }}=225 \mathrm{~W}$

6.5 Calculated waveform under boost-mode operation with $\mathrm{V}_{\text {in } 1}=5 \mathrm{~V}, \mathrm{~V}_{\text {in2 }}=5 \mathrm{~V}$, $\phi_{13}=0.13 \pi, \phi_{53}=0.13 \pi, \mathrm{L}_{\mathrm{r} 12}=\mathrm{L}_{\mathrm{r} 34}=0.4 \mu \mathrm{H}$, and $\mathrm{V}_{\text {out }}=90 \mathrm{~V}$ 


\section{LIST OF FIGURES (cont'd)}

Figure

Page

6.6 Measured waveform under boost-mode operation with $\mathrm{V}_{\text {in1 }}=15 \mathrm{~V}$,

$\mathrm{V}_{\text {in } 2}=11 \mathrm{~V}, \mathrm{I}_{1}=123 \mathrm{~A}, \mathrm{I}_{2}=92 \mathrm{~A}, \phi_{13}=0.25 \pi, \phi_{53}=0.25 \pi, \mathrm{L}_{\mathrm{r} 12}=0.5 \mu \mathrm{H}$,

$\mathrm{L}_{\mathrm{r} 34}=0.55 \mu \mathrm{H}, \mathrm{V}_{\text {out }}=310 \mathrm{~V}, \mathrm{R}=37 \mathrm{Ohm}$, and $\mathrm{P}_{\text {out }}=2597 \mathrm{~W}$

6.7 Calculated waveform under boost-mode operation with $\mathrm{V}_{\text {in } 1}=15 \mathrm{~V}$,

$\mathrm{V}_{\text {in } 2}=11 \mathrm{~V}, \mathrm{I}_{1}=123 \mathrm{~A}, \mathrm{I}_{2}=92 \mathrm{~A}, \quad \phi_{13}=0.25 \pi, \phi_{53}=0.25 \pi, \mathrm{L}_{\mathrm{r} 12}=0.5 \mu \mathrm{H}$,

$\mathrm{L}_{\mathrm{r} 34}=0.55 \mu \mathrm{H}, \mathrm{V}_{\text {out }}=310 \mathrm{~V}, \mathrm{R}=37 \mathrm{Ohm}$, and $\mathrm{P}_{\text {out }}=2597 \mathrm{~W}$

6.8 Measured waveform under boost mode operation with $\mathrm{V}_{\text {in } 1}=12.5 \mathrm{~V}, \mathrm{~V}_{\text {in2 }}=10 \mathrm{~V}$,

$\mathrm{I}_{1}=150 \mathrm{~A}, \mathrm{I}_{2}=100 \mathrm{~A}, \phi_{13}=0.35 \pi, \phi_{53}=0.25 \pi, \mathrm{L}_{\mathrm{r} 12}=0.5 \mu \mathrm{H}, \mathrm{L}_{\mathrm{r} 34}=0.55 \mu \mathrm{H}$,

$\mathrm{V}_{\text {out }}=315 \mathrm{~V}, \mathrm{R}=37 \mathrm{Ohm}$, and $\mathrm{P}_{\text {out }}=2681 \mathrm{~W}$.

6.9 Calculated waveform under boost-mode operation with $\mathrm{V}_{\text {in1 }}=12.5 \mathrm{~V}$,

$\mathrm{V}_{\text {in } 2}=10 \mathrm{~V}, \mathrm{I}_{1}=150 \mathrm{~A}, \mathrm{I}_{2}=100 \mathrm{~A}, \phi_{13}=0.35 \pi, \phi_{53}=0.25 \pi, \mathrm{L}_{\mathrm{r} 12}=0.5 \mu \mathrm{H}$,

$\mathrm{L}_{\mathrm{r} 34}=0.55 \mu \mathrm{H}, \mathrm{V}_{\text {out }}=315 \mathrm{~V}, \mathrm{R}=37 \mathrm{Ohm}$, and $\mathrm{P}_{\text {out }}=2681 \mathrm{~W}$ 


\section{LIST OF TABLES}

Table

5.1 Current rating for each device and leakage inductances.................................. 26

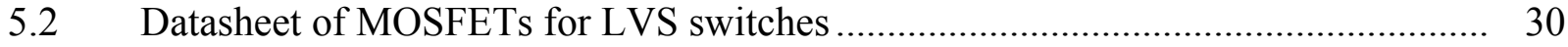

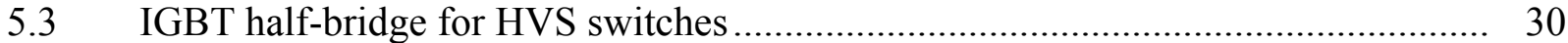




\section{ACRONYMS}

BU

dc

DSP

ESL

ESR

EV

FC

$\mathrm{HEV}$

HVS

IGBT

LVS

MOSFET

rms

UC

ZVS battery-storage unit direct current digital-signal processor estimated-series resistance estimated-series inductance electric vehicle fuel cell hybrid electric vehicle high-voltage side insulated gate bipolar transistor low-voltage side metal oxide semiconductor field-effect transistor root-mean square ultracapacitor zero-voltage switching 


\section{INTRODUCTION}

\subsection{BACKGROUND}

There is vital need for a compact, lightweight, and efficient energy-storage system that is both affordable and has an acceptable cycle life for the large-scale production of electric vehicles (EVs) and hybrid electric vehicles (HEVs).

Most of the current research employs a battery-storage unit (BU) combined with a fuel cell (FC) stack in order to achieve the operating voltage-current point of maximum efficiency for the FC system. A system block diagram is shown in Fig.1.1. In such a conventional arrangement, the battery is sized to deliver the difference between the energy required by the traction drive and the energy supplied by the FC system. Energy requirements can increase depending on the drive cycle over which the vehicle is expected to operate. Peak-power transients result in an increase of losses and elevated temperatures which result in a decrease in the lifetime of the battery.

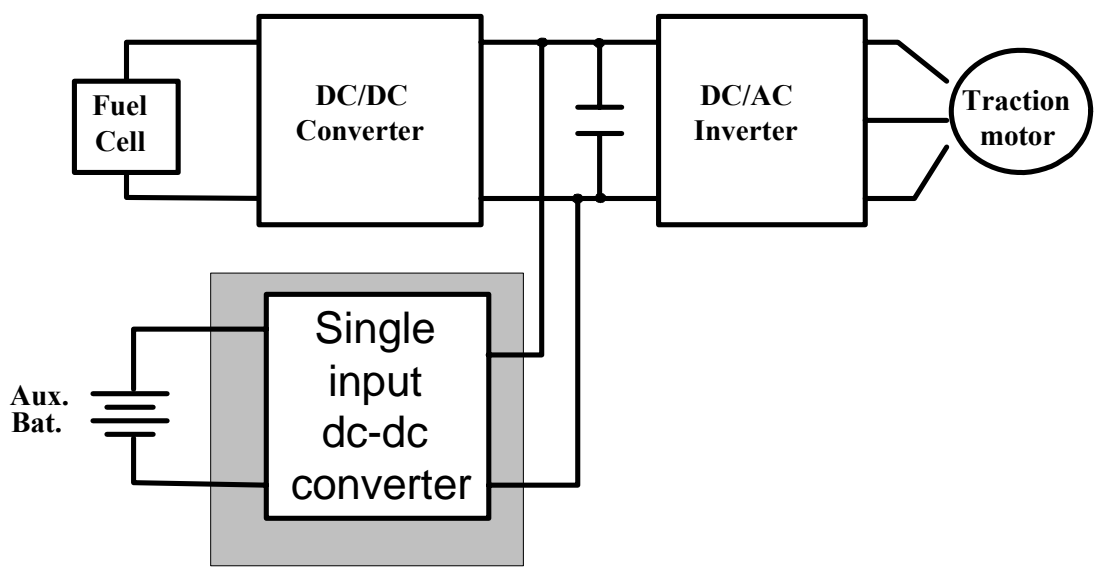

Fig. 1.1. Block diagram of a FC-BU system.

This research will propose a novel two-input direct current $(\mathrm{dc})$ dc to dc converter to interface an additional energy-storage element, an ultracapacitor (UC), which is shown in Fig.1.2. It will assist the battery during transients to reduce the peak-power requirements of the battery. 


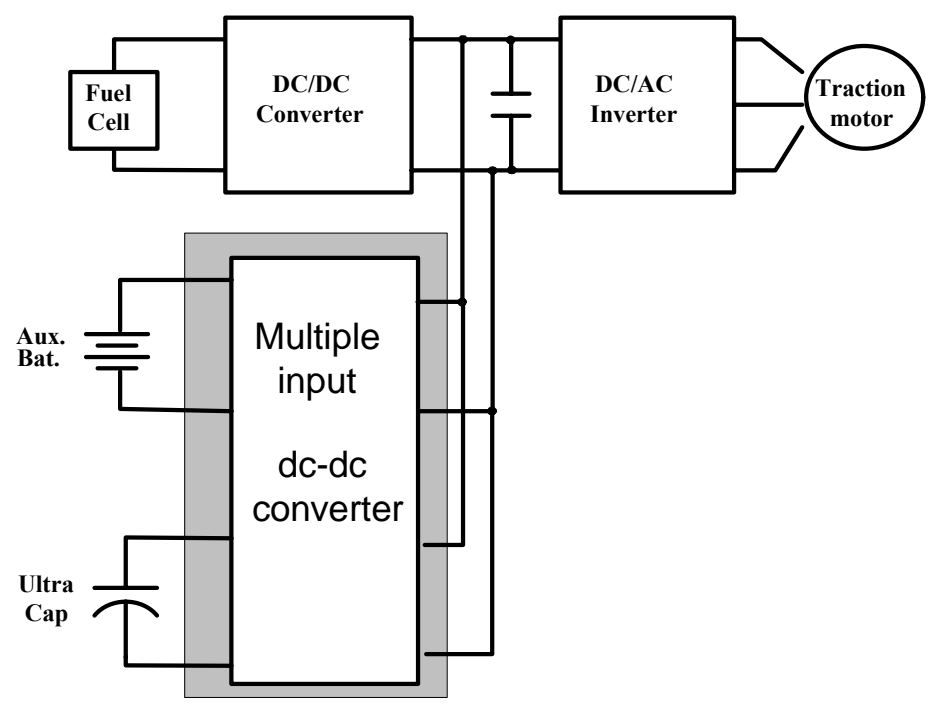

Fig. 1.2. Block diagram of a FC-BU-UC system using a multiple-input dc-dc converter.

\subsection{SYSTEM SPECIFICATIONS}

Specifications of the two-input bi-directional dc-de converter (Fig. 1.3) are as follows:

- The nominal voltage at the low-voltage side (LVS) of one input is $12 \mathrm{~V}$, and another input is $16 \mathrm{~V}$. These values can vary from $8-16 \mathrm{~V}$ and $12-20 \mathrm{~V}$ during charging and discharging.

- The nominal high-side voltage is $288 \mathrm{~V}$, with an operating range from $255-425 \mathrm{~V}$.

- Nominal discharging power of the two inputs is $2 \mathrm{~kW}$ and $3.5 \mathrm{~kW}$, respectively.

- The nominal output power is $5 \mathrm{~kW}$.

- Bus capacitance $\mathrm{C}_{\mathrm{o}}$ is less than $2000 \mu \mathrm{F}$.

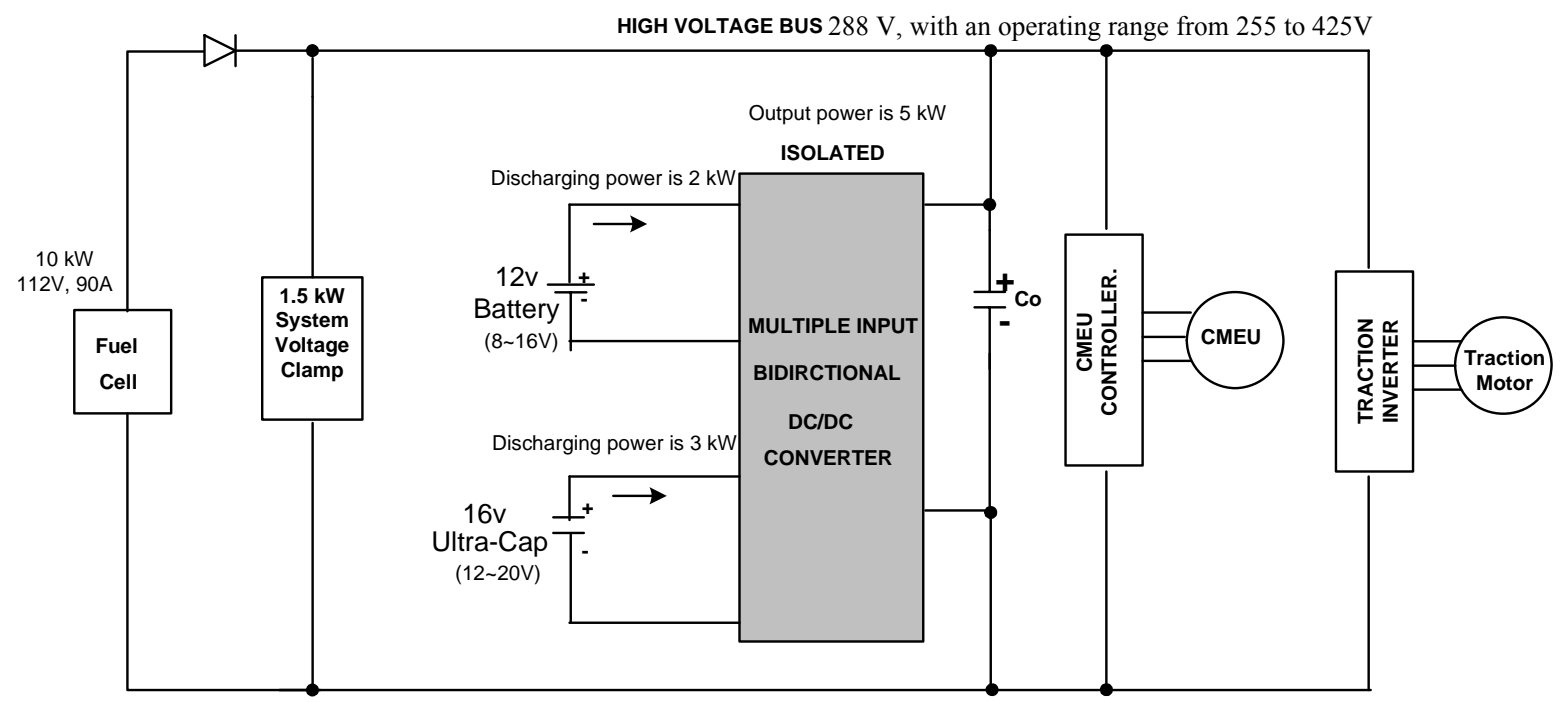

Fig. 1.3. Systematic diagram. 


\section{POWER-STAGE TOPOLOGY SELECTION}

\subsection{MULTIPLE-INPUT DC-DC CONVERTER TOPOLOGIES REVIEW}

The current research of multiple-input dc-dc converters is mainly focused on the uni-directional circuit topology for applications in a distributed energy system. There are two types of converter architectures that have been proposed. The first is to put different de sources in series to implement the multiple-input dc-dc converter [1-2]. Another circuit is to put dc sources in parallel by using the coupled transformer [3-4] or multi-winding transformer as shown in Fig. 2.1 [5]. The common problem with these converters is that power is only allowed to flow in one direction, which is impractical for vehicle application where power needs to flow in either direction.

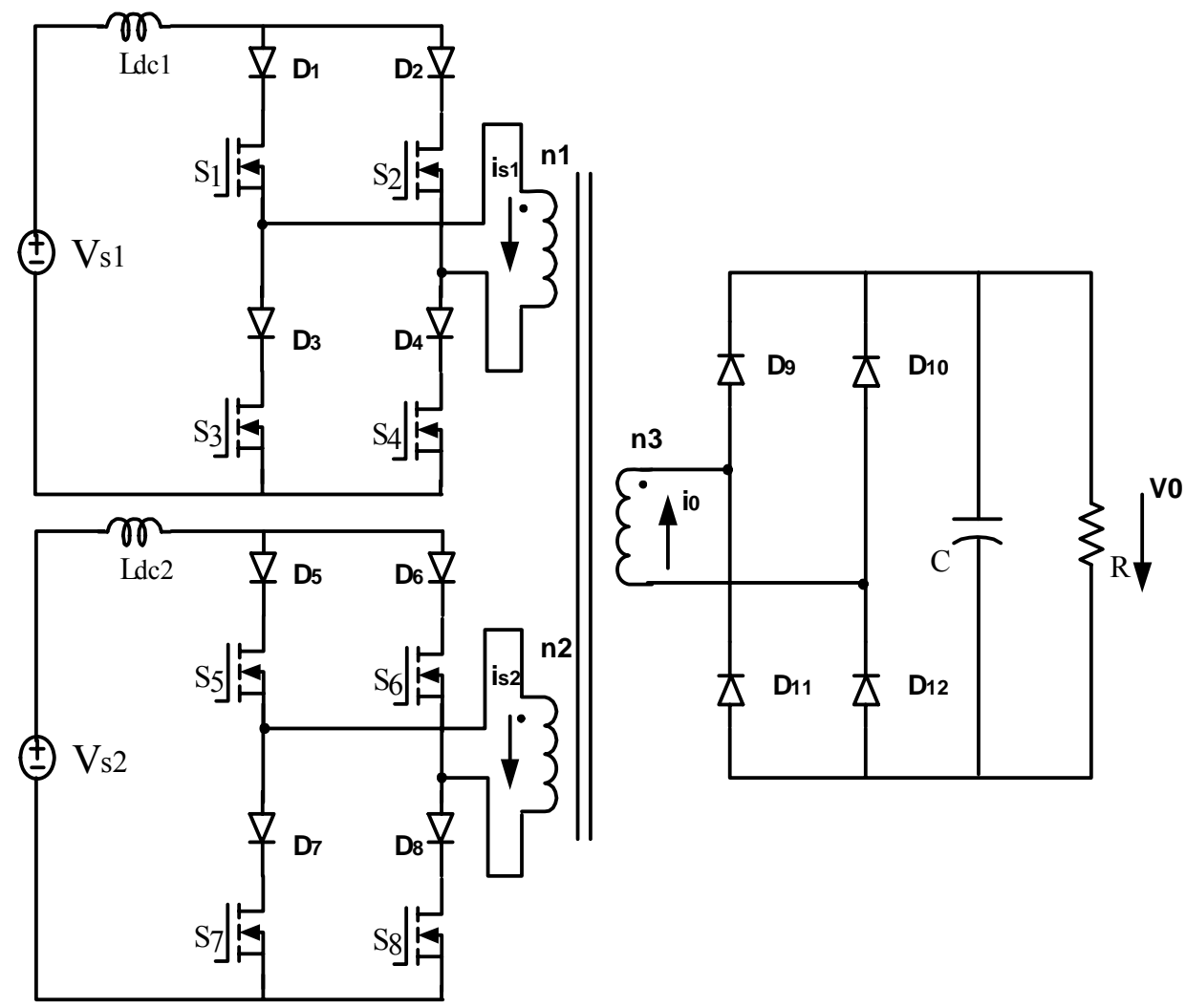

Fig. 2.1. Reported uni-directional multiple-input dc-dc converters by using multiwinding transformer [5].

Recently, a non-isolated bi-directional multiple-input dc-dc converter has been proposed for HEV applications as shown in Fig. 2.2 [6]. However, this circuit has several disadvantages. First, it lacks electric isolation. Second, it requires high-voltage BU and UC tanks. Limitations to the use of UC tanks are primarily due to the UCs low-cell voltage at their present stage of development, as well as cell-leakage current that may result in voltage imbalances in a stacked unit. This problem becomes worse for high-voltage UC tanks. In addition, high-voltage BUs and UCs will ultimately increase the cost and weight of the energy system. 


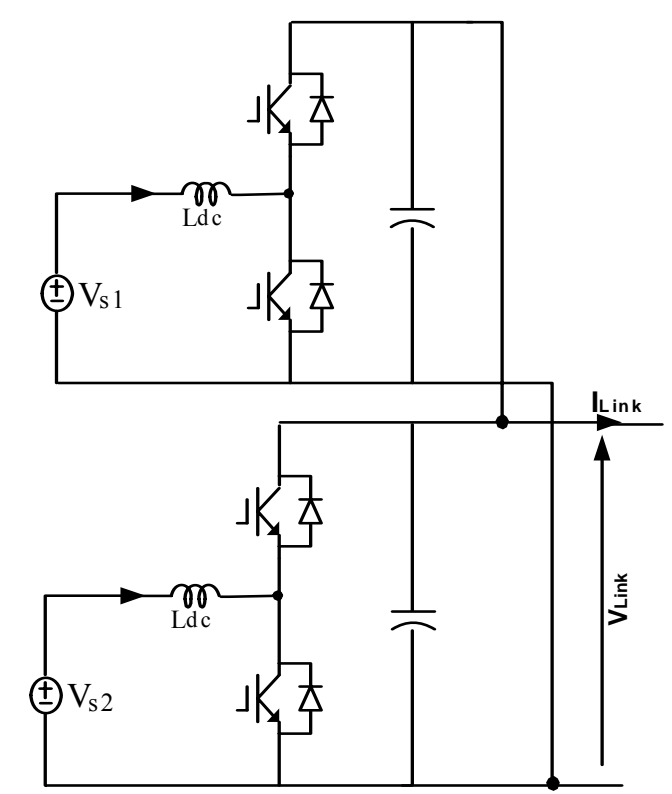

Fig. 2.2. Reported non-isolated bi-directional multiple-input dc-dc converters [6].

\subsection{PROPOSED TWO-INPUT DC-DC CONVERTER}

Figure 2.3 shows the proposed two-input zero-voltage switching (ZVS) isolated bi-directional dc-dc converter. It is an extension of a single-input dual half-bridge topology [7].

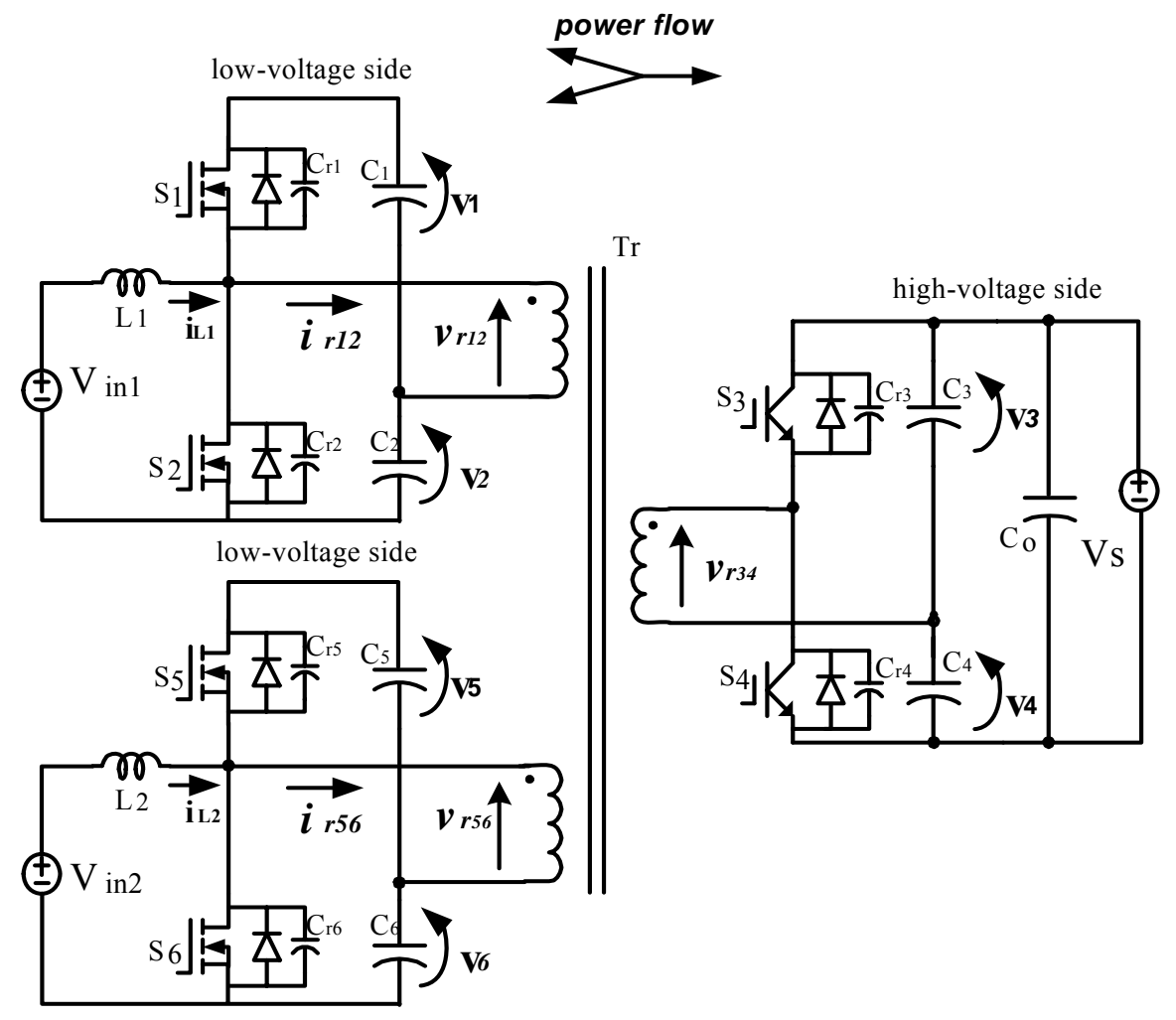

Fig. 2.3. Proposed two-input ZVS isolated bi-directional dc-dc converter. 
The proposed topology has the following innovations:

- Electrical isolation can be achieved naturally.

- Magnitude of de input voltages may be low and either similar or dissimilar.

- DC sources can deliver power individually, simultaneously, and bi-directionally.

- The soft-switching technology is achievable across a wide operating range.

- Minimum number of devices and simple control.

- High efficiency, lightweight, and high-power.

In addition, the combined storage unit (UC and battery) interfaced with this converter can increase the life cycle of energy-storage elements and reduce the cost of EVs. 


\section{OPERATION PRINCIPLE}

\subsection{INTRODUCTION}

Figure 3.1 illustrates the " $\Delta$ " type and "Y" type circuit model of a three-winding transformer. The primary-referred equivalent circuit based on the " $Y$ " type transformer model is redrawn in Fig. 3.2. The circuit consists of two current-source input-stage circuits, a three-winding coupled transformer, and a common output-stage circuit. This converter can be applied in FC vehicles to connect three ports: $12 \mathrm{~V}$ to approximately $42 \mathrm{~V}$ battery, UC bank, and the load. The load will be connected to a traction-motor drive through an inverter and the dc-bus voltage of a high-voltage side (HVS) that can reach from $288 \mathrm{~V}$ to approximately $400 \mathrm{~V}$. The transformer here has three functions: (1) combine input dc sources in magnetic form; (2) provide electrical isolation; and (3) step-up voltage from the LVS to the HVS.

When power flows from the LVS to the HVS, the circuit works in boost mode to keep the HVS at a desired high value which can be referred to as the acceleration mode in FC vehicle applications. In the other direction of power flow, the circuit works in buck mode to recharge the energy-storage elements from the FC or from absorbed regenerative energy which corresponds to cruise and braking modes respectively. In this section, the power-stage description and operation-principle analysis will be described for both the boost and buck mode respectively.

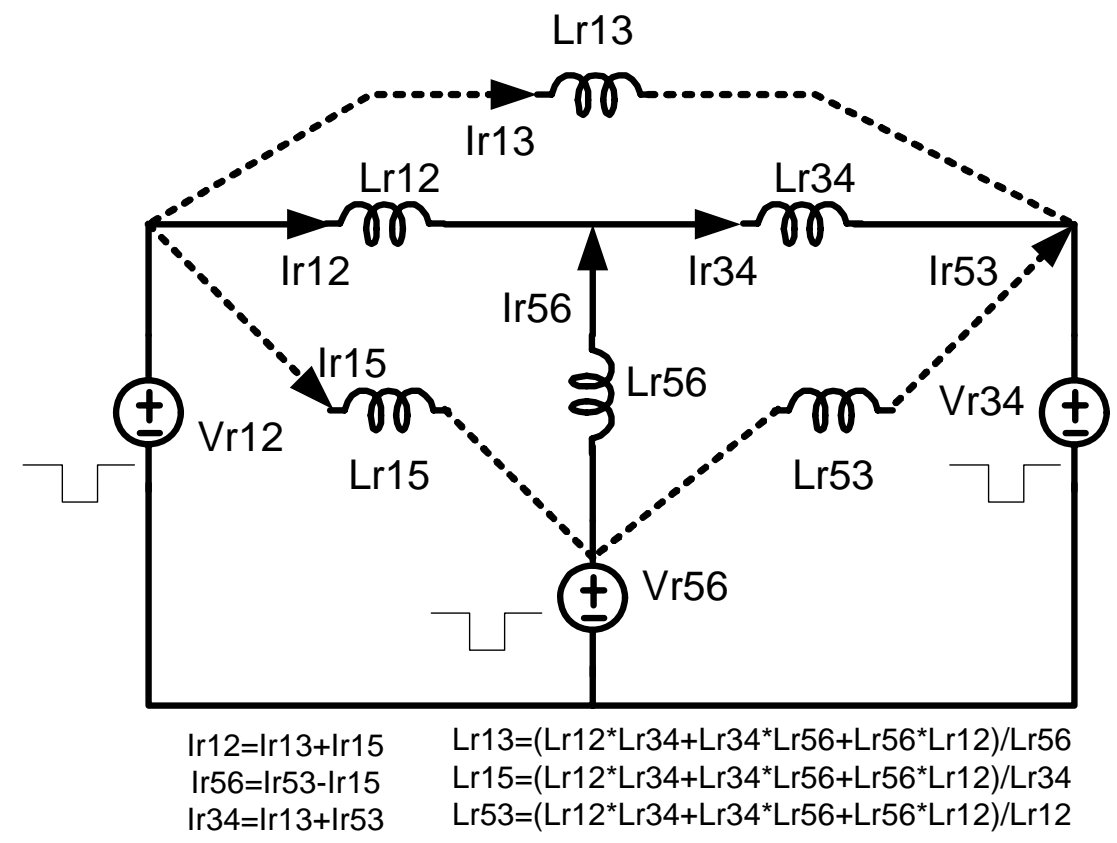

Fig. 3.1. Circuit model of a three-winding transformer including " $\Delta$ " type and "Y" type model. 


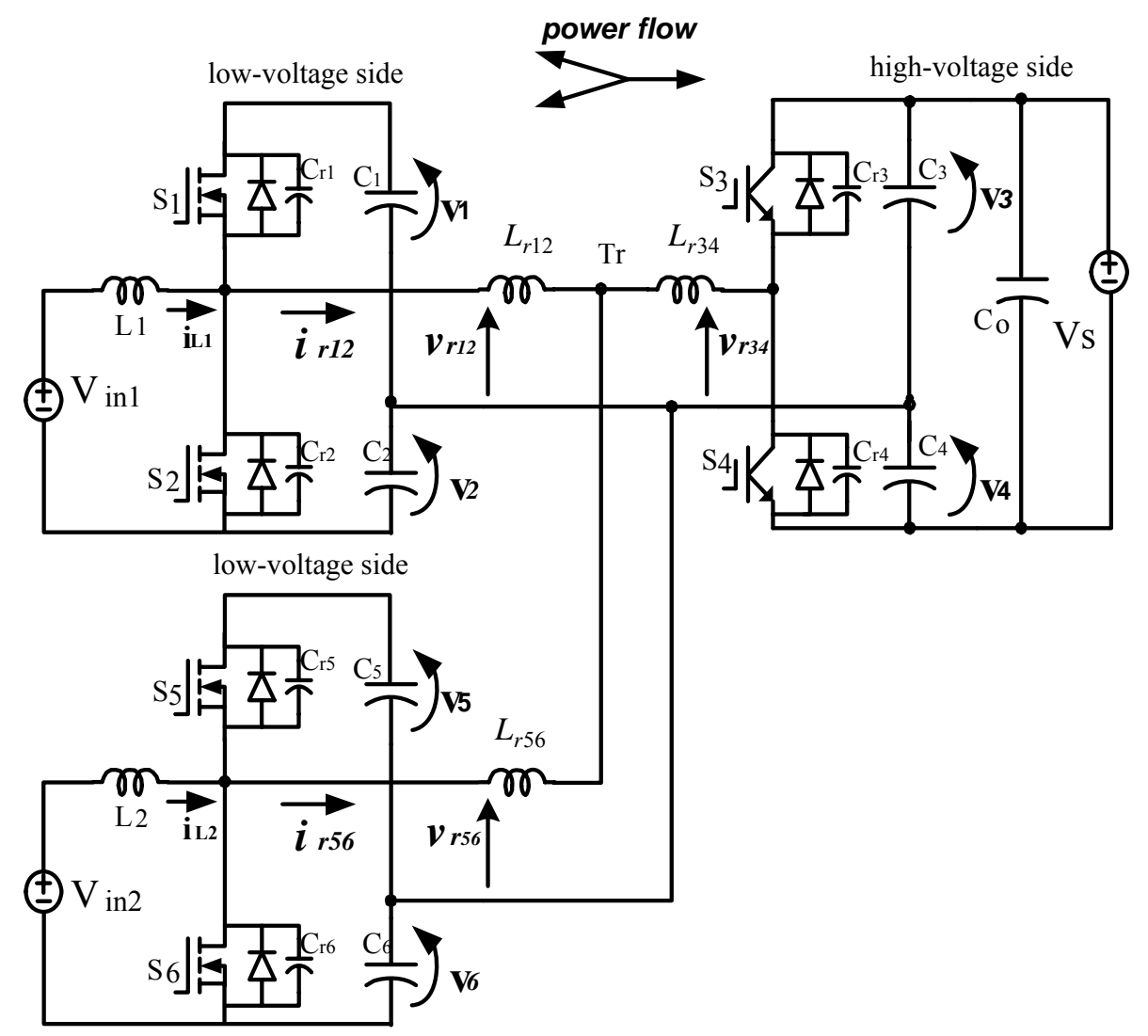

Fig. 3.2. Primary-referred equivalent circuit based on " $Y$ " transformer model.

\subsection{SOFT-SWITCHING OPERATION IN BOOST MODE}

Figure 3.3 illustrates the key waveforms in boost mode where the energy is transferred from each of the LVS to the HVS. Each LVS generates a square-wave voltage $\left(v_{r 12}\right.$ and $\left.v_{r 56}\right)$ on the primary side of the transformer. The HVS half-bridge generates a square-wave voltage $\left(v_{r 34}\right)$ on the secondary side of the transformer. The amount of power transferred is related to the phase-shift of square-wave voltages. The current waveforms in Fig. 3.3 are plotted depending on the phaseshift and voltage relationship. The interval $t_{0}$ to $t_{20}$ of Fig. 3.3 describes the various stages of operation during one switching period in boost mode. The converter operation is repetitive in the switching cycle. One complete switching cycle is divided into 20 steps. To aid in understanding each step, a set of corresponding annotated circuit diagrams is given in Fig. 3.4 with a brief description of each step. 

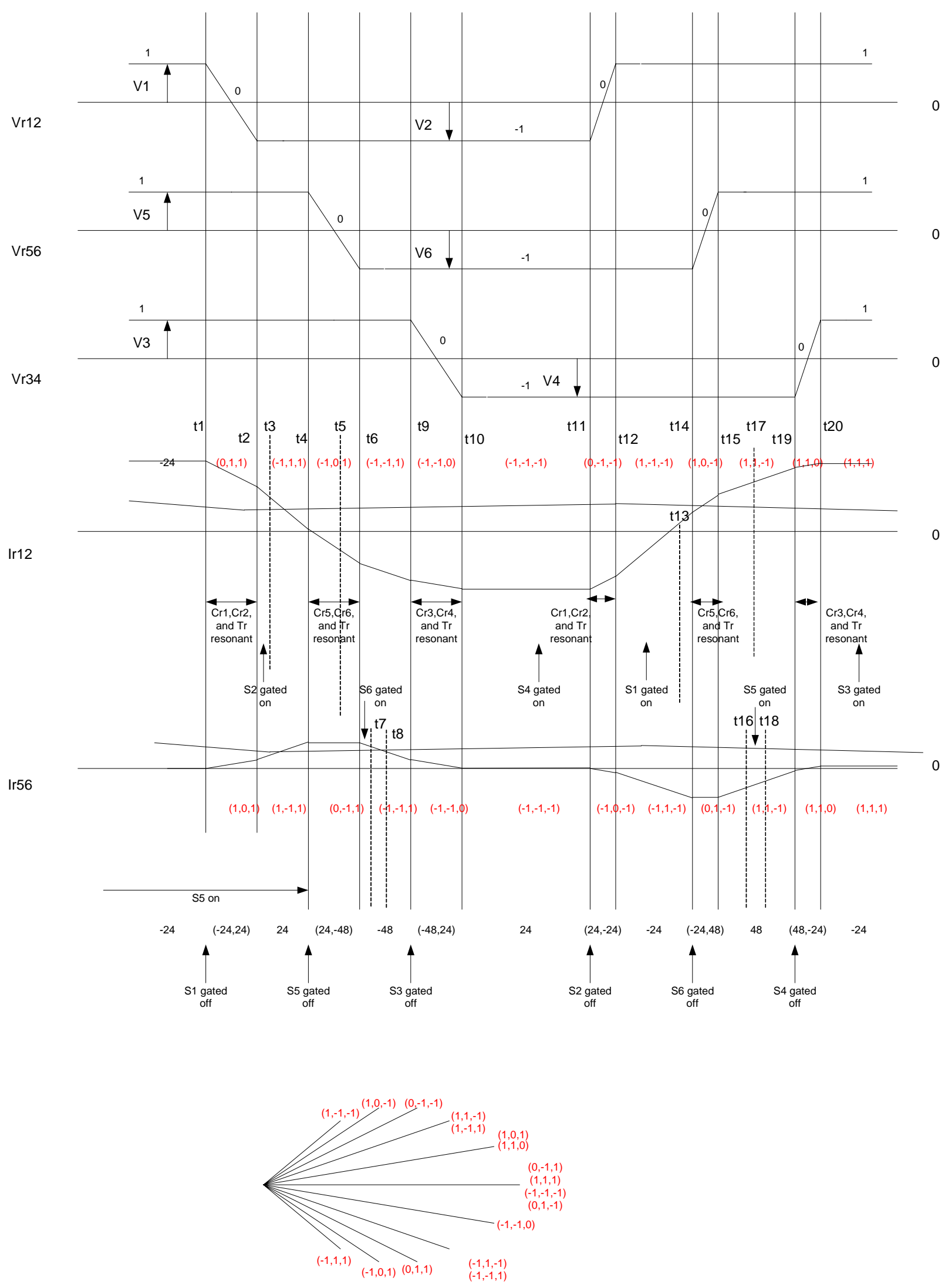

Fig. 3.3. Waveforms and switching timing of a boost mode. 

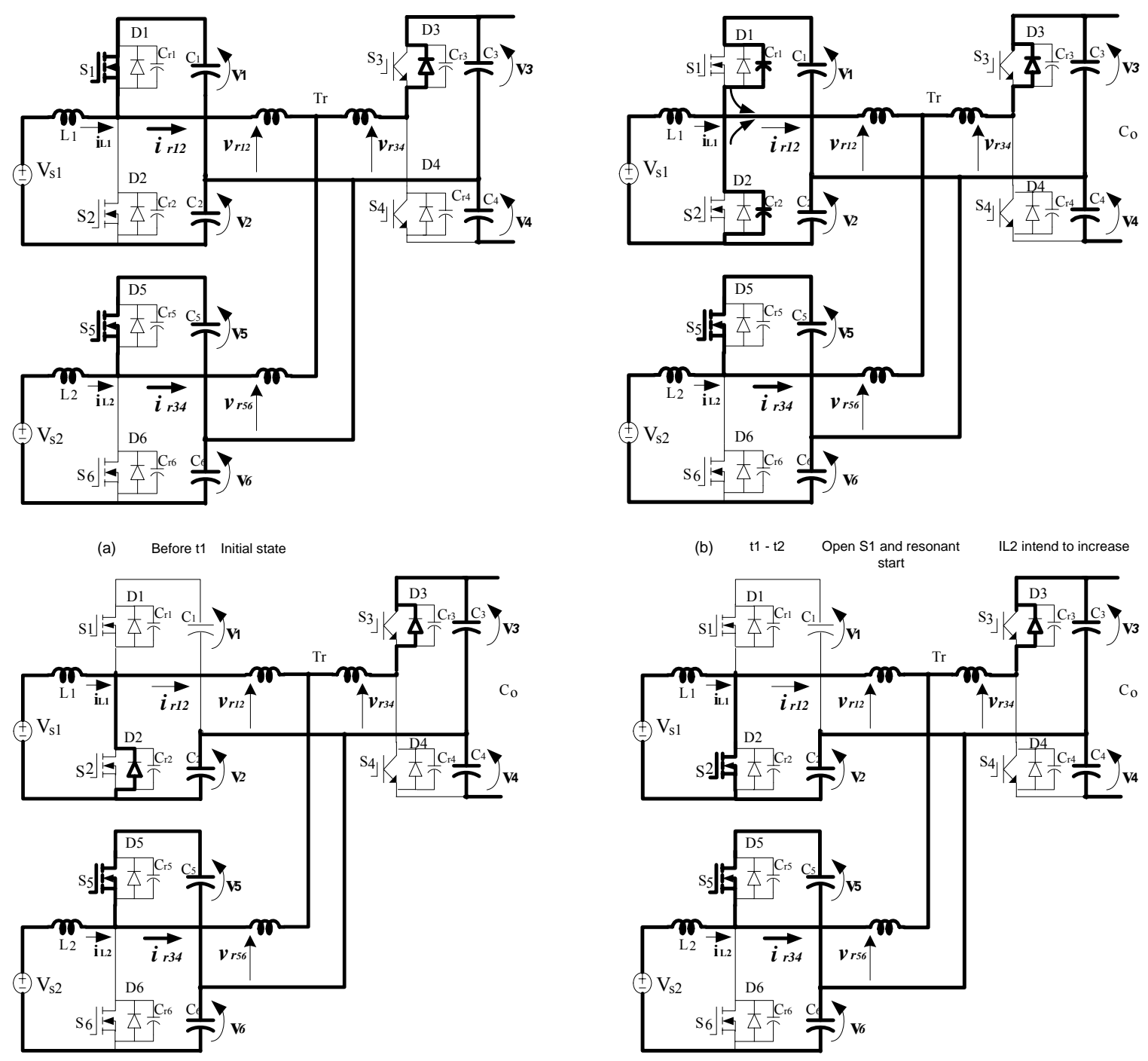

Resonant stoped, D2 intend to conduct
(c) t2-t3 $\quad$ IL2 increasing

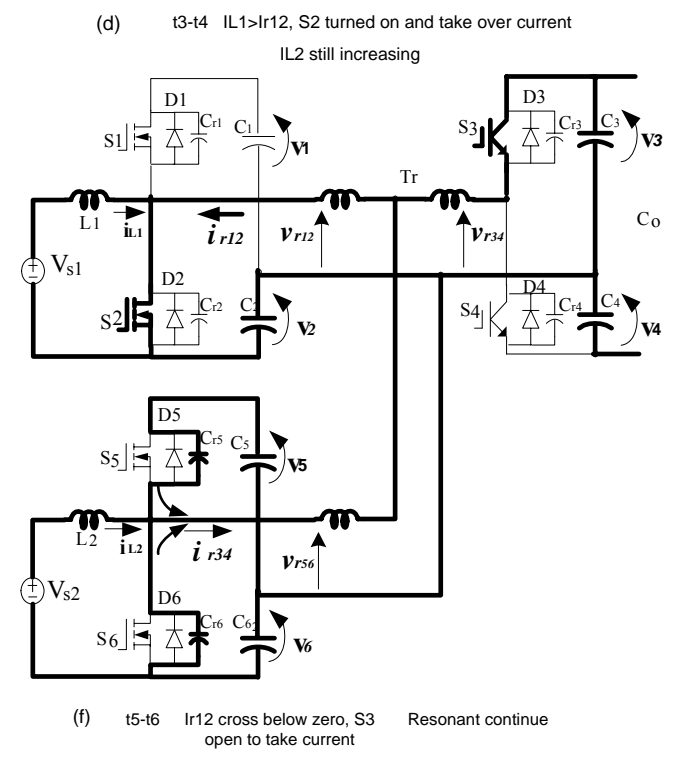

Fig. 3.4. Communication step diagrams during a switching cycle in boost mode. 

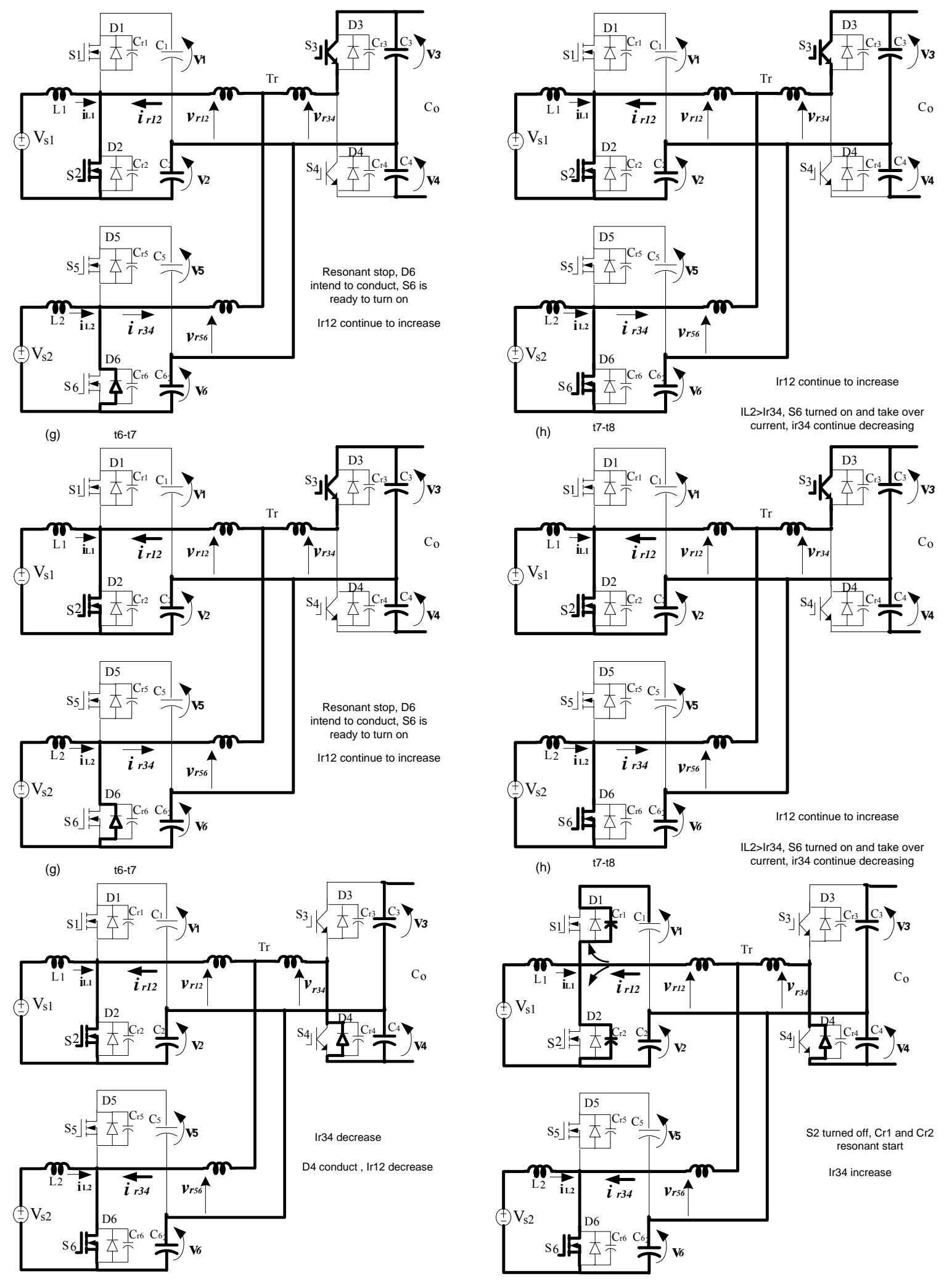

(k) $\mathrm{t}^{\mathrm{t} 0 \mathrm{-}} \mathrm{t11}$

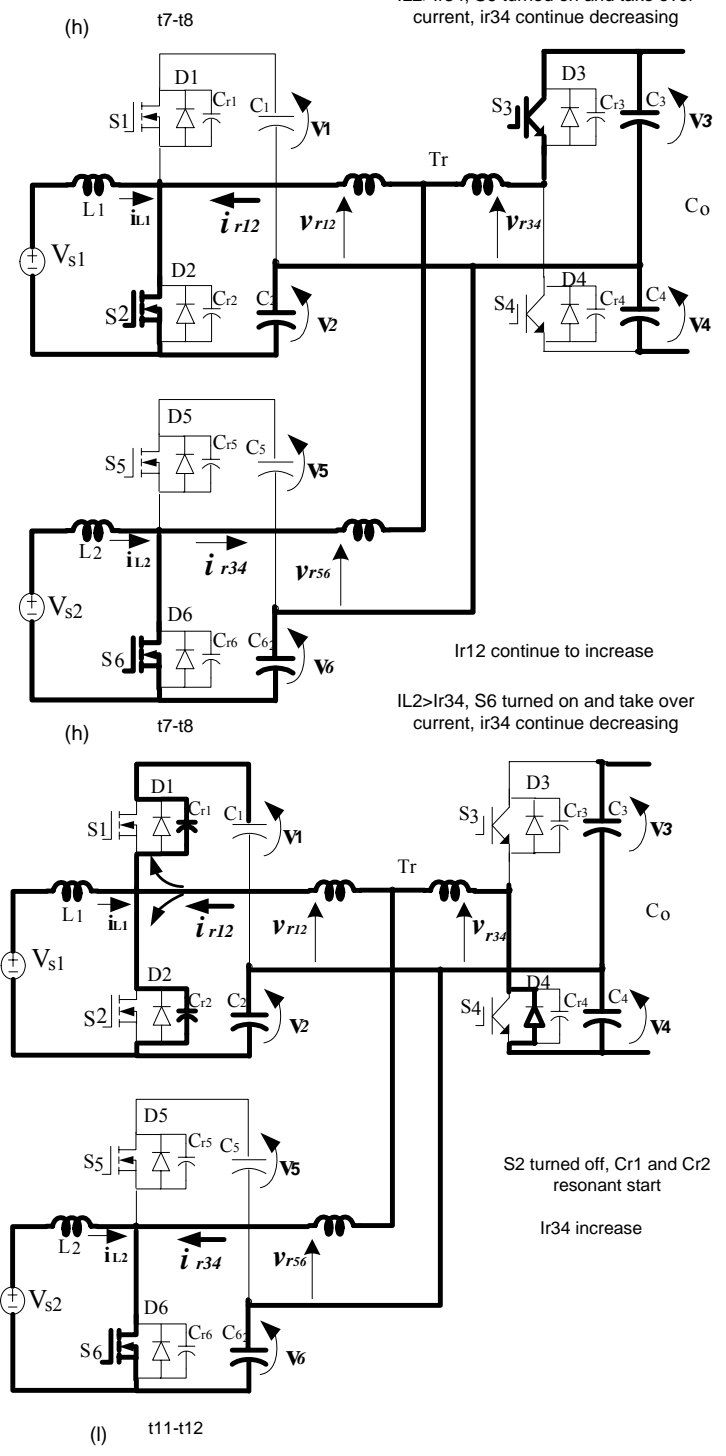

Fig. 3.4. Communication step diagrams during a switching cycle in boost mode (cont'd). 


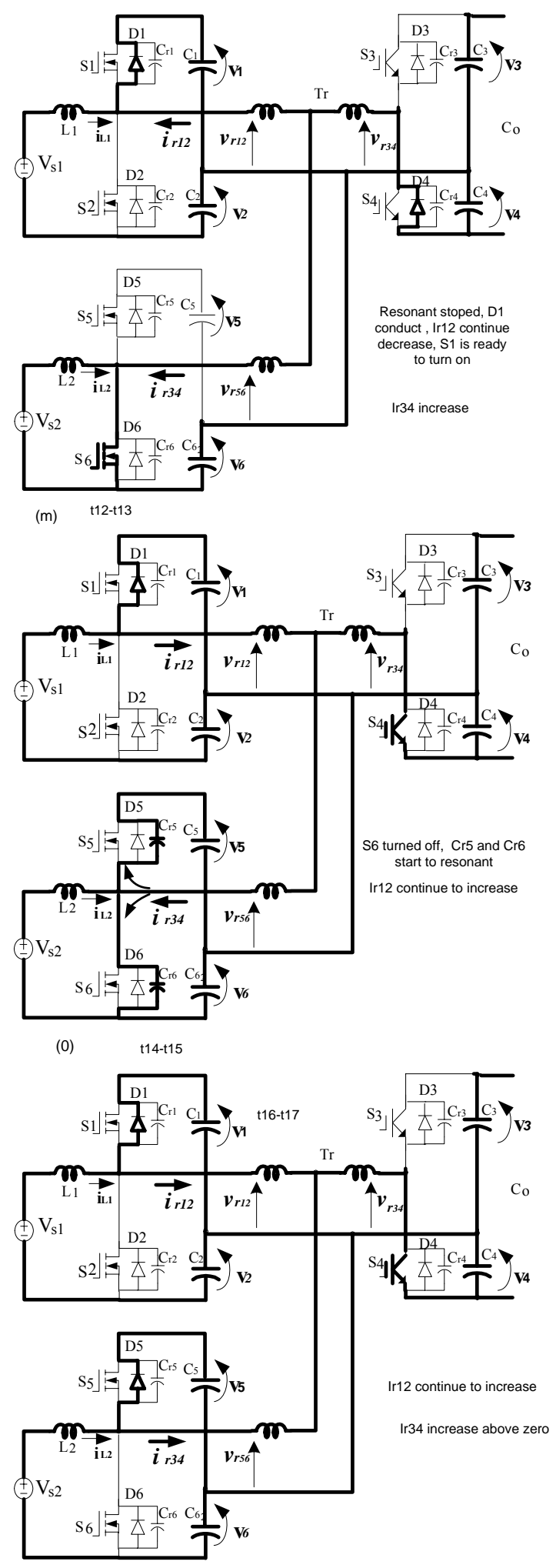

(q)
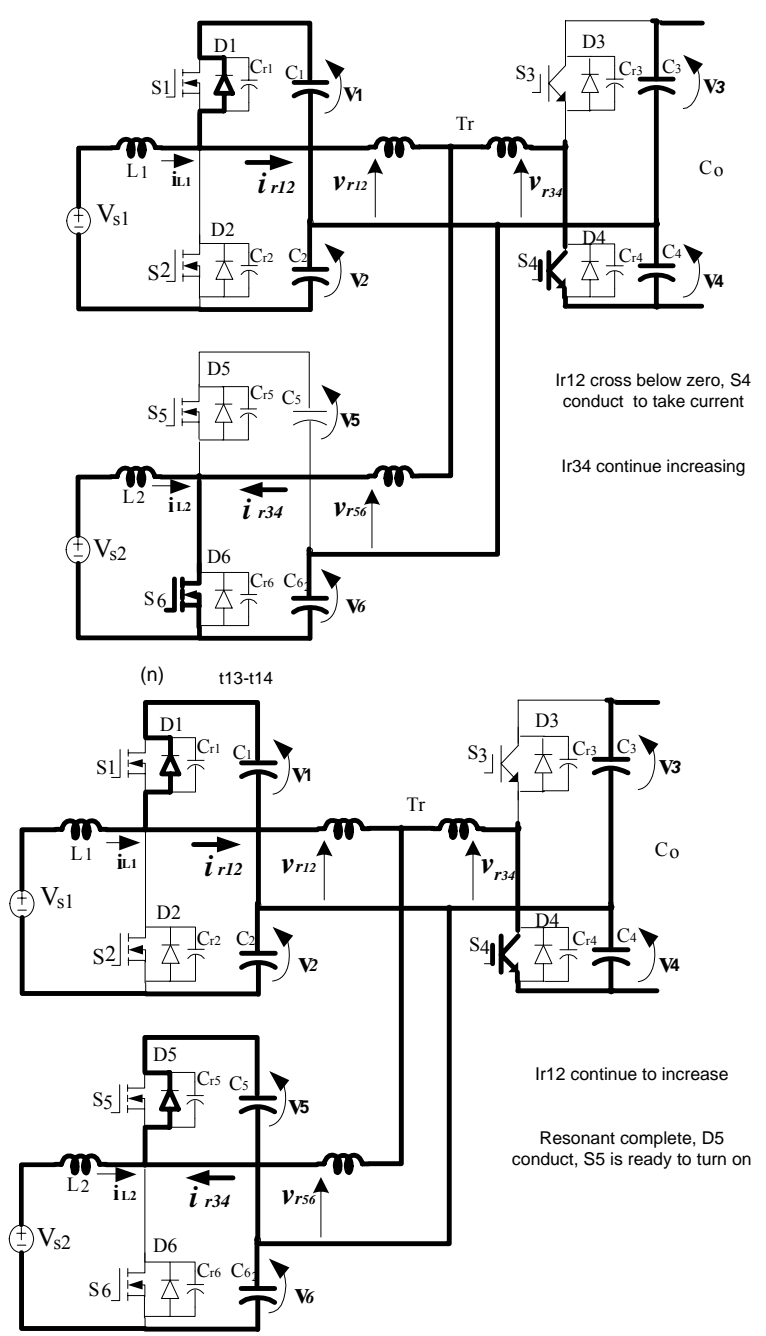

(p) $\quad \mathrm{t} 15-\mathrm{t} 16$

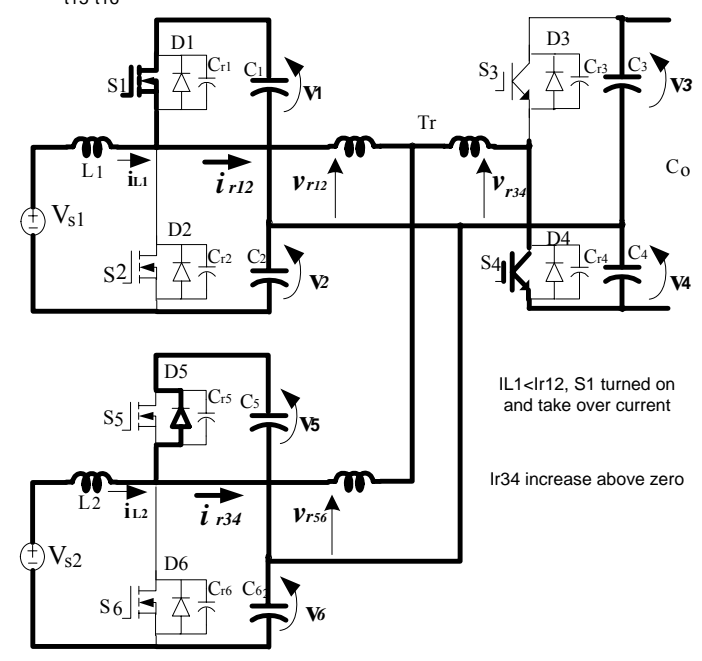

(r) $\quad \mathrm{t} 17-\mathrm{t} 18$

Fig. 3.4. Communication step diagrams during a switching cycle in boost mode (cont'd). 


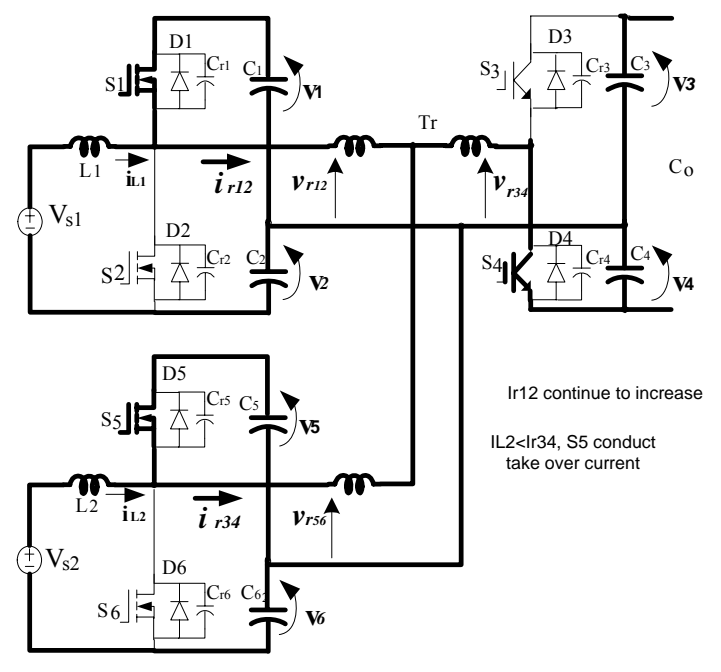

(s) t18-t19

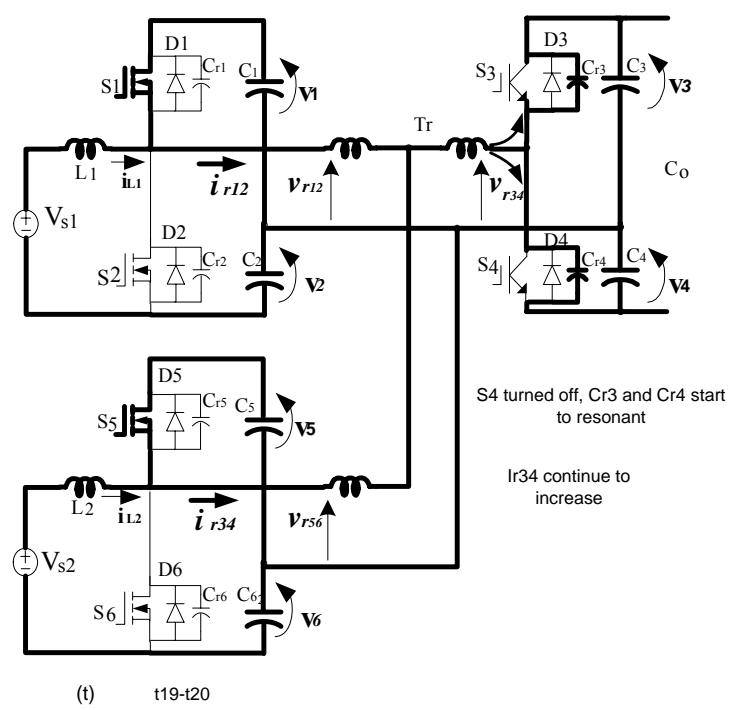

Fig. 3.4. Communication step diagrams during a switching cycle in boost mode (cont'd).

\subsection{SOFT-SWITCHING OPERATION IN BUCK MODE}

Because the half-bridge topology of the two sides is symmetrical, the soft-switching operation principles in buck mode are similar to those in boost mode. Figure 3.5 describes one switching cycle in buck mode. Due to the reversed power-flow direction, the phase of $V_{r 34}$ is leading $V_{r 12}$ and $V_{r 56}$. The buck-mode operation can be divided into 20 steps. To aid in understanding each step, a set of corresponding annotated circuit diagrams is given in Fig. 3.6; however, the description of each step can be analogously inferred and will not be discussed here. 


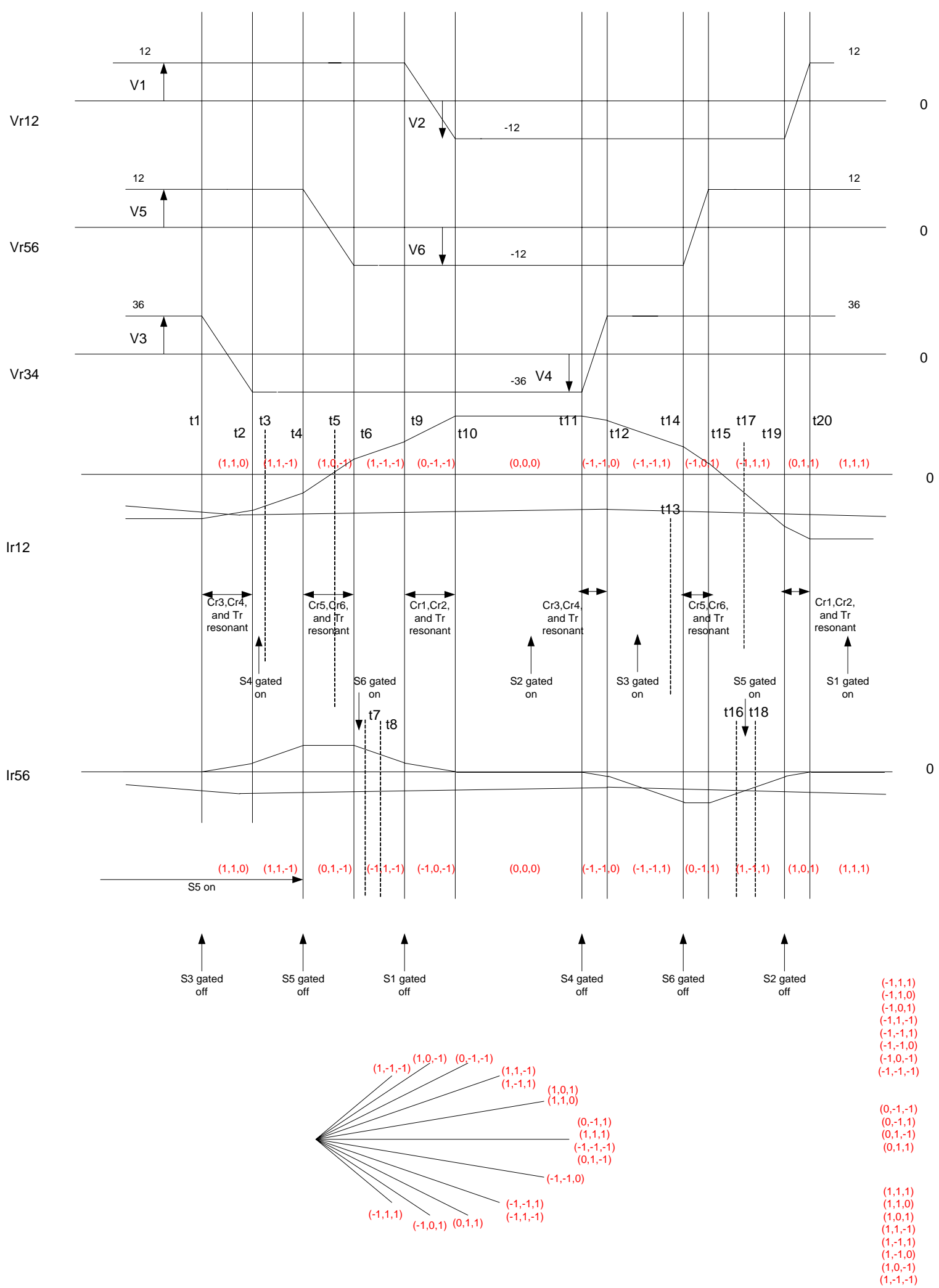

Fig. 3.5. Waveforms and switching timing of buck mode. 

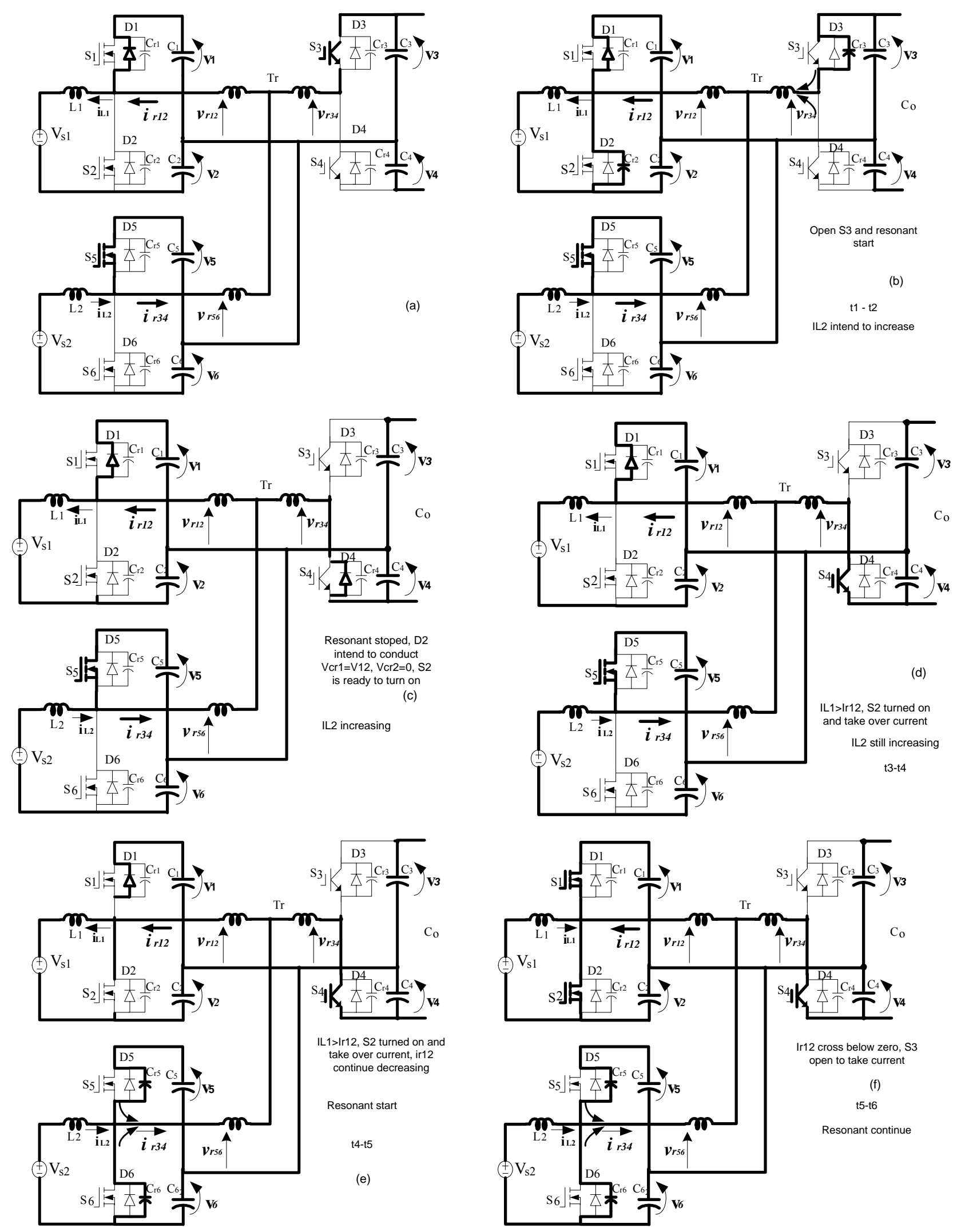

Fig. 3.6. Communication step diagrams during a switching cycle in buck mode. 

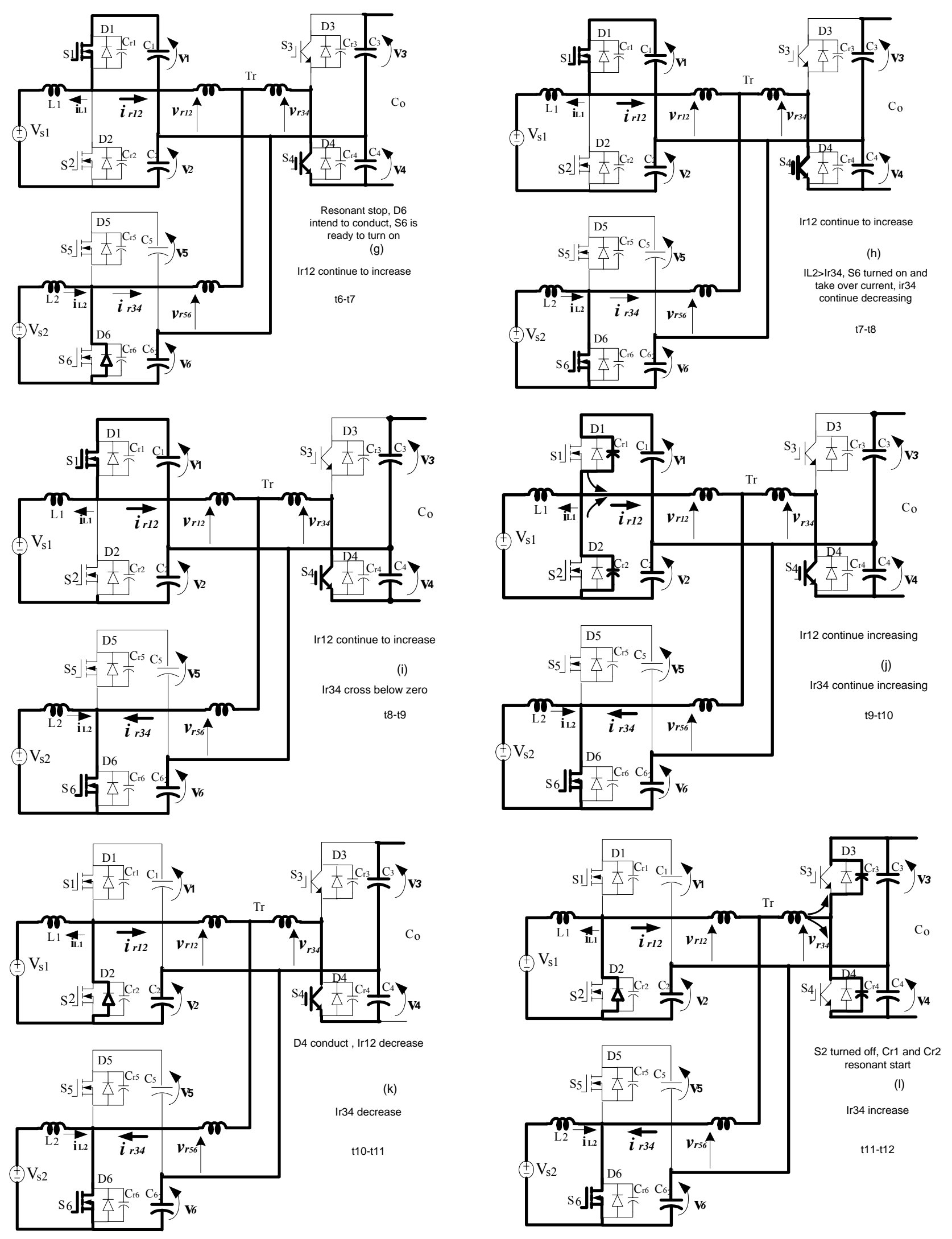

Fig. 3.6. Communication step diagrams during a switching cycle in buck mode (cont'd). 

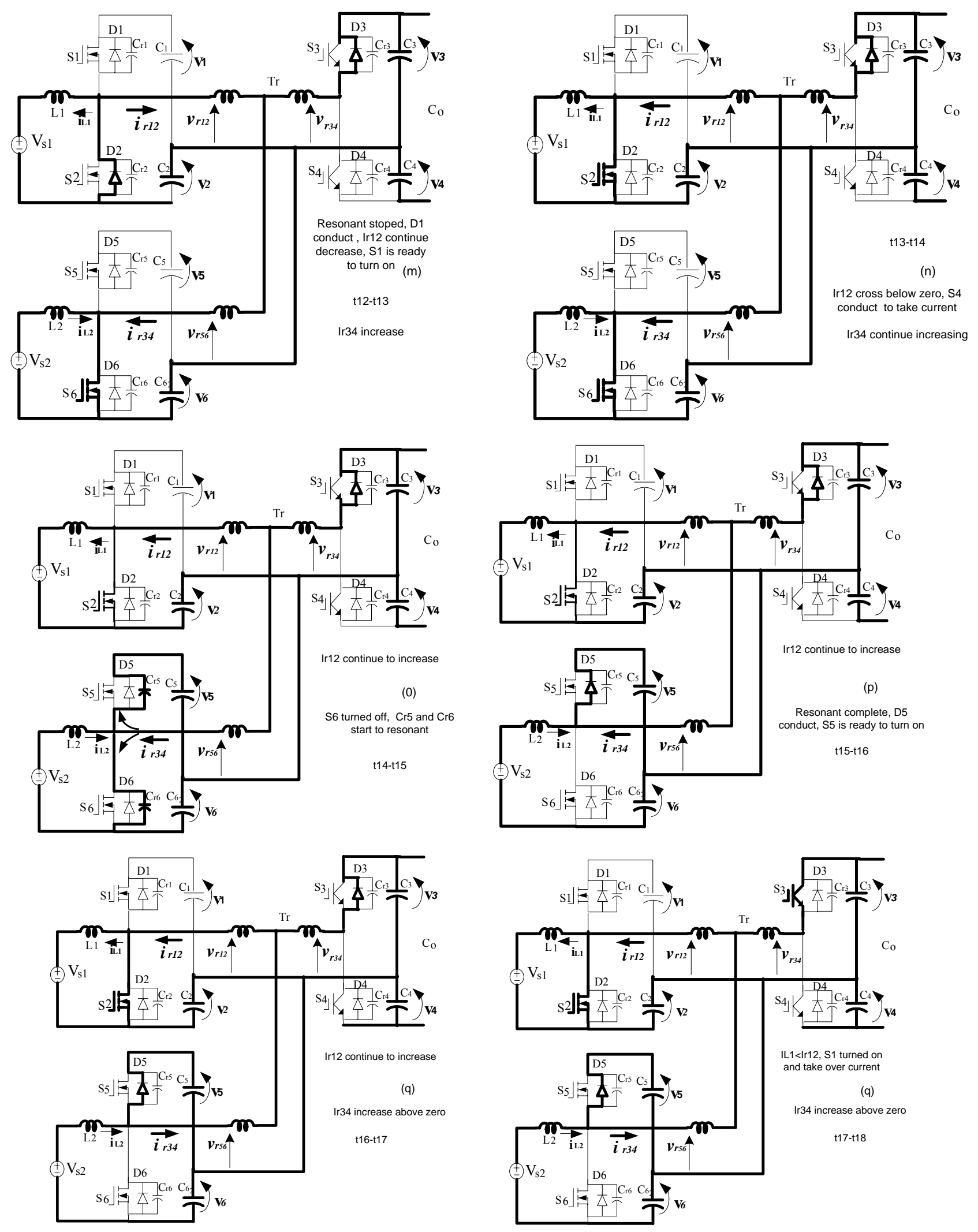

Fig. 3.6. Communication step diagrams during a switching cycle in buck mode (cont'd). 

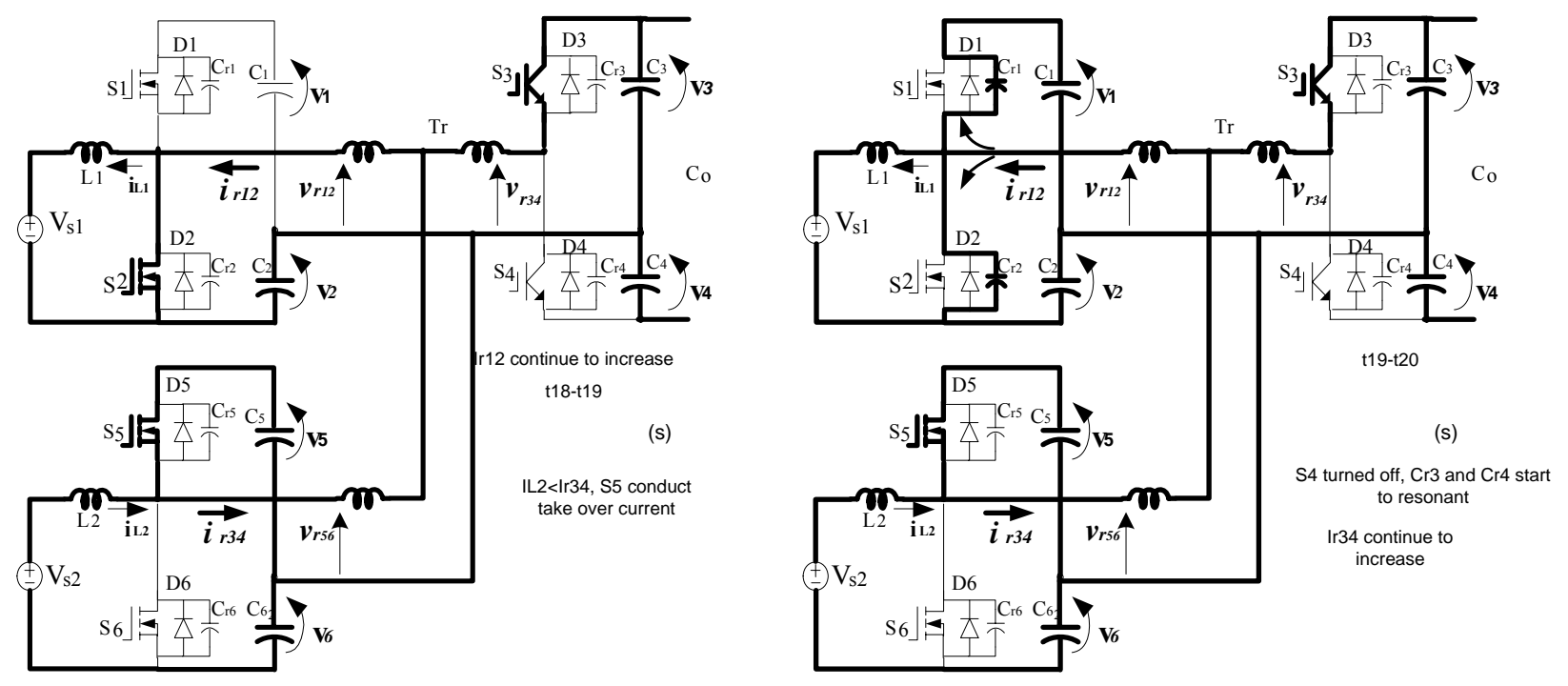

Fig. 3.6. Communication step diagrams during a switching cycle in buck mode (cont'd). 


\section{STEADY-STATE ANALYSIS AND DESIGN GUIDELINES}

\subsection{OUTPUT CHARACTERISTICS}

If no loss is considered in the converter, the input power equals the output power. The derivation of output power is based on the primary-referred equivalent circuit and the idealized waveforms in Fig. 4.1. The following assumptions are made to simplify the analysis:

- The inductance of $L_{1}$ and $L_{2}$ is large enough to maintain the currents flowing through them and the assumption is made that they are constant.

- All switching devices are considered ideal.

- The output filter capacitors C1-C6 are large enough that $V_{1} \sim V_{6}$ is considered constant.

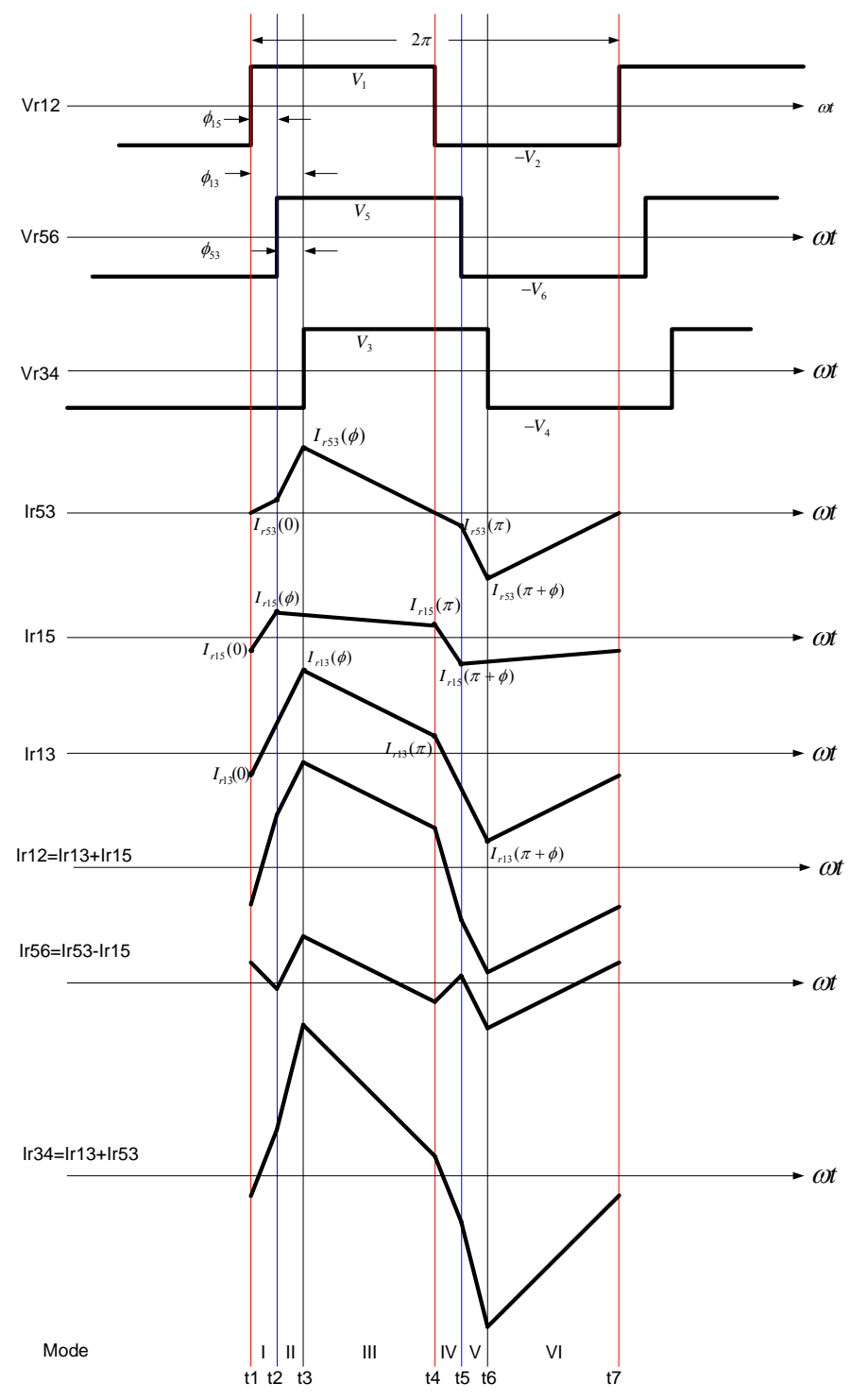

Fig. 4.1. Idealized voltages and current waveforms of a transformer on the condition that

$$
v_{1}=v_{2}=v_{5}=v_{6}<v_{3}=v_{4} \text {. }
$$


According to Fig. 4.1, there are six operating modes in one switching period. The transformer current $\mathrm{I}_{\mathrm{r} 13}, \mathrm{I}_{\mathrm{r} 53}$, and $\mathrm{Ir}_{15}$ is a function of $\theta=\omega t$, where $\omega$ is the switching frequency. In mode I

$$
\left\{\begin{array}{l}
I_{r 13}(\theta)=\frac{V_{1}+V_{4}}{\omega L_{r 13}} \theta+I_{r 13}(0) \\
I_{r 53}(\theta)=\frac{-V_{6}+V_{4}}{\omega L_{r 53}}\left(\theta-\pi-\phi_{13}\right)+I_{r 53}\left(\pi+\phi_{13}\right) \\
I_{r 15}(\theta)=\frac{V_{1}+V_{6}}{\omega L_{r 15}} \theta+I_{r 15}(0)
\end{array} .\right.
$$

Stage I ends at $\theta=\phi_{15}$. In mode II

$$
\left\{\begin{array}{l}
I_{r 13}(\theta)=\frac{V_{1}+V_{4}}{\omega L_{r 13}} \theta+I_{r 13}(0) \\
I_{r 53}(\theta)=\frac{V_{5}+V_{4}}{\omega L_{r 53}}\left(\theta-\phi_{15}\right)+I_{r 53}(0) \\
I_{r 15}(\theta)=\frac{V_{1}-V_{5}}{\omega L_{r 15}}\left(\theta-\phi_{15}\right)+I_{r 15}\left(\phi_{15}\right)
\end{array} .\right.
$$

Mode II ends at $\theta=\phi_{13}$. In mode III

$$
\left\{\begin{array}{l}
I_{r 13}(\theta)=\frac{V_{1}-V_{3}}{\omega L_{r 13}}\left(\theta-\phi_{13}\right)+I_{r 13}\left(\phi_{13}\right) \\
I_{r 53}(\theta)=\frac{V_{5}-V_{3}}{\omega L_{r 53}}\left(\theta-\phi_{13}\right)+I_{r 53}\left(\phi_{53}\right) \\
I_{r 15}(\theta)=\frac{V_{1}-V_{5}}{\omega L_{r 15}}\left(\theta-\phi_{15}\right)+I_{r 15}\left(\phi_{15}\right)
\end{array} .\right.
$$

Mode III ends at $\theta=\pi$. In mode IV

$$
\left\{\begin{array}{l}
I_{r 13}(\theta)=\frac{-V_{2}-V_{3}}{\omega L_{r 13}}(\theta-\pi)+I_{r 13}(\pi) \\
I_{r 53}(\theta)=\frac{V_{5}-V_{3}}{\omega L_{r 53}}\left(\theta-\phi_{13}\right)+I_{r 53}\left(\phi_{53}\right) \\
I_{r 15}(\theta)=\frac{-V_{2}-V_{5}}{\omega L_{r 15}}(\theta-\pi)+I_{r 15}(\pi)
\end{array}\right.
$$

Mode IV ends at $\theta=\pi+\phi_{15}$. In mode $\mathrm{V}$ 


$$
\left\{\begin{array}{l}
I_{r 13}(\theta)=\frac{-V_{2}-V_{3}}{\omega L_{r 13}}(\theta-\pi)+I_{r 13}(\pi) \\
I_{r 53}(\theta)=\frac{-V_{6}-V_{3}}{\omega L_{r 53}}\left(\theta-\phi_{15}-\pi\right)+I_{r 53}(\pi) \\
I_{r 15}(\theta)=\frac{-V_{1}+V_{6}}{\omega L_{r 15}}\left(\theta-\pi-\phi_{15}\right)+I_{r 15}\left(\pi+\phi_{15}\right)
\end{array} .\right.
$$

Mode V ends at $\theta=\pi+\phi_{13}$. In stage VI

$$
\left\{\begin{array}{l}
I_{r 13}(\theta)=\frac{-V_{2}+V_{4}}{\omega L_{r 13}}\left(\theta-\pi-\phi_{13}\right)+I_{r 13}\left(\pi+\phi_{13}\right) \\
I_{r 53}(\theta)=\frac{-V_{6}+V_{4}}{\omega L_{r 53}}\left(\theta-\pi-\phi_{13}\right)+I_{r 53}\left(\pi+\phi_{53}\right) \\
I_{r 15}(\theta)=\frac{-V_{1}+V_{6}}{\omega L_{r 15}}\left(\theta-\pi-\phi_{15}\right)+I_{r 15}\left(\pi+\phi_{15}\right)
\end{array}\right.
$$

The output power from $V_{i n 1}$ and $V_{i n 2}$ are found to be

$$
\left\{\begin{array}{l}
P_{1}=\frac{\int_{0}^{2 \pi} I_{r 12}(\theta) V_{r 12}(\theta) d \theta}{2 \pi}=\frac{\phi_{13}\left(\pi-\left|\phi_{13}\right|\right)}{\operatorname{con}_{13}} V_{12} V_{34}+\frac{\phi_{15}\left(\pi-\left|\phi_{15}\right|\right)}{\operatorname{con}_{15}} V_{12} V_{56} \\
P_{2}=\frac{\int_{0}^{2 \pi} I_{r 56}(\theta) V_{r 56}(\theta) d \theta}{2 \pi}=\frac{\phi_{53}\left(\pi-\left|\phi_{53}\right|\right)}{\operatorname{con}_{53}} V_{56} V_{34}+\frac{\phi_{51}\left(\pi-\left|\phi_{51}\right|\right)}{\operatorname{con}_{51}} V_{56} V_{12}
\end{array} .\right.
$$

Where $P_{1}$ and $P_{2}$ can be transferred power in boost mode or buck mode depending on the sign of the phase-shift angles. The output power $P_{o}$ is derived by

$$
P_{0}=P_{1}+P_{2}=\frac{\phi_{13}\left(\pi-\left|\phi_{13}\right|\right)}{\operatorname{con}_{13}} V_{12} V_{34}+\frac{\phi_{53}\left(\pi-\left|\phi_{53}\right|\right)}{\operatorname{con}_{53}} V_{56} V_{34}
$$

When the transferred power is derived, the input-inductor currents and output voltage can be found to be

$$
\left\{\begin{array}{l}
V_{34}=\frac{\phi_{13}\left(\pi-\left|\phi_{13}\right|\right) R}{\operatorname{con}_{13}} V_{12}+\frac{\phi_{53}\left(\pi-\left|\phi_{53}\right|\right) R}{\operatorname{con}_{53}} V_{56} \\
I_{L 1}=\frac{\phi_{13}\left(\pi-\left|\phi_{13}\right|\right)}{\operatorname{con}_{13}} \frac{V_{34}}{D}+\frac{\phi_{15}\left(\pi-\left|\phi_{15}\right|\right) R}{\operatorname{con}_{15}} \frac{V_{56}}{D} \\
I_{L 2}=\frac{\phi_{53}\left(\pi-\left|\phi_{53}\right|\right)}{\operatorname{con}_{53}} \frac{V_{34}}{D}+\frac{\phi_{51}\left(\pi-\left|\phi_{51}\right|\right) R}{\operatorname{con}_{51}} \frac{V_{12}}{D}
\end{array}\right.
$$

Where $\operatorname{con}_{13}=\operatorname{con}_{31}=4 \pi \omega L_{r 13}, \operatorname{con}_{53}=\operatorname{con}_{35}=4 \pi \omega L_{r 53}$, and $\operatorname{con}_{15}=\operatorname{con}_{51}=4 \pi \omega L_{r 15}$. 
According to Eqs. (1-8), the control variables of the proposed converter are $\phi_{13}$ and $\phi_{53}$. Figure 4.2 describes the output variables $P_{1}, P_{2}$, and $V_{34}$ as functions of these control variables. The interactions between the two input stages exist as expected.
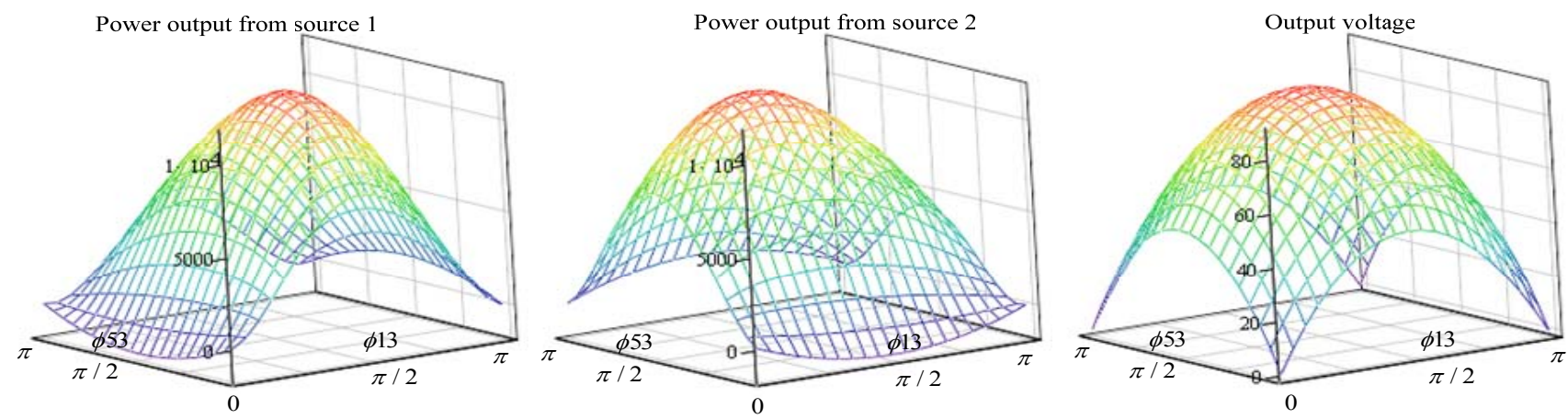

Fig. 4.2. Three-dimensional plot of output power and voltage as a function of control variables $\phi_{13}$ and $\phi_{53}$.

The effects of $\phi_{13}$ and $\phi_{53}$ upon output characteristics can be further illustrated in Fig. 4.3. In each subplot, the output variable has four different operation regions divided by certain values of $\phi_{13}$ and $\phi_{53}$. For example, in the first subplot of Fig. 4.3, $P_{1}$ and $I_{L 1}$ will increase with $\phi_{13}$ and $\phi_{53}$ if $\phi_{13}<\phi_{c r i t 13-P 1}$ and $\phi_{53}<\phi_{c r i t 53-P 1}$, which is denoted in the shaded operation region located at the bottom left corner. Critical points are derived from Eqs. (7) and (8). The critical points will depend on the circuit parameters, such as input voltage or transformer-leakage inductance as well as load resistance. At critical points, the corresponding output will reach the maximum value and the values of these three critical points are different. The critical points are not only useful for converter steady-state design, but also important for the closed-loop controller design. The phase-shift angles should be limited in one of the three shaded operation regions based on which output variable is required to be regulated. For example, if both $I_{L 1}$ and $I_{L 2}$ are required to be controlled, tradeoffs need to be made between them and a smaller value of $\phi_{\text {crit13 }}$ and $\phi_{\text {crit53 }}$ will be chosen to remain stable. In this case, the shaded area shrinks which means a smaller operation range and degraded output capability.
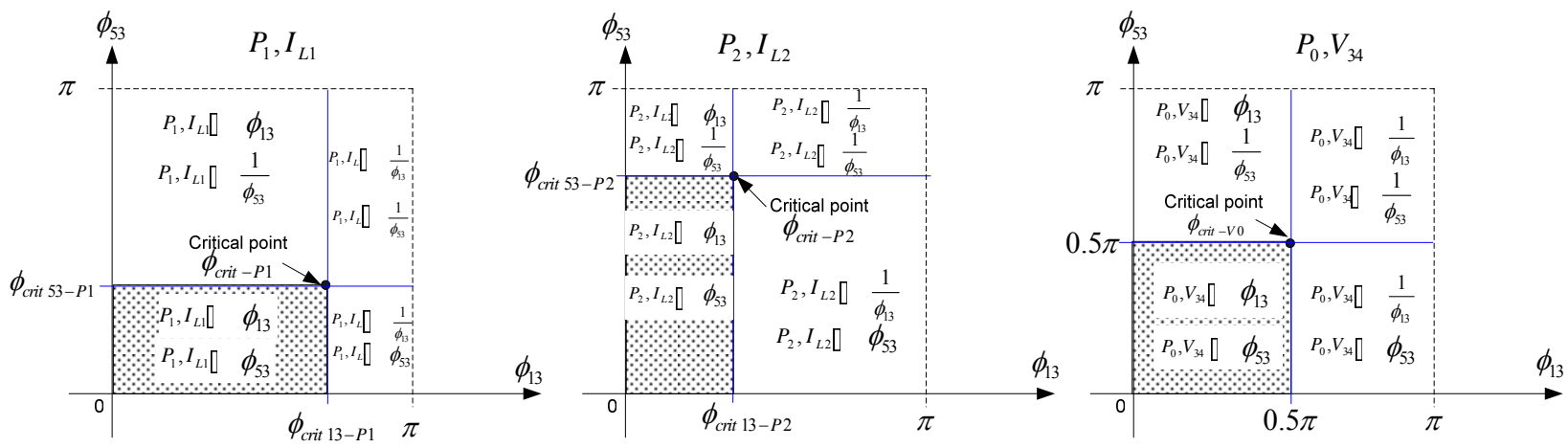

Fig. 4.3. The relation between output characteristics and control variables $\phi_{13}$ and $\phi_{53}$. 


\subsection{SOFT-SWITCHING CONDITIONS}

The commutation mechanism is similar to the single-input ZVS bi-directional converter; i.e., the turn-off device diverts the current to the corresponding resonant capacitors to realize a zero voltage turn-off and the zero voltage turn-on is achieved by gating on the incoming device while the anti-parallel diode is conducting. However, the soft-switching condition becomes more complicated due to the interactions between the two input stages. The soft-switching condition in boost mode is derived in Eq. (10) where the corresponding times can be referred to from Fig. 4.1.

$$
\left\{\begin{array}{l}
f_{1}=I_{r 12}\left(t_{4}\right)-I_{L 1}>0 \\
f_{2}=I_{r 56}\left(t_{5}\right)-I_{L 2}>0 \\
f_{3}=-I_{r 34}\left(t_{6}\right)>0 \\
f_{4}=I_{L 1}-I_{r 12}\left(t_{1}\right)>0 \\
f_{5}=I_{L 2}-I_{r 56}\left(t_{2}\right)>0 \\
f_{6}=I_{r 34}\left(t_{3}\right)>0
\end{array} .\right.
$$

Functions $f_{1}$ to $f_{6}$ denote the six conditions corresponding to switches $S_{2}, S_{6}, S_{4}, S_{1}, S_{5}$, and $S_{3}$ respectively. They can be derived in terms of the control variables $\phi_{13}$ and $\phi_{53}$ that are plotted in Fig. 4.4. The phase-shift angle could be in the range $[-\pi, \pi]$, but only the range $[0, \pi]$ is considered as an example here since $[-\pi, 0]$ is symmetrical to it. As we can see from Fig. 4.4, the soft-switching conditions of $S_{1}$ and $S_{2}$ will be easier to be met with the increase of $\phi_{13}$ and the decrease of $\phi_{53}$, which means the soft-switching conditions of one input stage is influenced by the control variable of the other input stage. Functions $f_{2}$ and $f_{5}$ are always positive, which means $S_{6}$ and $S_{5}$ will remain soft-switching regardless of the values of $\phi_{13}$ and $\phi_{53}$. However, the interactions between the two input stages exist as well. The soft-switching conditions of $S_{3}$ and $S_{4}$ will be satisfied with large values for $\phi_{13}$ and $\phi_{53}$. 
Soft-switching condition 1

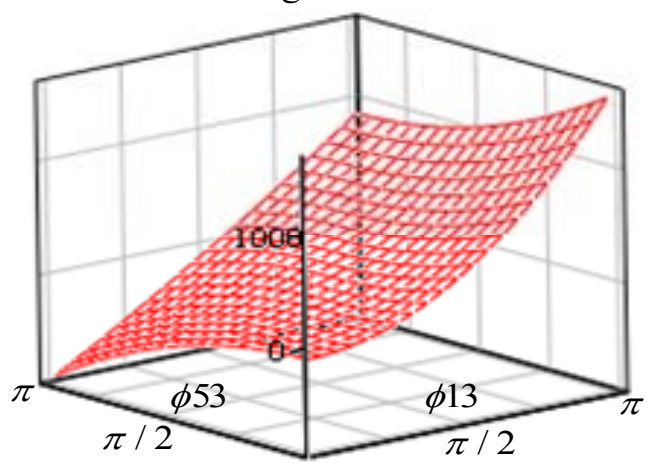

Soft-switching condition 4

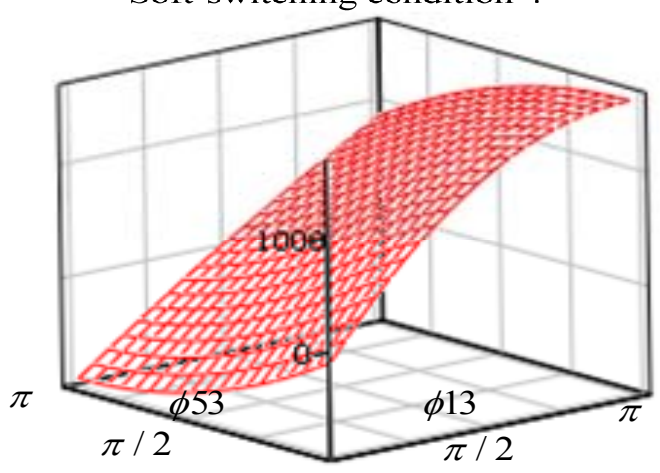

Soft-switching condition 2

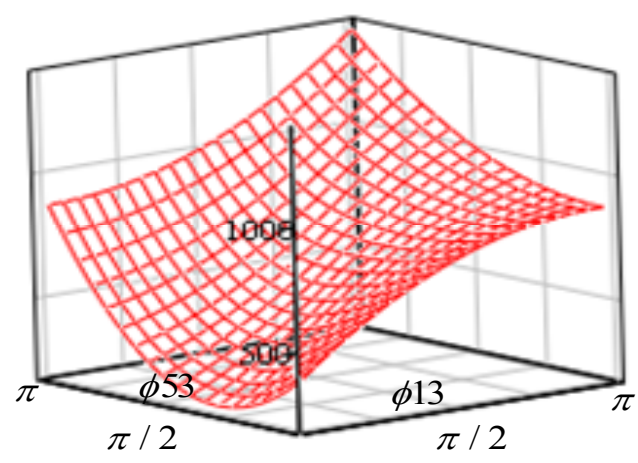

Soft-switching condition 5

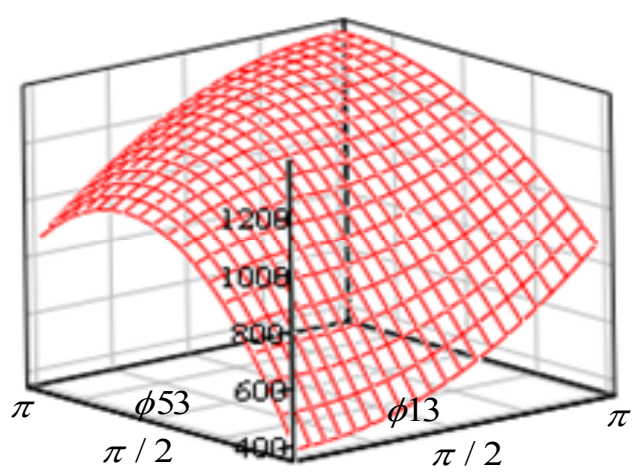

Soft-switching condition 3

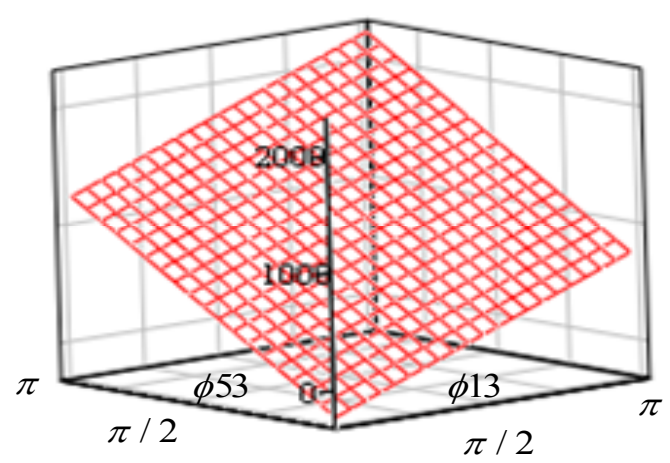

Soft-switching condition 6

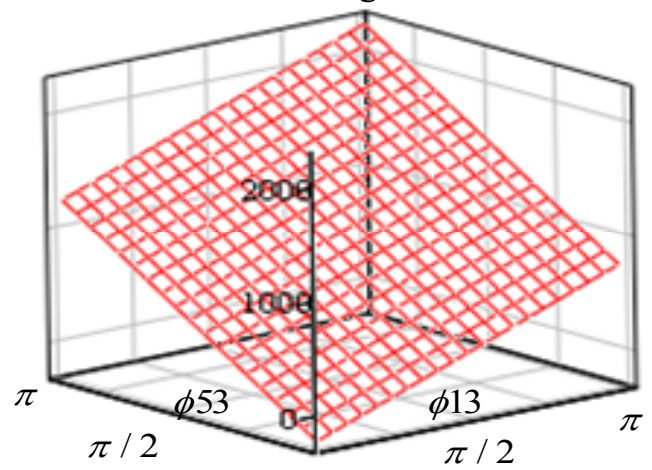

Fig. 4.4. The relation between soft-switching conditions and control variables $\phi_{13}$ and $\phi_{53}$. 


\subsection{SIMULATION VERIFICATION}

The circuit simulation results for boost and buck modes are presented to verify the theoretical analysis. The parameters used for simulation are described as

$$
L_{1}=L_{2}=5 \mu \mathrm{H} .
$$

The switching frequency is $f_{s}=20 \mathrm{kHz}$, and the transformer ratios are $N_{12}: N_{56}: N_{34}=1: 1: 12$, with $L_{r 13}=L_{r 53}=0.3 \mu \mathrm{H}$, and $L_{r 15}=0.6 \mu \mathrm{H}$.

The filter capacitors values are $C_{1}=C_{2}=C_{3}=C_{4}=C_{5}=C_{6}=0.01 \mathrm{~F}$ and the resonant capacitors are $C_{r 1}=C_{r 2}=C_{r 3}=C_{r 4}=C_{r 5}=C_{r 6}=3 u F$. The output voltage with transformer ratio is selected to be $v_{o}=\left(v_{3}+v_{4}\right) \times 12=288 \mathrm{~V}$.

\subsubsection{Boost Mode}

Simulated waveforms for the boost mode use $\phi_{13}=0.35 \pi, \phi_{53}=0.25 \pi, I_{L 1}=295 \mathrm{~A}$, $I_{L 2}=142.5 \mathrm{~A}, P_{1}=3540 \mathrm{~W}, P_{2}=2565 \mathrm{~W}, V_{i n 1}=12 \mathrm{v}$, and $V_{i n 2}=18 \mathrm{v}$. Simulated waveforms are presented in Fig. 4.5.

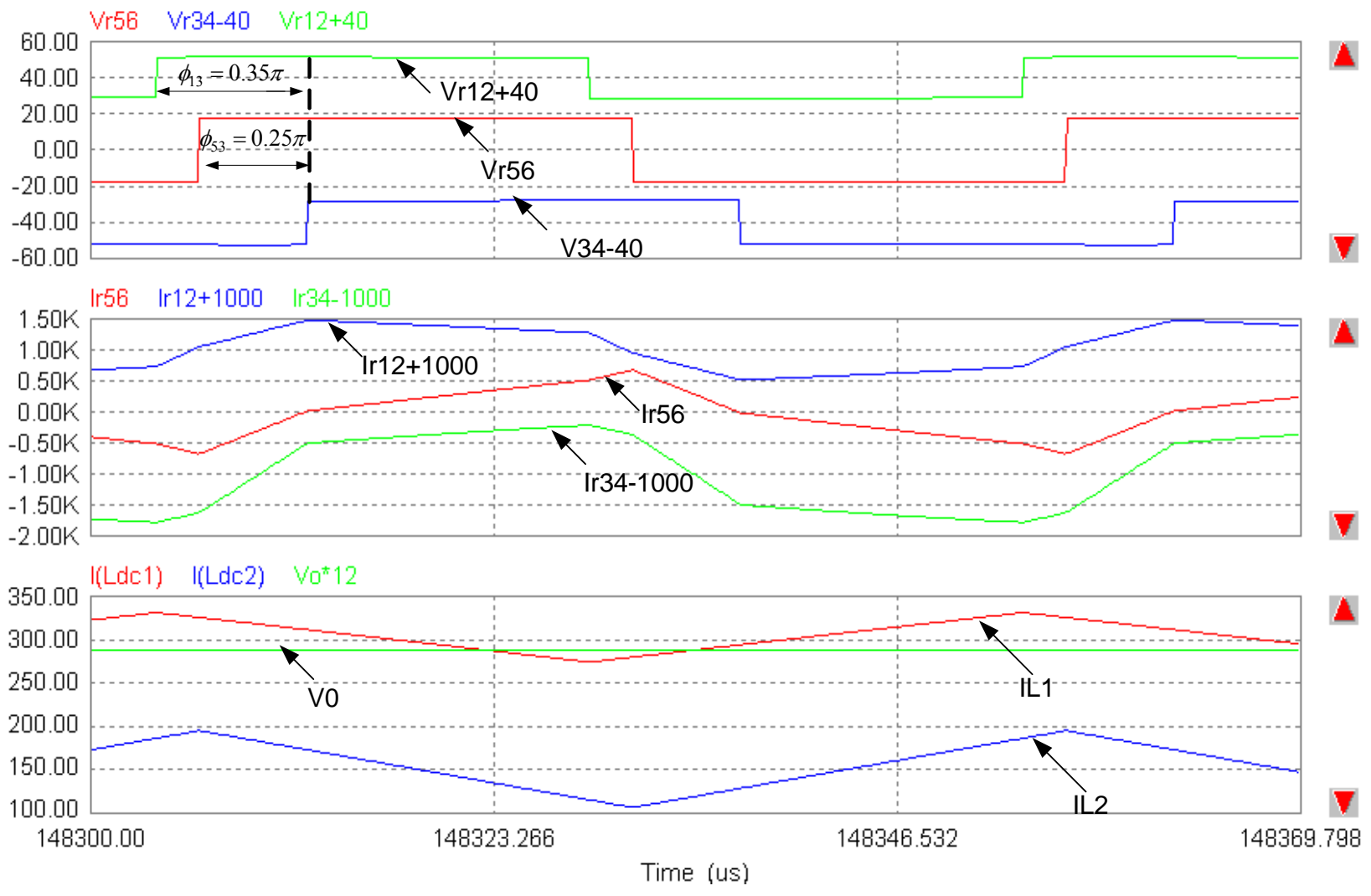

Fig. 4.5. Simulated waveforms for boost mode. 


\subsubsection{Buck Mode}

Simulated waveforms for the buck mode use $\phi_{13}=-0.2 \pi, \phi_{53}=-0.274 \pi, I_{L 1}=-108.6 \mathrm{~A}$, $I_{L 2}=-233.1 A, P_{1}=1976 \mathrm{~W}$, and $P_{2}=4778.5 \mathrm{~W}$. The charge voltages are $V_{i n 1}=18 \mathrm{~V}$ and $V_{\text {in } 2}=20 \mathrm{~V}$. Simulated waveforms are presented in Fig. 4.6.

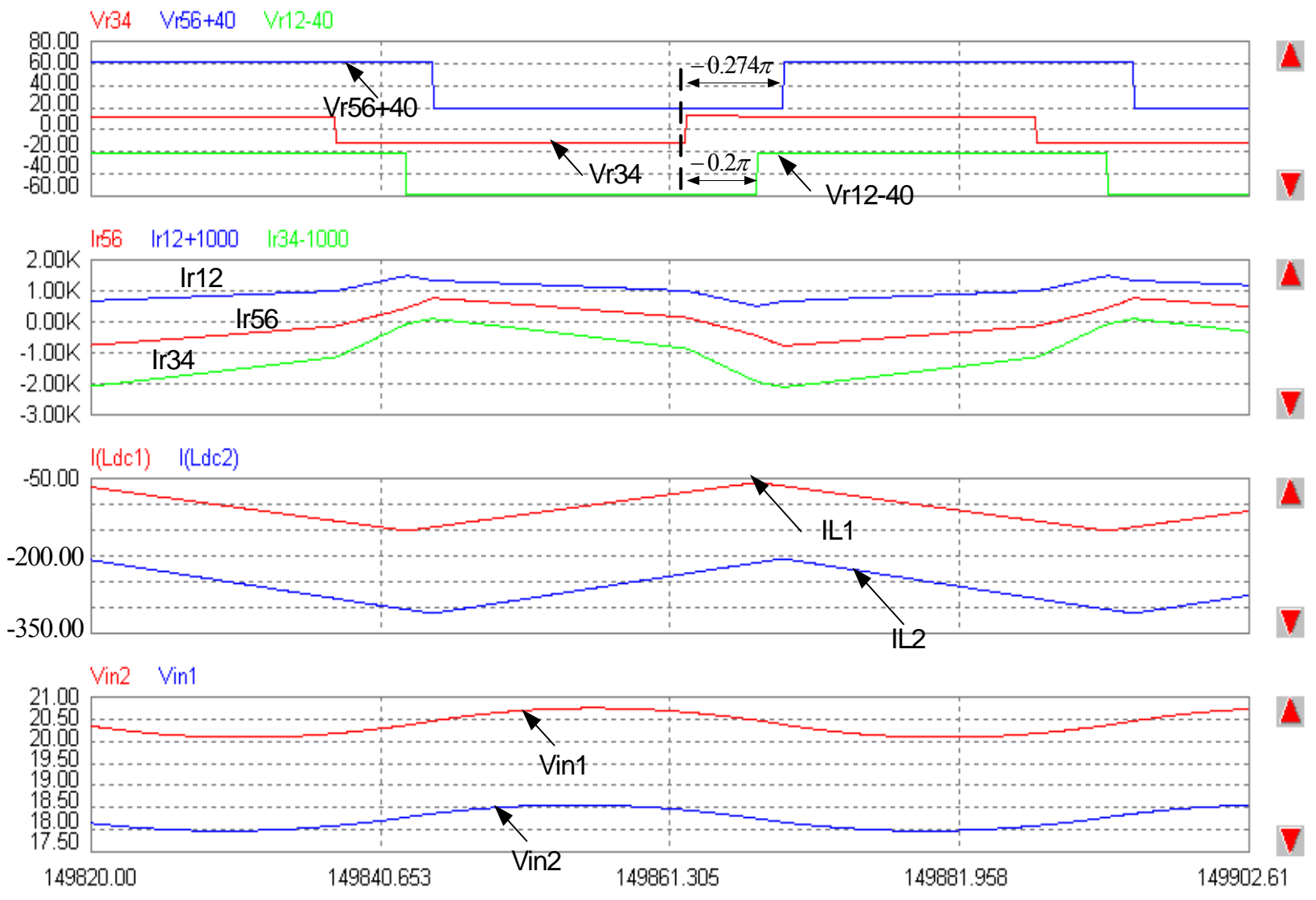

Fig. 4.6. Simulated waveforms for buck mode. 


\section{DESIGN AND IMPLEMENTATION}

The specifications of the proposed dc-dc converter application are reviewed as

- The nominal voltage at the LVS of one input is $12 \mathrm{~V}$ and another input is $16 \mathrm{~V}$. These values can vary from $8-16 \mathrm{~V}$ and from $12-20 \mathrm{~V}$ during charging and discharging.

- The nominal high-side voltage is $288 \mathrm{~V}$, with an operating range of $255-425 \mathrm{~V}$.

- Nominal discharging power of the two inputs is $2 \mathrm{~kW}$ and $3.5 \mathrm{~kW}$, respectively.

- The nominal output power is $5 \mathrm{~kW}$.

- Bus capacitance $\mathrm{C}_{\mathrm{o}}$ is less than $2000 \mu \mathrm{F}$.

The numerical design guidelines are briefly listed here (see Appendix A for Mathcad Design file). If $L_{d c 1}$ and $L_{d c 2}$ are designed as $6 \mu \mathrm{H}, L_{r 12}$ is selected as $0.5 \mu \mathrm{H}, L_{r 56}$ is $0.4 \mu \mathrm{H}, \phi_{13}=0.4 \pi$, $\phi_{53}=0.4 \pi, \eta=90 \%, \mathrm{~V}_{\text {out }}=380 \mathrm{~V}$, and $\mathrm{R}=27 \Omega$; then the discharging power of the two inputs are calculated as $P_{1}=2.2 \mathrm{~kW}, P_{2}=3.7 \mathrm{~kW}$, and $P_{o}=5.3 \mathrm{~kW}$. The average currents provided by the two inputs can be found to be $I_{d 1}=185 \mathrm{~A}$ and $I_{d 2}=232 \mathrm{~A}$ with current ripple of $50 \mathrm{~A}$ for $L_{d c 1}$ and $67 \mathrm{~A}$ for $L_{d c 2}$. The root-mean square (rms) and peak current for each device and leakage inductances $L_{r 12}, L_{r 56}$, and $L_{r 34}$ are derived as indicated in Table 5.1.

Table 5.1. Current rating for each device and leakage inductances

\begin{tabular}{|l|c|c|c|c|c|c|c|c|}
\hline & S1 & S2 & S3 & S4 & S5 & S6 & Lr12 & Lr56 \\
\hline RMS current (A) & 104 & 193 & 33 & 33 & 293 & 369 & 237 & 363 \\
\hline Peak current (A) & 400 & 400 & 59 & 59 & 625 & 618 & 328 & 393 \\
\hline
\end{tabular}

\subsection{MAGNETIC-COMPONENT DESIGN}

\subsubsection{Transformer Design}

A multi-winding transformer plays an important role in this converter circuit. The leakage inductance of the transformer is utilized as an energy-transfer element between the inputs and the load. The leakage inductance is dependent on the geometry of the windings. Figure 5.1 is the designed physical structure of a three-winding transformer for the proposed converter. Only the right half of the transformer is illustrated because of symmetrical characteristics. Windings P11 and P12 are connected in parallel to allow higher current, the same as S11 and S12, and P21 and P22. Fluxes flowing across the core are $\Phi_{m}$ and $\Phi_{0}$. Fluxes between windings are represented as $\Phi_{10}-\Phi_{16}$. 


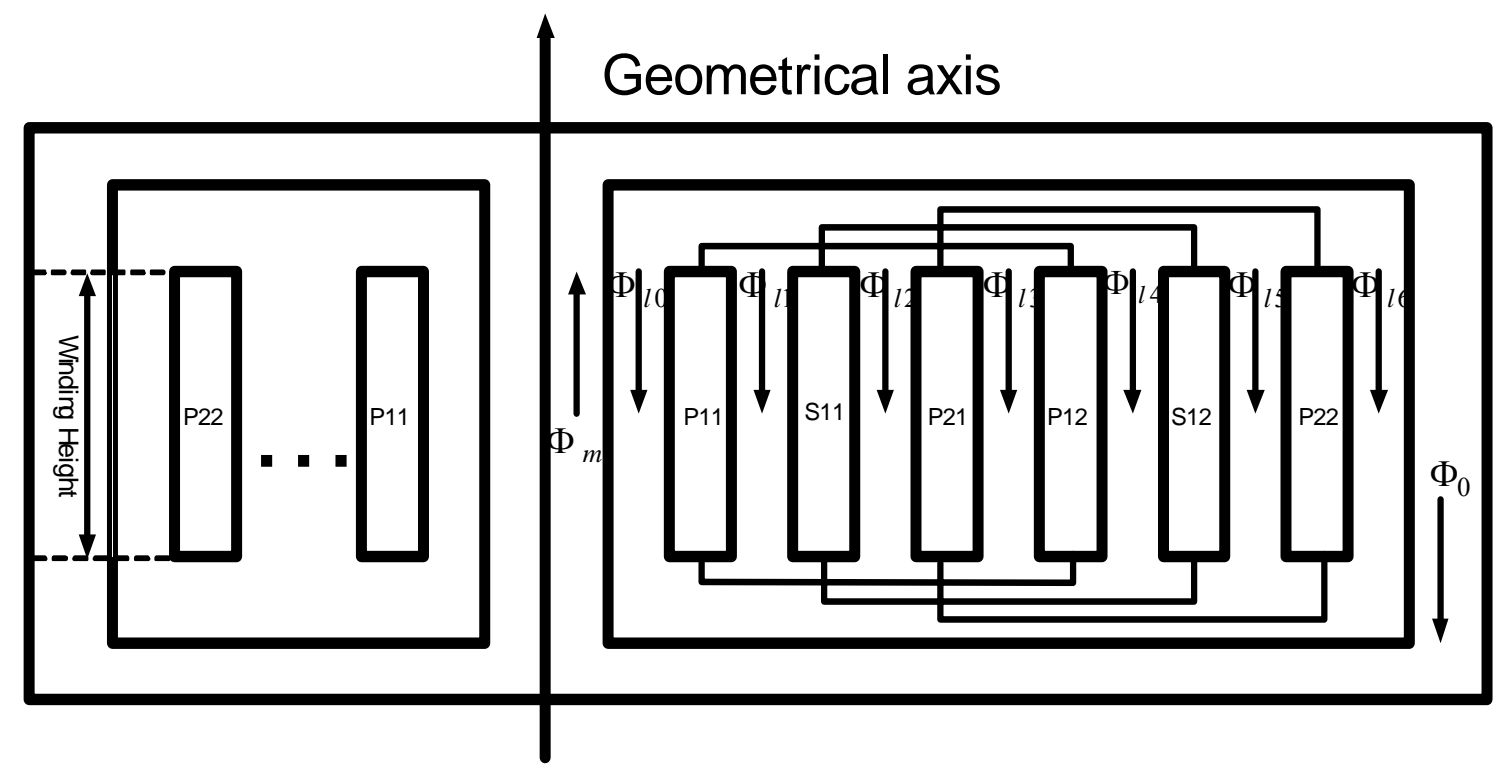

Fig. 5.1. Designed physical structure of a three-winding transformer.

The transformer is very important for the converter design. The ideal transformer should be of high-power density, high efficiency, and high-switching frequency. The issues of core material selection and winding geometry for the minimum core and copper losses at the highest possible switching frequency need to be considered. In addition, the designed-leakage inductance is small and requires the use of special low-leakage transformer design techniques.

\subsubsection{Core-Material Selection}

The characteristics of a good core material include high-operating frequency, low specific-core loss, and low-power/weight ratio. With the selected switching frequency, $f_{s}=20 \mathrm{kHz}$, the Ferroxcube E80/38/20-3C81 core was selected.

The designed winding structure and parameters are shown in Fig. 5.2. The sandwich structure is used to decrease the leakage inductance.

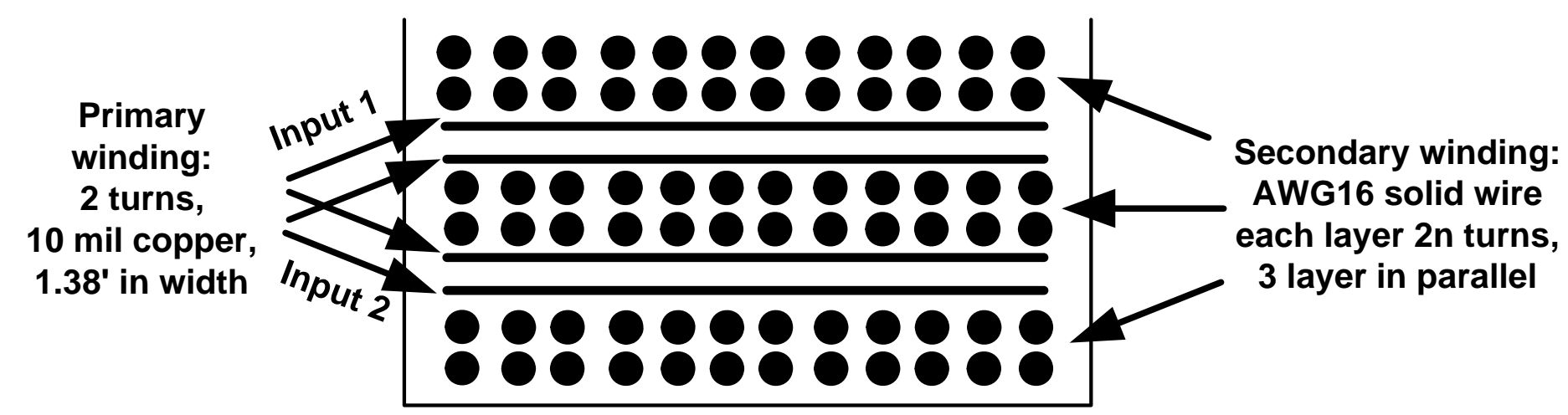

Fig. 5.2. Transformer winding structure. 


\subsubsection{Turns-Ratio Selection}

The main consideration for turns-ratio selection depends on the output voltage matching capability in the full regions of battery, UC, and load variations. It is required that $255 \mathrm{~V} \leq v_{o} \leq 425 \mathrm{~V}$ and $n$ was selected as 12 .

\subsection{BOOST INDUCTOR $\mathrm{L}_{\mathrm{dc}}$ DESIGN}

The boost inductor is designed according to the peak-input current and the required inductance value. In addition, it should not saturate during maximum power-peak charging. The boost inductance $L_{d c}$ was selected as $6 \mu \mathrm{H}$. A Metglas core with high-saturation flux density, AMCC25 from Allied Signal, was selected for the prototype. An eight-turn copper-foil winding was used with an air gap of 0.07 inches on each side. Figure 5.3 is a photo of two boost inductors.

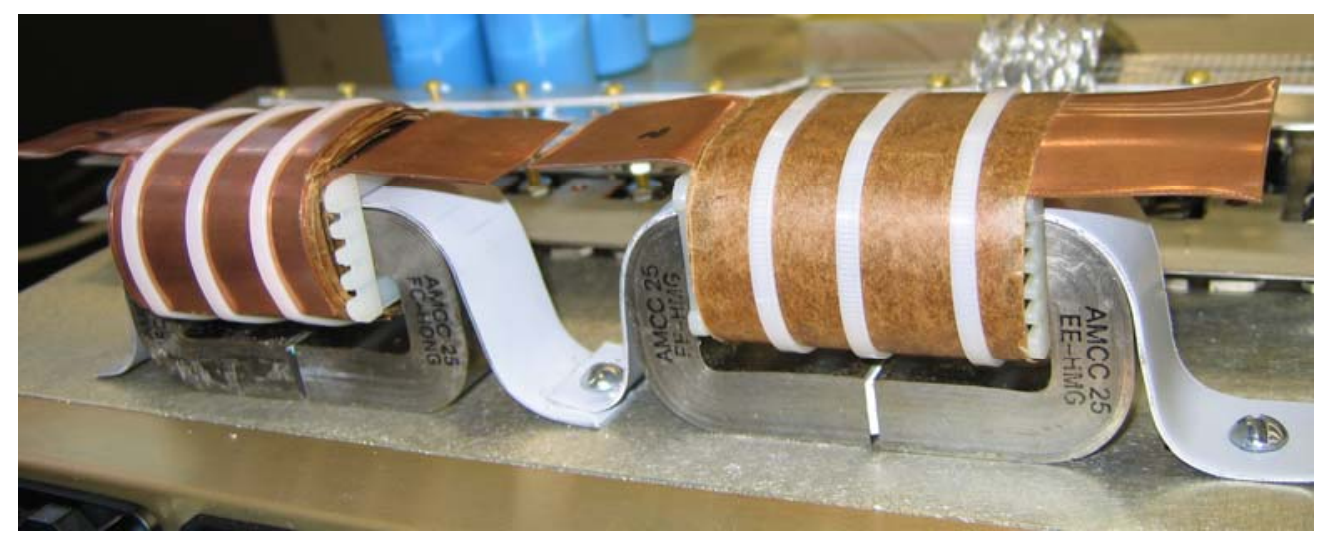

Fig. 5.3. Photo of two boost inductors.

\subsection{LEAKAGE-INDUCTANCE DESIGN}

The leakage inductance of a transformer can be designed to be a very small value. Therefore, the external inductances are required to provide the controllable power to the output. The external leakage inductance, $L_{r 12}$ and $L_{r 56}$, was designed with consideration as to the rms and peak current of transformer. Figure 5.4 is a photo of the fabricated $L_{r 12}$ and $L_{r 56}$. 


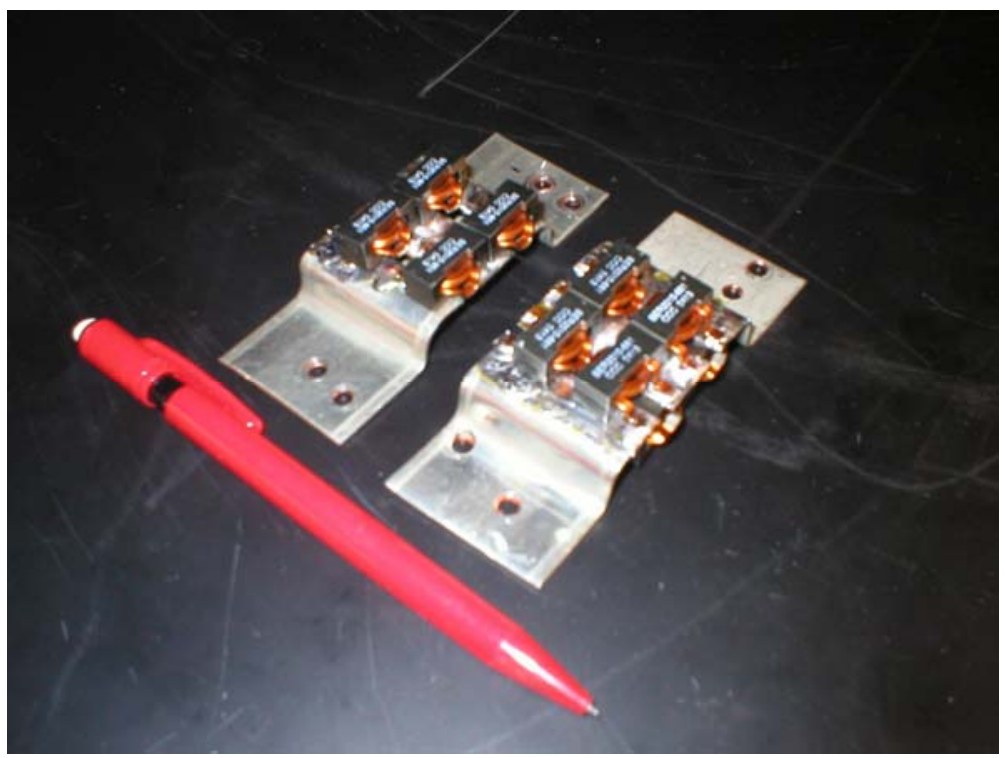

Fig. 5.4. Photo of external leakage inductance $L_{r 12}$ and $L_{r 56}$

\subsection{CAPACITOR SELECTION}

\subsubsection{Resonant Capacitor Selection}

For the LVS and HVS, the capacitances of the resonant capacitors are designed according to the required $d v / d t$ range. A low estimated-series resistance (ESR) and estimated-series inductance (ESL) capacitor is preferred. A polypropylene capacitor was not available with the necessary low-voltage rating, so a ceramic capacitor of $0.1 \mathrm{uF} @ 50 \mathrm{~V}$ was selected for each metal oxide semiconductor field-effect transistor (MOSFET).

The resonant capacitor on the HVS was selected as 0.033uF@600V. A polypropylene capacitor (orange drop) 716P33396K was utilized.

\subsubsection{Capacitor Selection}

The electrolytic capacitors are C1, C2, C3, and C4. The main concerns for selecting the capacitors are the ESR value, the ripple-current capability, and the size. To facilitate the circuit layout, higher density was also considered. United Chemi-Con's 747D812M035AA2A, $8100 \mu \mathrm{F}$ (a) $35 \mathrm{VDC}$, size $\mathrm{D} \times \mathrm{L}$ (inch) $1.375 \times 2.125$, ESR $5.9 \pm 30 \% \mathrm{~m} \Omega$, with a maximum ripple current of $12.8 \mathrm{~A}(\mathrm{rms})$ at $20 \mathrm{kHz}$ was selected for $C_{1}$ and $C_{2}$.

The capacitors for the HVS are Sprague's 80D101P250JA5D, $100 \mu \mathrm{F} @$ 250VDC. The high-

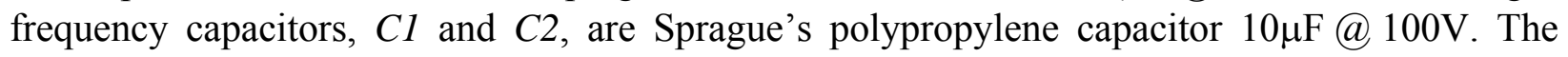
high-frequency capacitors of $C 3$ and $C 4$ are $0.47 \mathrm{uF} @ 400 \mathrm{~V}$ polypropylene capacitors, part number 716P47494M. 


\subsection{POWER SWITCHES}

\subsubsection{LVS Switches}

The low voltage and high-current requirements of the LVS switches are optimized with MOSFETs. When $\mathrm{D}=50 \%$, the voltage across the switch is two times $v_{\text {in }}$ during steady state. Because of the soft-switching characteristics, the overshoot voltage during switching transients is small. Thus, 55V MOSFETs satisfy the requirements. However, a $100 \mathrm{~V}$ device was selected to provide an additional safety margin.

Analysis shows that the peak current of S5 and S6 in steady-state operation in the discharging mode will be more than 600A. The rms current of S6 is estimated at $400 \mathrm{~A}$. Paralleling of MOSFETs is required to handle this large current. Fortunately, the positive temperature coefficient nature of their on-resistance makes current sharing among the paralleled devices a minor concern.

Of greater concern is the on-resistance. Because of high current on the LVS, the conduction loss is significant. Therefore, the on-resistance should be as small as possible. In addition, the onresistance will increase with the temperature above $25^{\circ} \mathrm{C}$.

For the prototype design, the FB180SA10, SOT-227 MOSFETs were selected because of their fast speed, low on-resistance, large current rating, and easy packaging. The related parameters can be found in Table 5.2.

Table 5.2. Datasheet of MOSFETs for LVS switches

\begin{tabular}{|l|l|c|c|c|l|}
\hline Maker & Model & Vds & $\mathbf{I}_{\mathbf{D}}$ & $\mathbf{R d s} \boldsymbol{0} \mathbf{2 5}^{\mathbf{0}} \mathbf{C}$ & Input capacitance \\
\hline IR & FB180SA10 & $100 \mathrm{~V}$ & $180 \mathrm{~A}$ & $0.0065 \mathrm{~W}$ & $10700 \mathrm{pF}$ \\
\hline
\end{tabular}

\subsubsection{HVS Switches}

Since the output voltage range is $255-425 \mathrm{~V}$, the voltage ratings of the high-side switches can be specified at $600 \mathrm{~V}$. For the prototype, a $600 \mathrm{~V} / 75 \mathrm{~A}$ device is first selected. The half-bridge insulated gate bipolar transistor (IGBT) modules are favored due to their packaging design.

A Fuji 2MBI, 75N-060, 600V/75A IGBT half-bridge was selected because of its fast speed. Additional data can be found in Table 5.3.

Table 5.3. IGBT half-bridge for HVS switches

\begin{tabular}{|c|c|c|c|c|c|c|c|c|c|}
\hline \multirow{2}{*}{ Make } & \multirow{2}{*}{ Model } & \multirow{2}{*}{$\mathbf{V}_{\text {CES }}$} & \multirow{2}{*}{$\mathbf{I}_{\mathbf{C}}$} & \multirow{2}{*}{$\mathbf{V}_{\mathbf{C E}}$ (sat) } & \multirow{2}{*}{ Input cap. } & \multicolumn{4}{|c|}{ Switching time $(\mu \mathbf{s e c})$} \\
\cline { 6 - 10 } & & & & & & $\mathbf{t}_{\mathbf{o n}}$ & $\mathbf{t}_{\mathbf{r}}$ & $\mathbf{t}_{\mathbf{o f f}}$ & $\mathbf{t}_{\mathbf{f}}$ \\
\hline Fuji & $2 \mathrm{MBI} 75 \mathrm{~N}-060$ & $600 \mathrm{~V}$ & $75 \mathrm{~A}$ & $3 \mathrm{~V}$ & $4950 \mathrm{pF}$ & 1.2 & 0.6 & 1.0 & 0.35 \\
\hline
\end{tabular}




\subsection{AUXILIARY POWER SUPPLY AND GATE-DRIVE CIRCUITS}

In the proposed converter system, the six switches need six isolated power supplies for gate drivers. According to the devices' characteristics, it was decided to use $+10 \mathrm{~V}$ for the four MOSFET drivers on the LVS and a positive $20 \mathrm{~V}$ for the two IGBT drivers on the high side. In the digital-signal processor (DSP) control board, $+15 \mathrm{~V},-15 \mathrm{~V}$, and $+5 \mathrm{~V}$ power supplies are needed. The schematic view of the power supplies are shown in Fig. 5.5. All of them need accurate regulation.
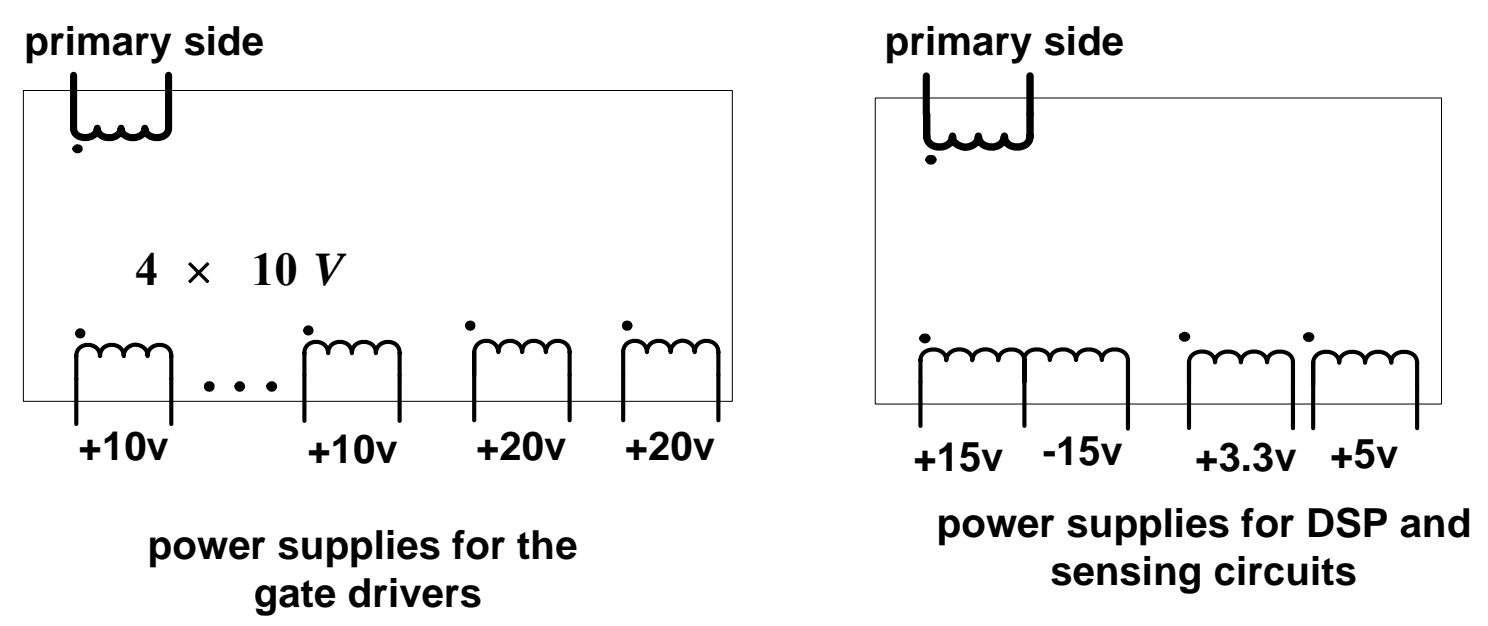

Fig. 5.5. Schematic view of power supplies.

The proper marriage of a MOSFET gate driver and the power MOSFET is essential for good switching performance. Using a gate driver that matches the MOSFET characteristics provides fast rise/fall times and reduces associated losses. The gate drivers selected are MICREL, MIC4451, and MIC4452. With the output of the fly-back power supply for the MOSFET at $10 \mathrm{~V}$, the total maximum gate-driver output current is $8 \mathrm{~A}$. MIC4451 is an inverting driver and the MIC4452 is a non-inverting driver. The supply voltage can be as high as $20 \mathrm{~V}$ and must be capable of providing $12 \mathrm{~A}$ peak-current output.

The power MOSFETs used were six IR's FB180SA10 in parallel. The gate-input capacitance is $10700 \mathrm{pF}$ per device and the gate charge Qg is $250 \mathrm{nC}$ per device. For switches on the LVS, six devices in parallel will have a total gate charge of $1500 \mathrm{nC}$. The device rise and fall times are $351 \mathrm{~ns}$ and $350 \mathrm{~ns}$ at the switching current of $180 \mathrm{~A}$, which is compatible with a switching frequency of $20 \mathrm{kHz}$.

An HP2212 opto-coupler is used to provide electrical isolation between the control circuit and the power stage mainly for its high speed and high-common mode noise rejection. The HP2212 can work with a supply voltage up to $20 \mathrm{~V}$. The output of the opto-coupler drives the MIC4451 and 4452 chip via a pull-up resistor of 350 ohms.

A gate-drive opto-coupler HCPL-316J is used to drive the IGBT modules. Like the traditional IGBT-driver IC EXB840/850, it can also provide over-current protection and fault-status feedback. In addition, it has a smaller footprint size than older drivers. 


\subsection{POWER-STAGE LAYOUT DESIGN}

Low-leakage inductance packaging is important to minimize the conduction loss of the switches. The resonant capacitors must be as close as possible to the main devices to reduce the leakage inductance of the loop and avoid any ringing effects. The connection resistance must be as low as possible; otherwise, the large current flowing through it will add extra losses to the system. The layout of the prototype is shown in Fig. 5.6.

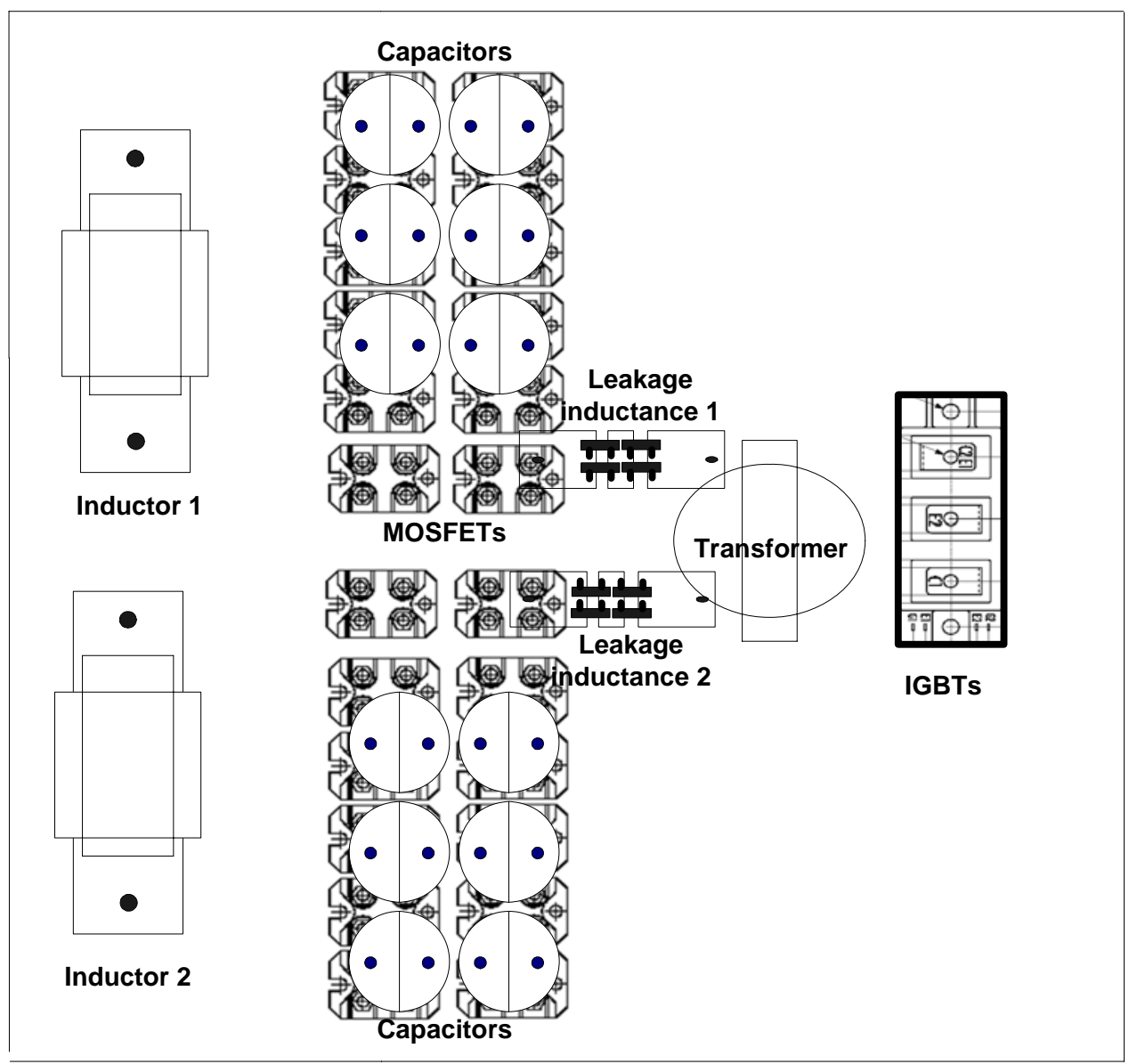

Fig. 5.6. Layout of power circuit. 


\section{EXPERIMENTAL RESULTS}

\subsection{EXPERIMENTAL SETUP}

In order to validate the analysis and simulation results obtained in the previous chapters, a $5 \mathrm{~kW}$ dc-dc converter was built and tested. The prototype is pictured in Fig. 6.1. The power stage is laid on a fan-cooled heat sink and has an overall size of 16 inches in length and 15 inches in width. The size of the converter is 12 inches by 15 inches by 7 inches. The converter is operated at a switching frequency of $20 \mathrm{kHz}$. The transformer-turns ratio is $1: 12$.

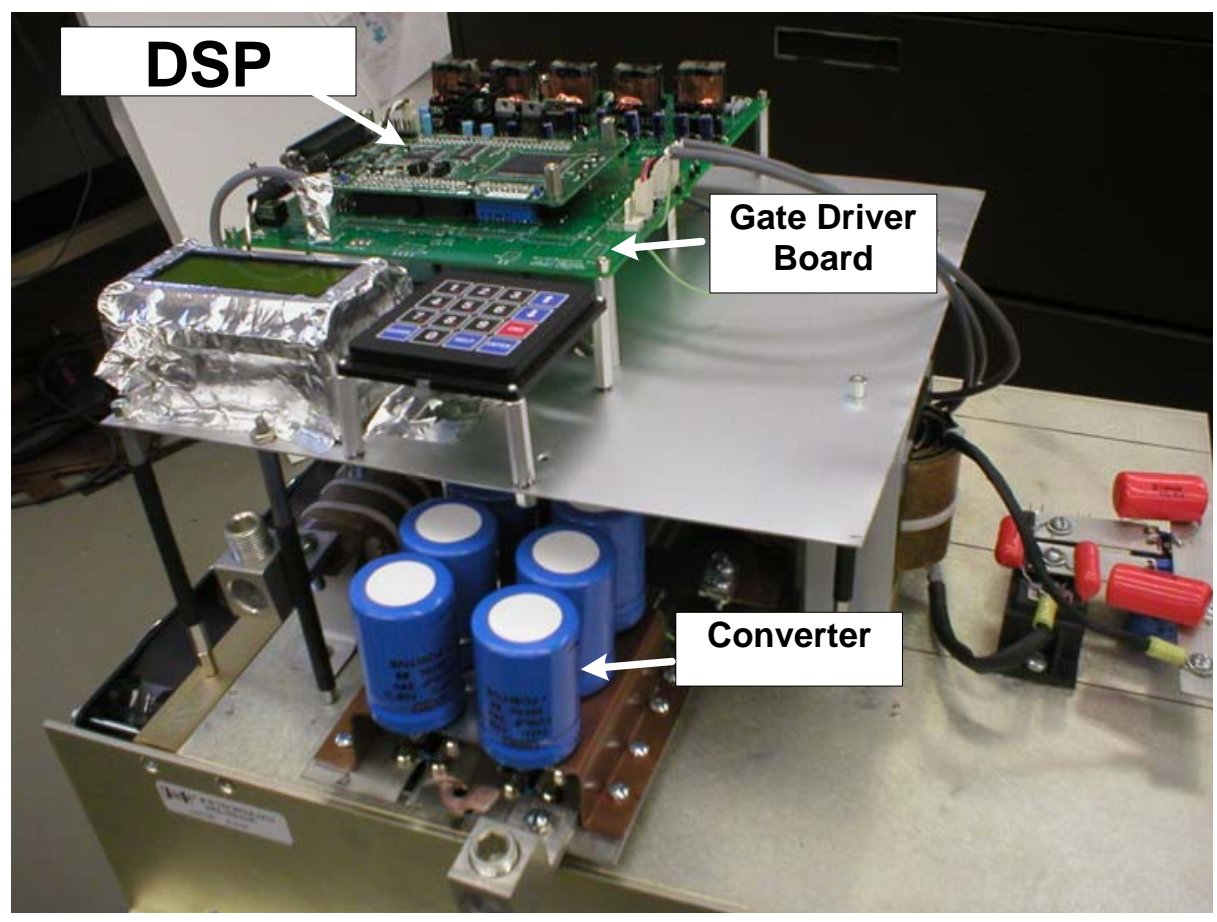

10

Fig. 6.1. Picture of prototype.

S1, S2, S5, S6: $\quad$ IR FB180SA10 100V/80A, SOT-227 MOSFET $\times 6$

S3, S4: $\quad$ FUJI 2MBI75N-060 600V/75A, a half-bridge IGBT module

C1, C2, C5, C6: 747D812M035AA2A, $35 \mathrm{~V}, 8100 \mathrm{uF}$ electrolytic capacitor $\times 3$ (United Chemi-Con)

C3, C4: $\quad$ 80D101P250JA5D, 250V, $100 \mu \mathrm{F}$ electrolytic capacitor (Sprague)

Tr: $\quad 2: 24: 24$ turns, E80/38/20-3C81 core (Ferroxcube)

$\mathrm{L}_{\mathrm{dc}}: \quad 6 \mu \mathrm{H}, 8$ turns copper foil, AMCC-25 Metglas C-core

$\mathrm{L}_{\mathrm{r} 12}: \quad 0.68 \mu \mathrm{H}$ SER2010-681 $\quad 0.80$ (Coilcraft)

$\mathrm{L}_{\mathrm{r} 34:} \quad 0.80 \mu \mathrm{H} \mathrm{SER} 2010-801 \times 8$ (Coilcraft)

Cr1-Cr2: $\quad 0.1 \mu \mathrm{F}, 50 \mathrm{~V}$ ceramic capacitor

Cr3-Cr4: $\quad 600 \mathrm{~V}, 0.033 \mu \mathrm{F}$ polypropylene capacitor 


\subsection{EXPERIMENTAL RESULTS}

\subsubsection{With Phase-Shift Degree}

The measured-circuit waveform during discharging operation at a reduced power rating is shown in Fig.6.2. It can be seen that the first input will provide more power than the second because of its larger phase-shift degree referred to the secondary side. The voltage waveforms of $V_{r 12}, V_{r 34}$, and $V_{r 56}$ do not have high oscillations and large overshoots, which indicate the switches have achieved soft-switching. The soft-switching of each device can be further verified with the derived soft-switching condition as follows

$$
\left\{\begin{array}{l}
f_{1}=I_{r 12}\left(t_{4}\right)-I_{L 1}>0 \\
f_{2}=I_{r 56}\left(t_{5}\right)-I_{L 2}>0 \\
f_{3}=-I_{r 34}\left(t_{6}\right)>0 \\
f_{4}=I_{L 1}-I_{r 12}\left(t_{1}\right)>0 \\
f_{5}=I_{L 2}-I_{r 56}\left(t_{2}\right)>0 \\
f_{6}=I_{r 34}\left(t_{3}\right)>0
\end{array} .\right.
$$

We can see that $f_{1}$ to $f_{6}$ are positive, which means S1-S6 are soft-switching. Figure 6.3 shows the calculated results using Mathcad. The experimental waveform is consistent with the design values.

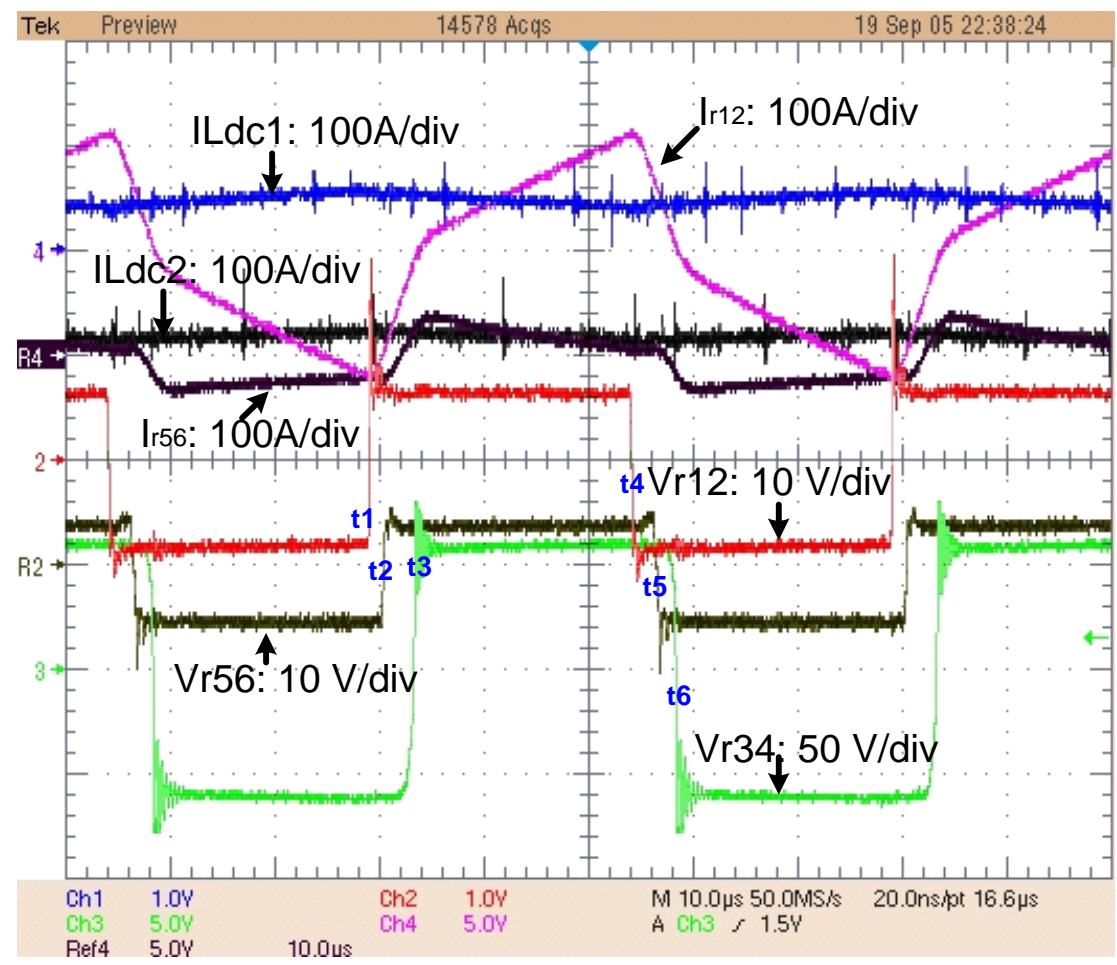

Fig. 6.2. Measured waveform under boost-mode operation with $V_{\text {in1 }}=8 \mathrm{~V}, V_{\text {in2 }}=5 \mathrm{~V}, I_{1}=52 \mathrm{~A}$, $I_{2}=24 \mathrm{~A}, \phi_{13}=0.15 \pi, \phi_{53}=0.1 \pi, L_{r 12}=L_{r 34}=0.4 \mu \mathrm{H}, V_{\text {out }}=123 \mathrm{~V}$, and $P_{\text {out }}=420 \mathrm{~W}$. 


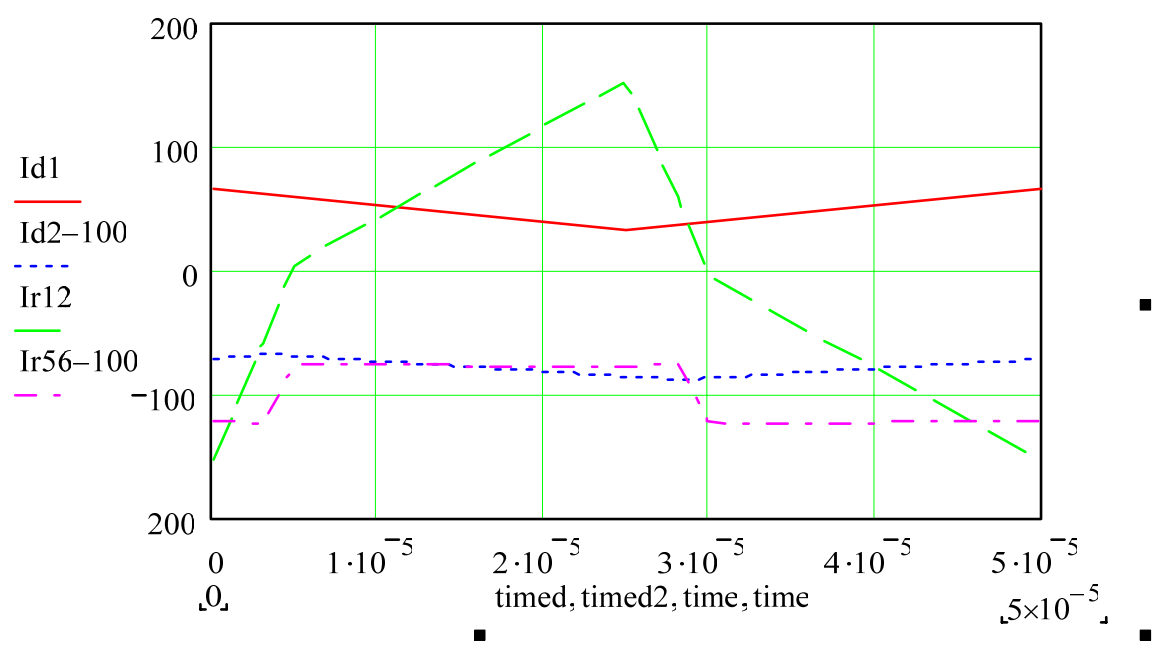

Fig. 6.3. Calculated-current waveform under boost-mode operation with $V_{\text {in1 }}=8 \mathrm{~V}, V_{\text {in2 }}=5 \mathrm{~V}$, $\phi_{13}=0.15 \pi, \phi_{53}=0.1 \pi, L_{r 12}=L_{r 34}=0.4 \mu \mathrm{H}$, and $V_{\text {out }}=123 \mathrm{~V}$.

\subsubsection{No Phase-Shift Degree}

The measured circuit waveforms with no phase-shift degrees are shown in Fig. 6.4. Both inputs provide the same power to the output because they share the same phase-shift degree, which can be observed from $V_{r 12}$ and $V r_{56}$. The input currents $\mathrm{I}_{\mathrm{dc1}}$ and $\mathrm{I}_{\mathrm{dc} 2}$ have the same magnitude and shape as does $I_{r 12}$ and $I_{r 56}$, which are the currents flowing through the primary sides of the transformer. The soft-switching of all six switches provides no high-voltage overshoot or oscillations. The analytical results from Mathcad are compared with the experimental results in Fig. 6.5. 


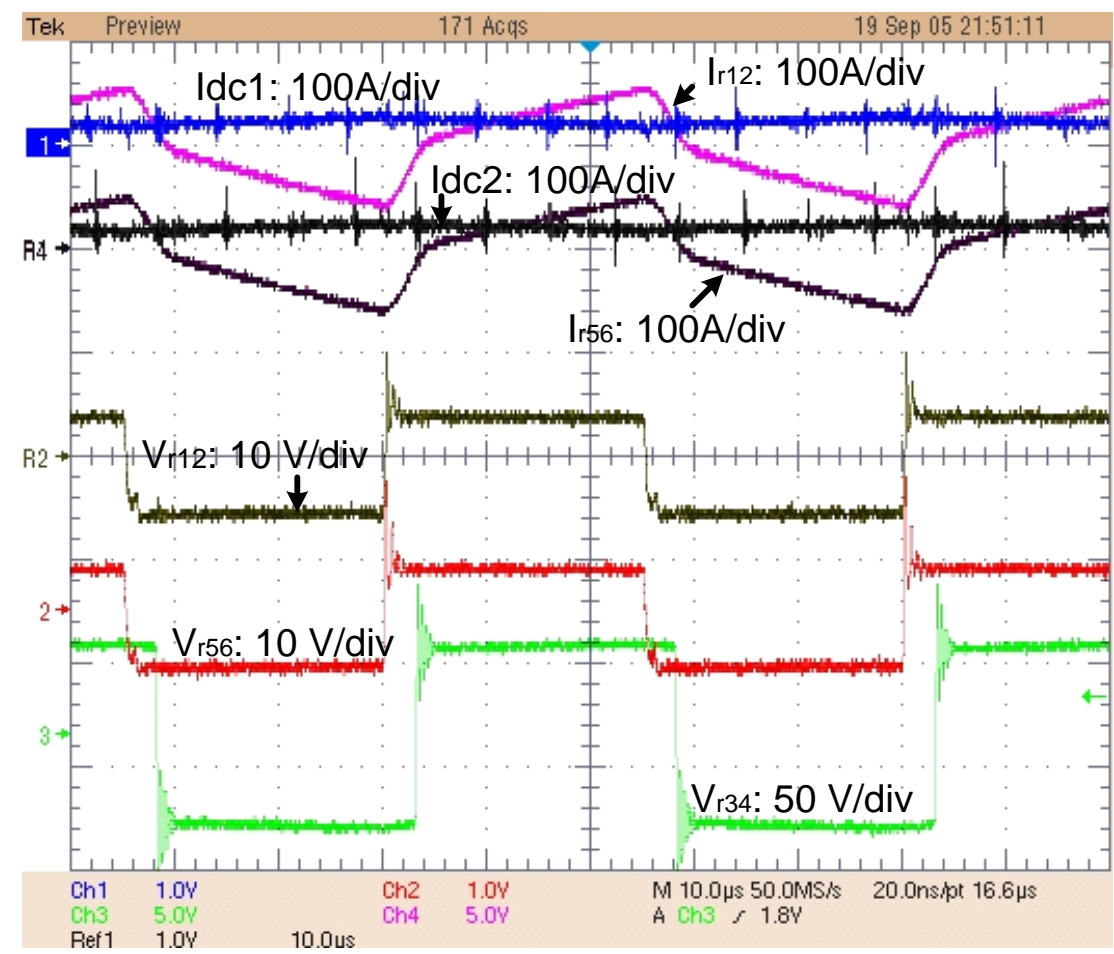

Fig. 6.4. Measured waveform under boost-mode operation with $V_{\text {in } 1}=5 \mathrm{~V}, V_{\text {in2 }}=5 \mathrm{~V}, I_{1}=27 \mathrm{~A}$, $I_{2}=27 \mathrm{~A}, \phi_{13}=0.13 \pi, \phi_{53}=0.13 \pi, L_{r 12}=L_{r 34}=0.4 \mu \mathrm{H}, V_{\text {out }}=90 \mathrm{~V}$, and $P_{\text {out }}=225 \mathrm{~W}$.

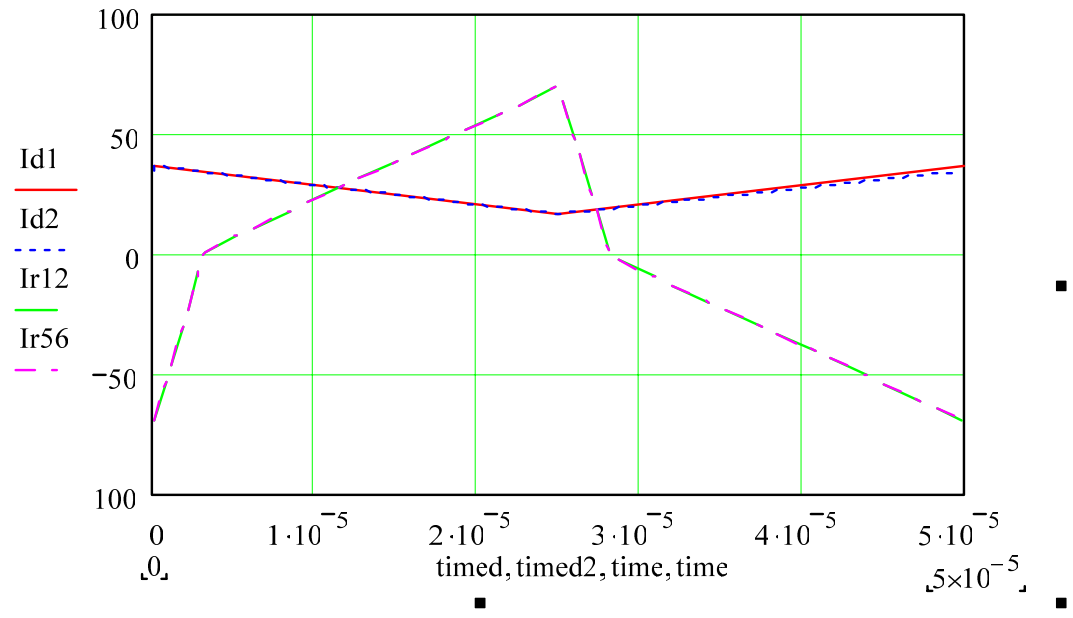

Fig. 6.5. Calculated waveform under boost-mode operation with $V_{\mathrm{in} 1}=5 \mathrm{~V}, \mathrm{~V}_{\mathrm{in} 2}=5 \mathrm{~V}$, $\phi_{13}=0.13 \pi, \phi_{53}=0.13 \pi, L_{r 12}=L_{r 34}=0.4 \mu \mathrm{H}$, and $V_{\text {out }}=90 \mathrm{~V}$.

\subsubsection{Additional Experimental Results}

After the concept of the proposed topology had been verified, the converter was redesigned and tested at a higher-power rating. Figure 6.6 shows the experimental waveforms measured at an output power of $2.597 \mathrm{~kW}$. There is no phase shift between two inputs, so there is no energy 
transferred between the inputs. The analytical result is presented in Fig. 6.7 and shows consistency with the experimental results.

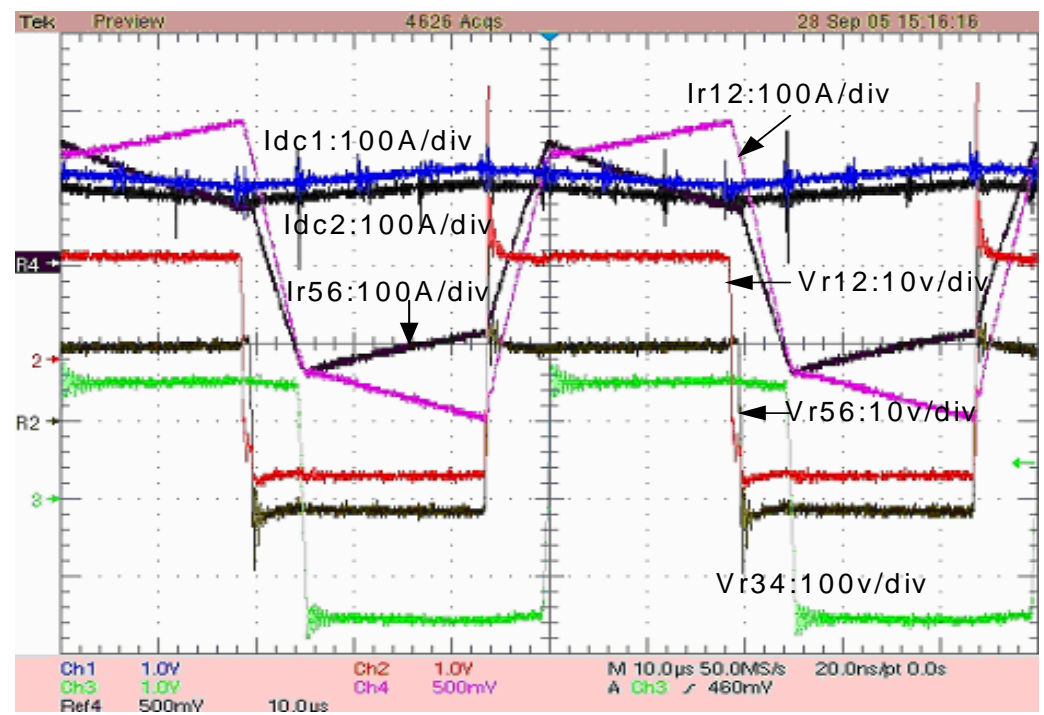

Fig. 6.6. Measured waveform under boost-mode operation with $V_{\mathrm{in} 1}=15 \mathrm{~V}, V_{\mathrm{in} 2}=11 \mathrm{~V}, \mathrm{I}_{1}=123 \mathrm{~A}, I_{2}=92 \mathrm{~A}$, $\phi_{13}=0.25 \pi, \phi_{53}=0.25 \pi, L_{r 12}=0.5 \mu \mathrm{H}, L_{r 34}=0.55 \mu \mathrm{H}, V_{\text {out }}=310 \mathrm{~V}, \mathrm{R}=37 \mathrm{Ohm}$, and $P_{\text {out }}=2597 \mathrm{~W}$.

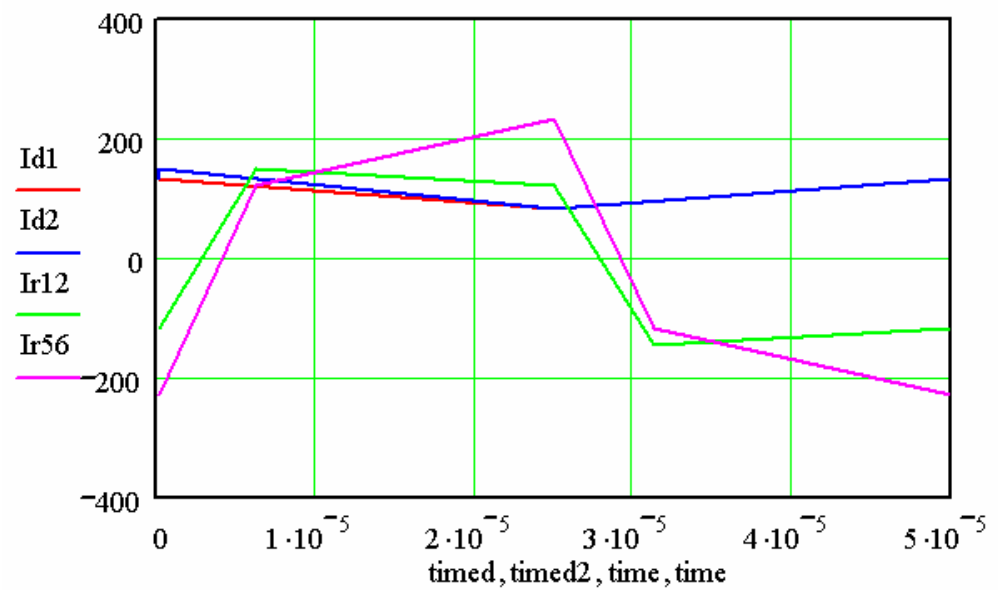

Fig. 6.7. Calculated waveform under boost-mode operation with $V_{\text {in } 1}=15 \mathrm{~V}, V_{\text {in } 2}=11 \mathrm{~V}, I_{1}=123 \mathrm{~A}$, $I_{2}=92 \mathrm{~A}, \phi_{13}=0.25 \pi, \phi_{53}=0.25 \pi, \mathrm{L}_{\mathrm{r} 12}=0.5 \mu \mathrm{H}, \mathrm{L}_{\mathrm{r} 34}=0.55 \mu \mathrm{H}, \mathrm{V}_{\text {out }}=310 \mathrm{~V}, \mathrm{R}=37 \mathrm{Ohm}$, and $P_{\text {out }}=2597 \mathrm{~W}$.

Figure 6.8 shows the experimental waveforms with a phase shift between the two inputs. The output power is $2.681 \mathrm{~kW}$. The analytical result is presented in Fig. 6.9 and shows the consistency with the experimental results. 


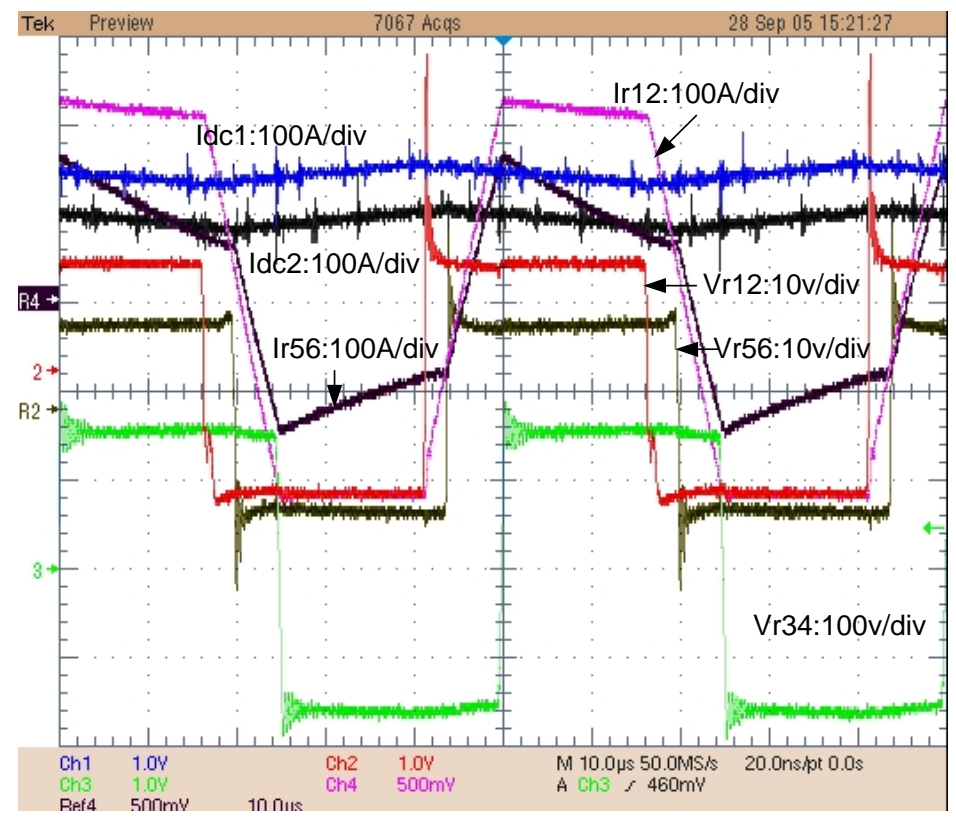

Fig. 6.8. Measured waveform under boost-mode operation with $V_{\text {in1 }}=12.5 \mathrm{~V}, \mathrm{~V}_{\mathrm{in} 2}=10 \mathrm{~V}$, $I_{1}=150 \mathrm{~A}, I_{2}=100 \mathrm{~A}, \phi_{13}=0.35 \pi, \phi_{53}=0.25 \pi, L_{r 12}=0.5 \mu \mathrm{H}, L_{r 34}=0.55 \mu \mathrm{H}, V_{\text {out }}=315 \mathrm{~V}$, $R=370 h m$, and $P_{\text {out }}=2681 \mathrm{~W}$.

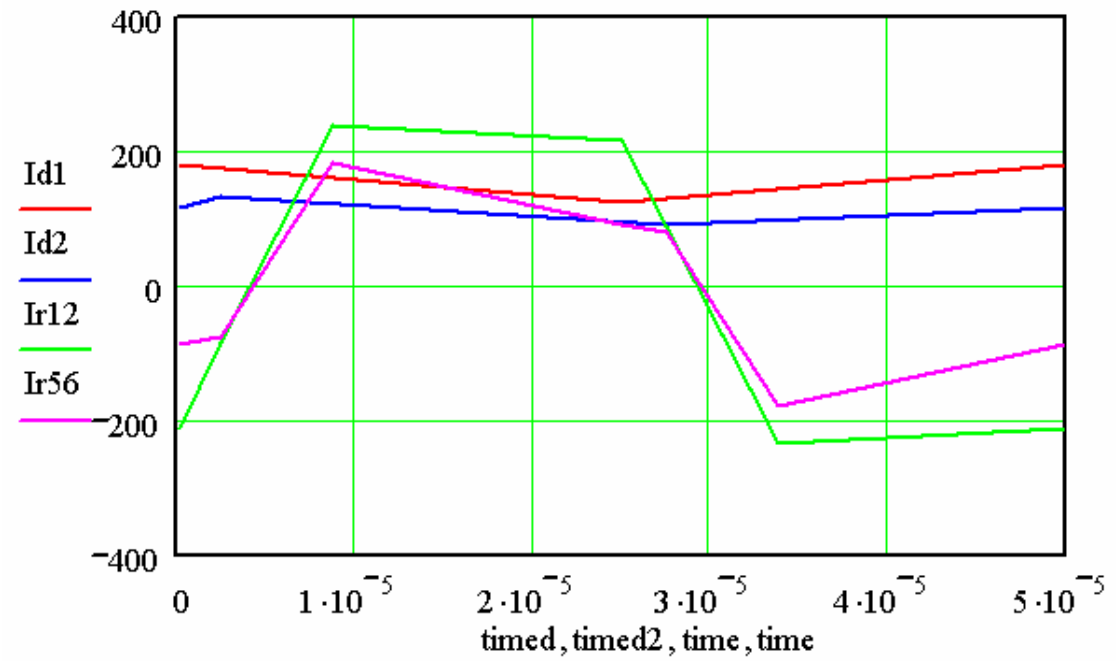

Fig. 6.9. Calculated waveform under boost-mode operation with $V_{\text {in } 1}=12.5 \mathrm{~V}, V_{\text {in } 2}=10 \mathrm{~V}, I_{1}=150 \mathrm{~A}$, $I_{2}=100 \mathrm{~A}, \phi_{13}=0.35 \pi, \phi_{53}=0.25 \pi, L_{r 12}=0.5 \mu \mathrm{H}, L_{r 34}=0.55 \mu \mathrm{H}, V_{\text {out }}=315 \mathrm{~V}, \mathrm{R}=37 \mathrm{Ohm}$, and $P_{\text {out }}=2681 \mathrm{~W}$. 


\title{
APPENDIX A: MATHCAD DESIGN FILE
}

\section{DHB Converter Design File}

\author{
Date : 9/20/06
}

"Filename: twoinput_experi.med

\section{DESIGN INPUT}

$$
\begin{aligned}
& \text { Vin1 }:=12 \quad \text { Vin2 }:=16 \quad \text { fs }:-20 \cdot 10^{3} \quad \mathrm{n}=3.14159265359 \\
& \text { Ldo1 }:=6.10^{-6} \quad \text { Las } 2>-6 \cdot 10^{-6} \quad \text { Vo } 5=330 \quad \eta>0.9
\end{aligned}
$$

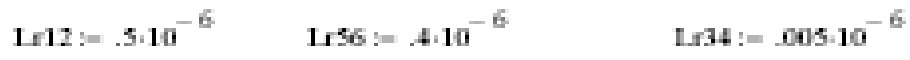

$$
\begin{aligned}
& \phi 13:-4 \pi \quad 453:-4 n \\
& \mathrm{D}=\mathrm{s} \quad \mathrm{n}:=12
\end{aligned}
$$

DESIGN PARAMETERS

$$
\begin{aligned}
& \mathrm{V} 12:=\frac{\mathrm{Vinl}}{\mathrm{D}} \quad \mathrm{V} 56:=\frac{\mathrm{Vin} 2}{\mathrm{D}} \quad \mathrm{V} 1=\mathrm{Vin1} \quad \mathrm{V} 2:=\mathrm{V1} \quad \mathrm{Vs}:=\frac{\mathrm{V} s 6}{2}
\end{aligned}
$$

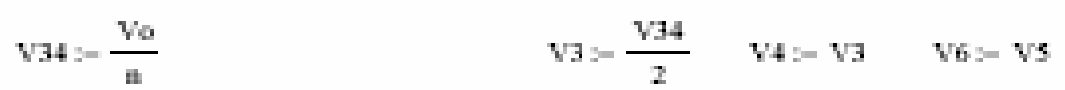

$$
\begin{aligned}
& \phi 15:=\phi 13-\$ 53 \quad \phi 51:=-\phi 15
\end{aligned}
$$

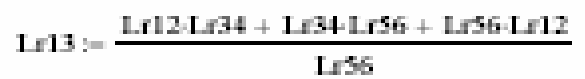

$$
\begin{aligned}
& \operatorname{Lr15}:=\frac{\operatorname{Lr} 12 \operatorname{Lr} 34+\operatorname{Lr} 34 \operatorname{Lr} 56+\operatorname{LrS6} \operatorname{Lr12}}{\operatorname{Lr} 34} \\
& \operatorname{Lr53}:=\frac{\operatorname{Lr} 12 \operatorname{Lr} 34+\operatorname{Lr} 34 \operatorname{Lr} 56+\operatorname{Lr} 56 \cdot \operatorname{Lr12}}{\operatorname{Lr12}} \\
& \mathrm{Ts}:=\frac{1}{\mathrm{is}} \quad \omega=2 \cdot \pi \cdot \mathrm{s}
\end{aligned}
$$

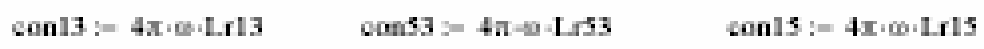




\begin{tabular}{|c|c|c|c|c|}
\hline $112=24$ & $\sqrt{34}-31.6664156-32$ & $\sqrt{0}=320$ & $\mathrm{M}=12$ & $12-12$ \\
\hline $415=0$ & $\$ 61=0$ & \multicolumn{3}{|c|}{$\sqrt{3}-1533 \mathrm{v}-1533 \mathrm{v}-16 \mathrm{~g}$} \\
\hline $1.12=3 \times 10^{-7}$ & $134-5=10^{-9}$ & \multicolumn{2}{|c|}{$1.56-4 \times 10^{-7}$} & $\sqrt{6}=16$ \\
\hline
\end{tabular}

\section{DESIGN VARIABLES}

\section{Qutput Power and output reaister}

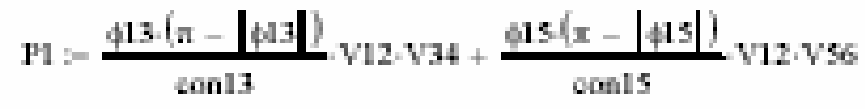

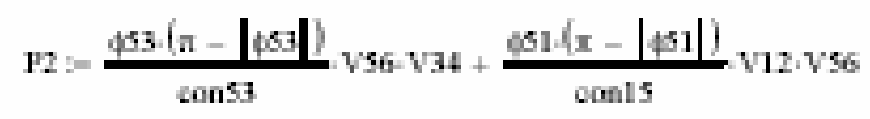

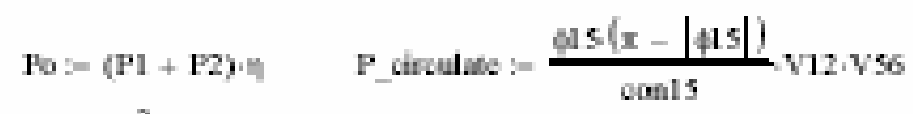

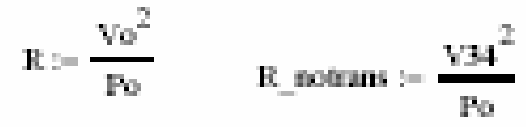

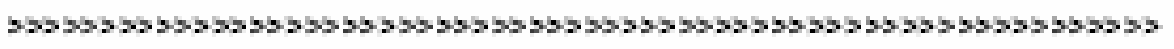

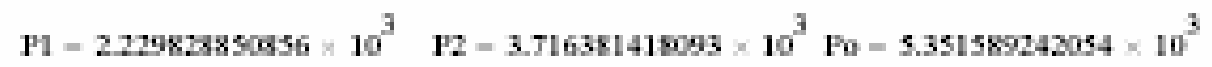

$$
\begin{aligned}
& \text { P_dinulate }=0 \quad \text { R_ndens }-0.18737943672
\end{aligned}
$$

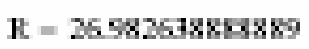

\section{Inductor Current}

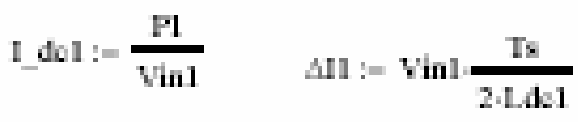

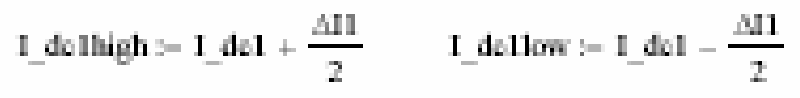

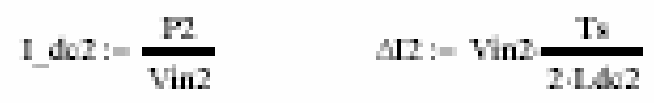

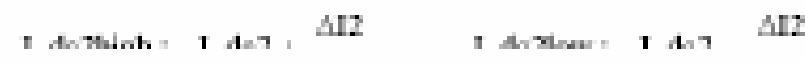




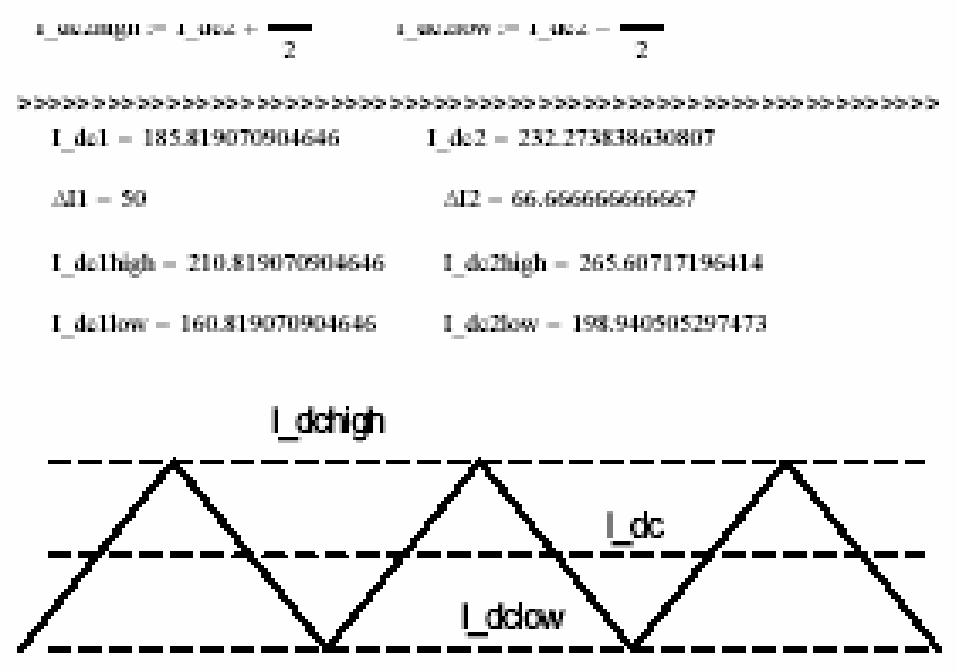

\section{Iransformercaurrent.}

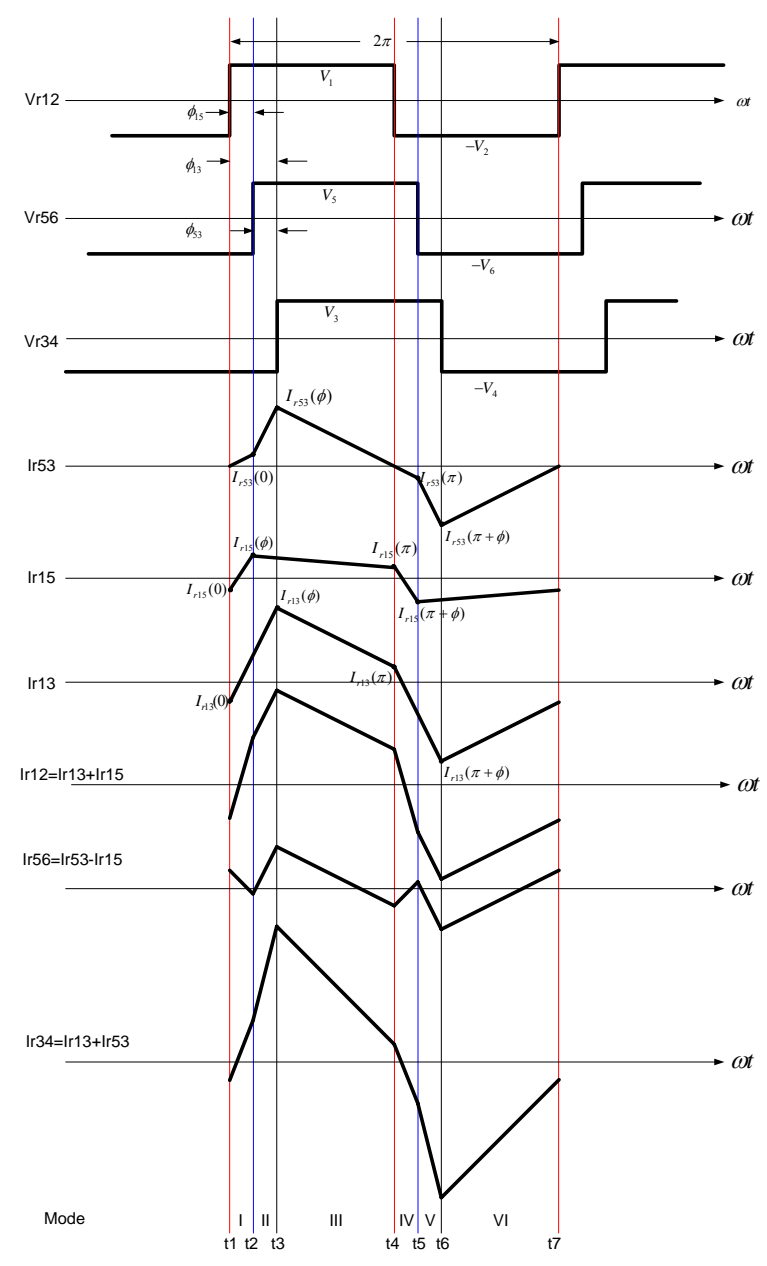


Initial conditions: Ir13

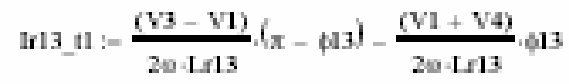

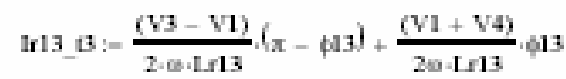

$$
\begin{aligned}
& \text { If13_4 :- - -1613_t1 }
\end{aligned}
$$

Ir13 is : - - - Ir13 13

Initial conditions: Ir15

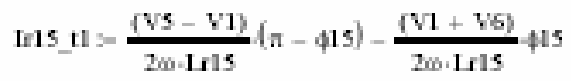

$$
\begin{aligned}
& \text { Ir15_L }=\frac{(\mathrm{V} s-\mathrm{V} 1)}{2+1 \mathrm{n} 15}(\pi-\phi 15)+\frac{(\mathrm{V} 1+\mathrm{V} 6)}{2 \omega \cdot 1 \mathrm{n} 15}+15 \\
& \text { In } 14=- \text { In } 15 \text { t1 } \\
& \text { In15 B :- -In15 D }
\end{aligned}
$$

Mode : t1-12

$$
\begin{aligned}
& \text { if } 13(\mathrm{x}):=\frac{(\mathrm{V} 1+\mathrm{V} 4)}{\omega-\mathrm{L} 13} ; \mathrm{x}+\mathrm{Ir} 13 \mathrm{t} \\
& \operatorname{ir} 53(x)=\frac{(-\mathrm{V} 6+\mathrm{V} 4)}{0.1453}(x-\pi-\phi 13)+\log 5306 \\
& \text { ir } 15(\mathrm{x}):=\frac{(\mathrm{V} 1+\mathrm{V} 6)}{\omega-\mathrm{L} 15} \cdot \mathrm{x}+\mathrm{Ir} 15 \mathrm{t}
\end{aligned}
$$




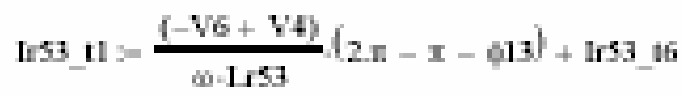

I53 14:- Ins II

Made I: tat3

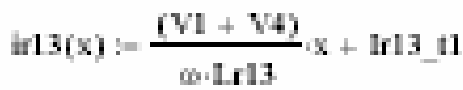

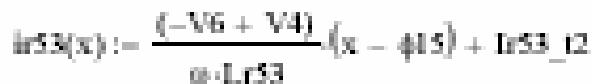

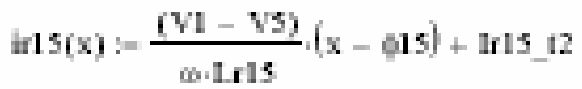

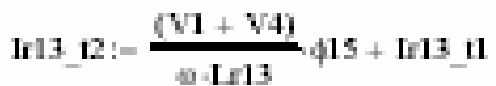

I 13 15:- $-113 \mathrm{n}$

Mode III: th-4

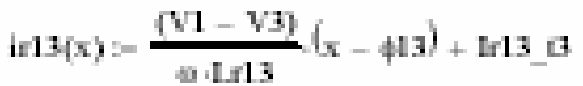

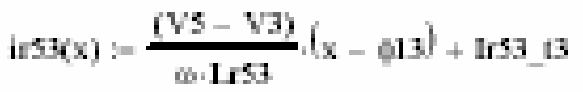

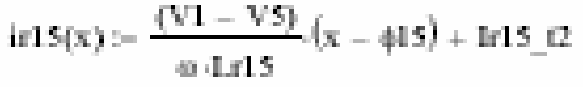

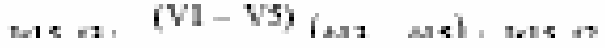




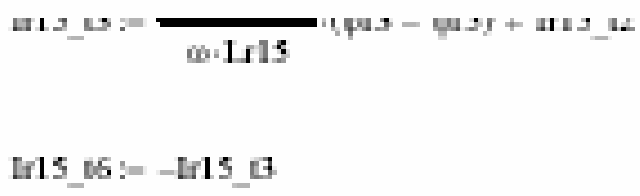

Mode $\mathrm{N}$ : 4

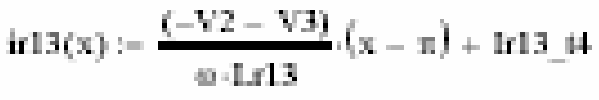

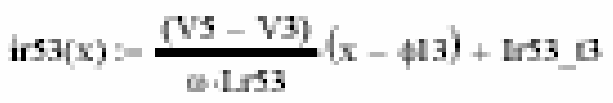

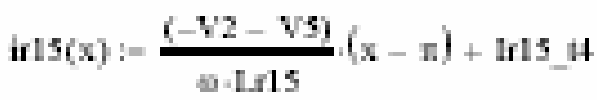

Made vis tos

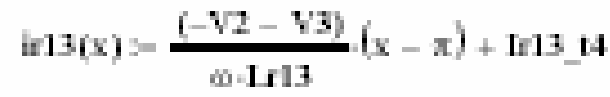

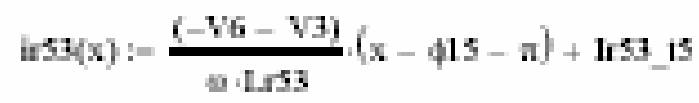

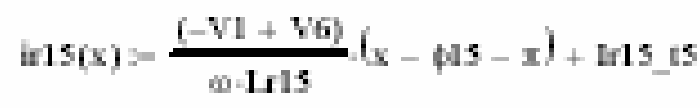

\section{Made va $\mathrm{t} \cdot \mathrm{T}$}

$$
\begin{aligned}
& 413)=\frac{(-\sqrt{2}+14)}{4+13}(x-\pi-43)+413+6 \\
& 454 x):-\frac{(-16+84)}{4+53}(x-413-\pi)+153
\end{aligned}
$$




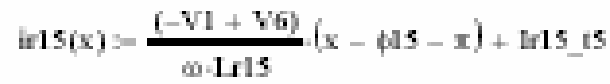

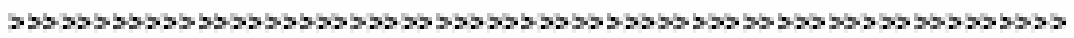

$$
\begin{aligned}
& \mathbf{t}=0 \quad 12:=\phi 15 \frac{\mathrm{Ts}}{2 \mathrm{x}} \quad \mathrm{B}:=\phi 3 \cdot \frac{\mathrm{Ts}}{2 \pi} \quad \mathrm{A}:=\frac{\mathrm{Ts}}{2} \\
& \mathrm{~B} s=(\mathrm{n}+\phi 15) \frac{\mathrm{Ts}}{2 \cdot \pi} \quad 16:=(\mathbf{x}+\phi 13) \cdot \frac{\mathrm{Ts}}{2 \cdot \pi} \quad \text { is }:=\mathrm{Ts}
\end{aligned}
$$

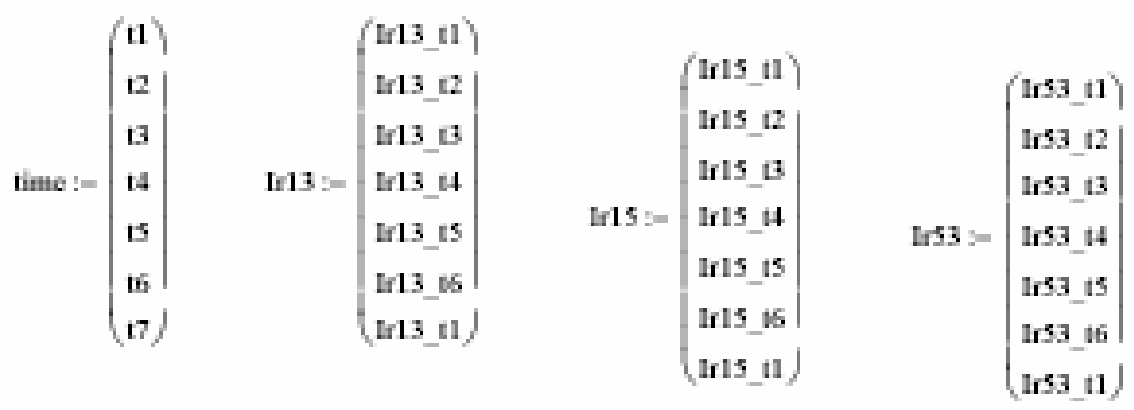




\begin{tabular}{|c|c|c|c|c|c|}
\hline \multirow{7}{*}{$\operatorname{Lin}=$} & $\left(\mathrm{H} 12 \_\mathrm{il}\right)$ & & $\left.\cos \_11\right)$ & & 1140 \\
\hline & $|4| 2 \_12$ & & Lus_ $\mathrm{a}$ & & 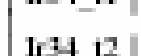 \\
\hline & 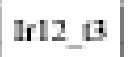 & & Irse 13 & & 15413 \\
\hline & |HII_H & $156:=$ & $\mathrm{L} 5 \mathrm{~s}$ & 1074 & 14 \\
\hline & Iflz is & & ISt is & & 15 \\
\hline & |loly_of & & I 55 & & IIS if \\
\hline & Ir $12 \_$i1 & & 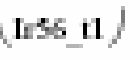 & & III 11 \\
\hline
\end{tabular}

Soft switahing osnditions

\begin{tabular}{|c|c|c|}
\hline 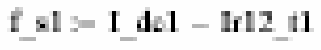 & 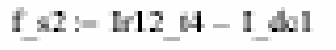 & f_a:-1134_a \\
\hline$=4=-113+16$ & 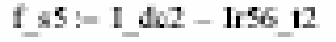 & 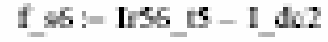 \\
\hline
\end{tabular}

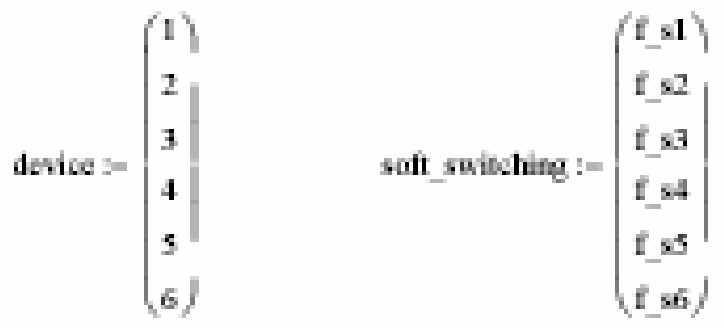




\section{RMS cument for devices}

\section{Deves 51}

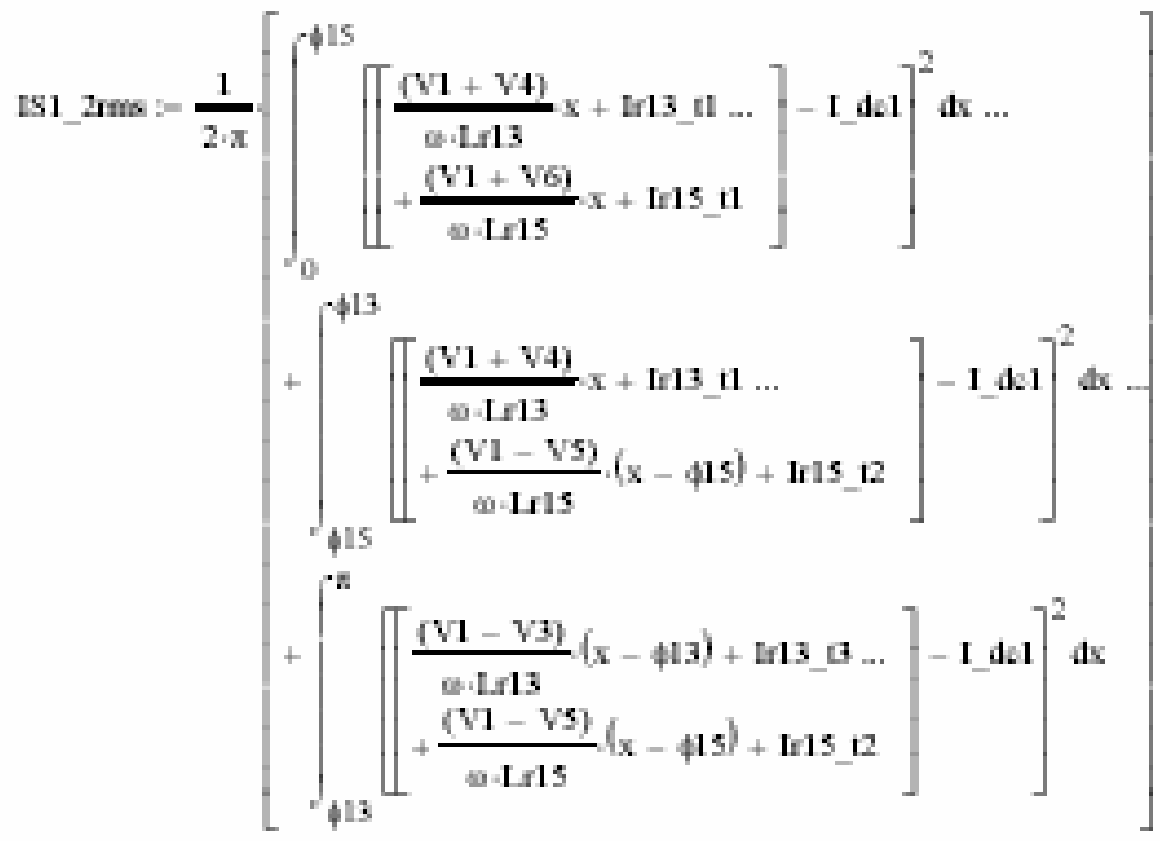

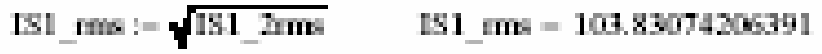

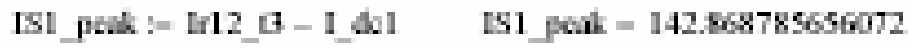
D1_pol 3- Ir12_1 - I_dEI D1_pale $=-40570497147514$

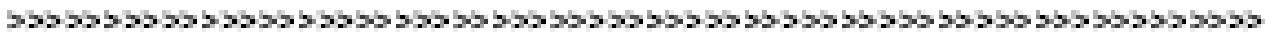




\section{Device 52}

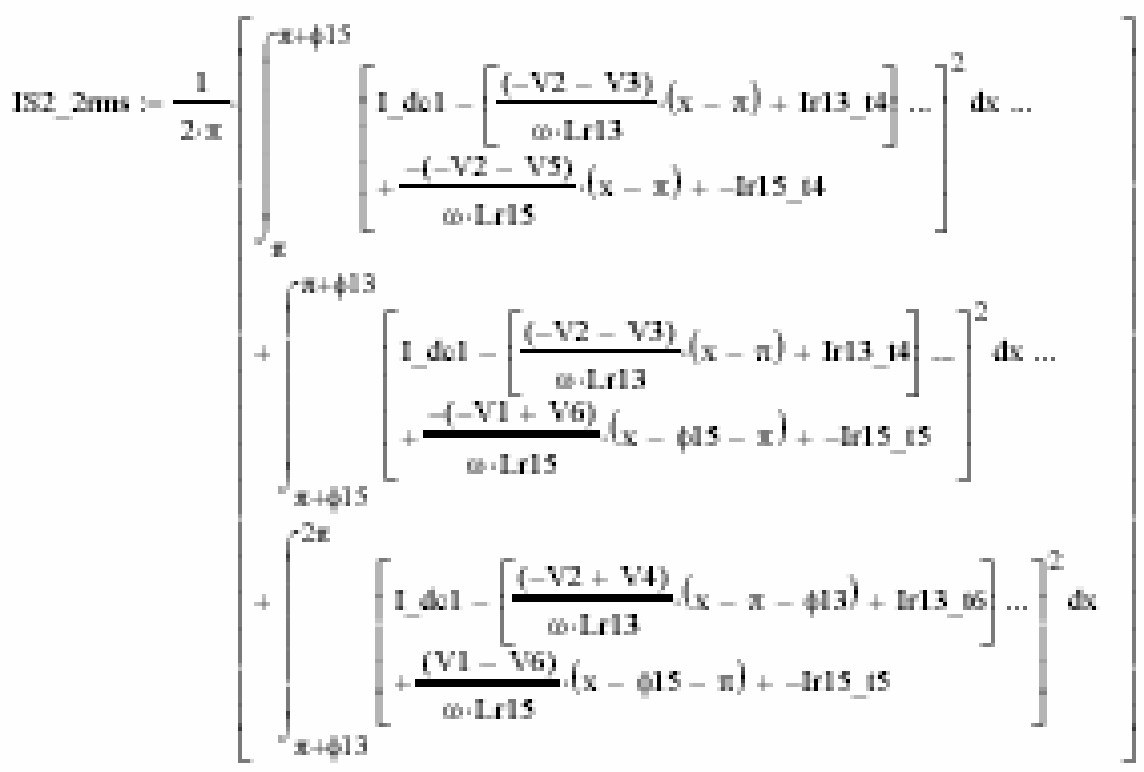

\section{Device 53}

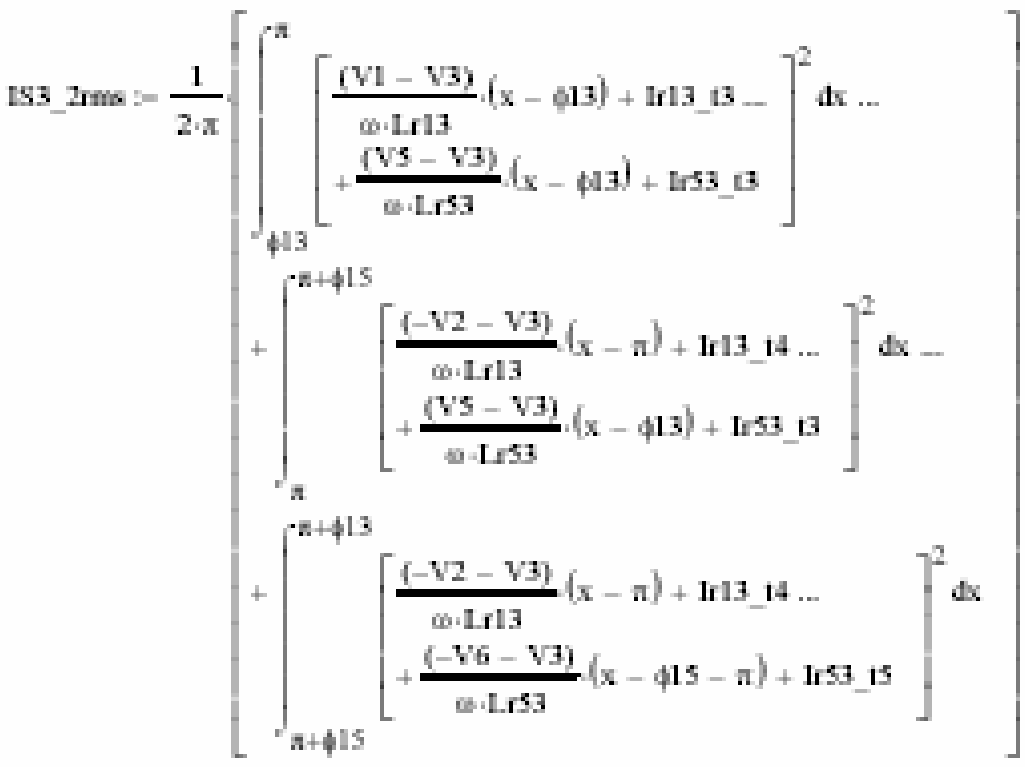




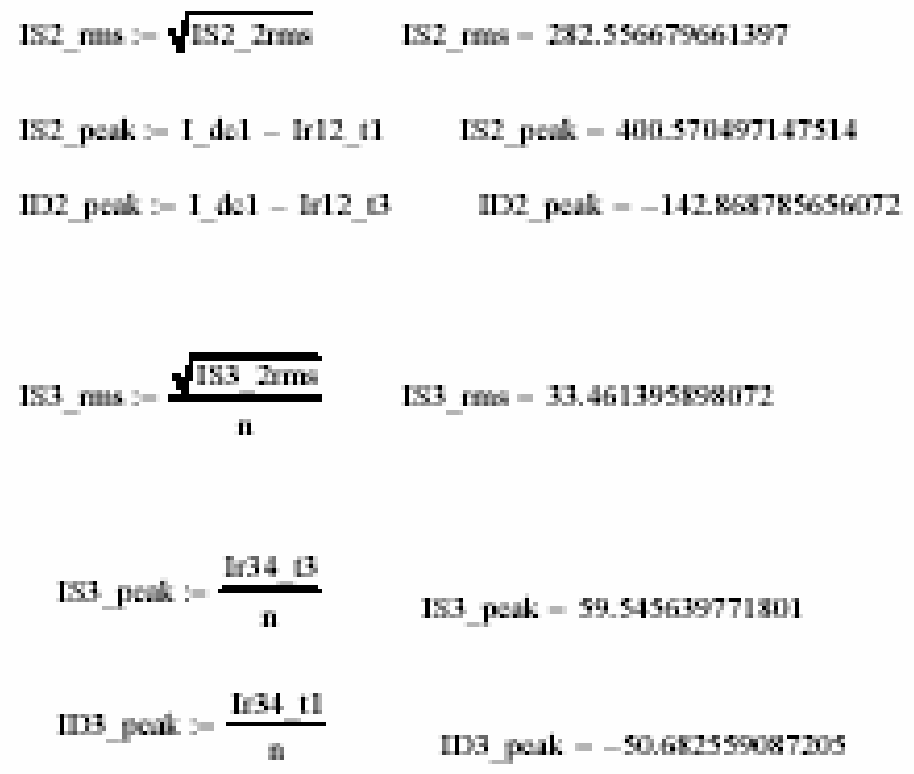

\section{Device 45}

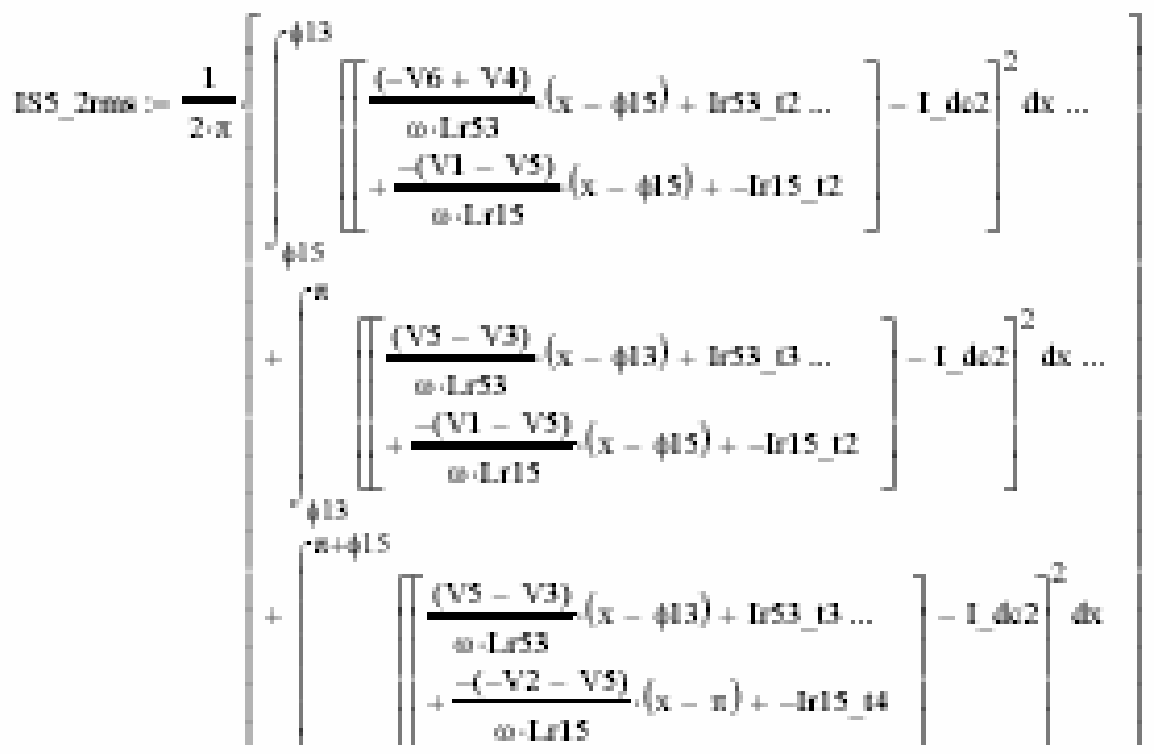


L

\section{Deves sb}

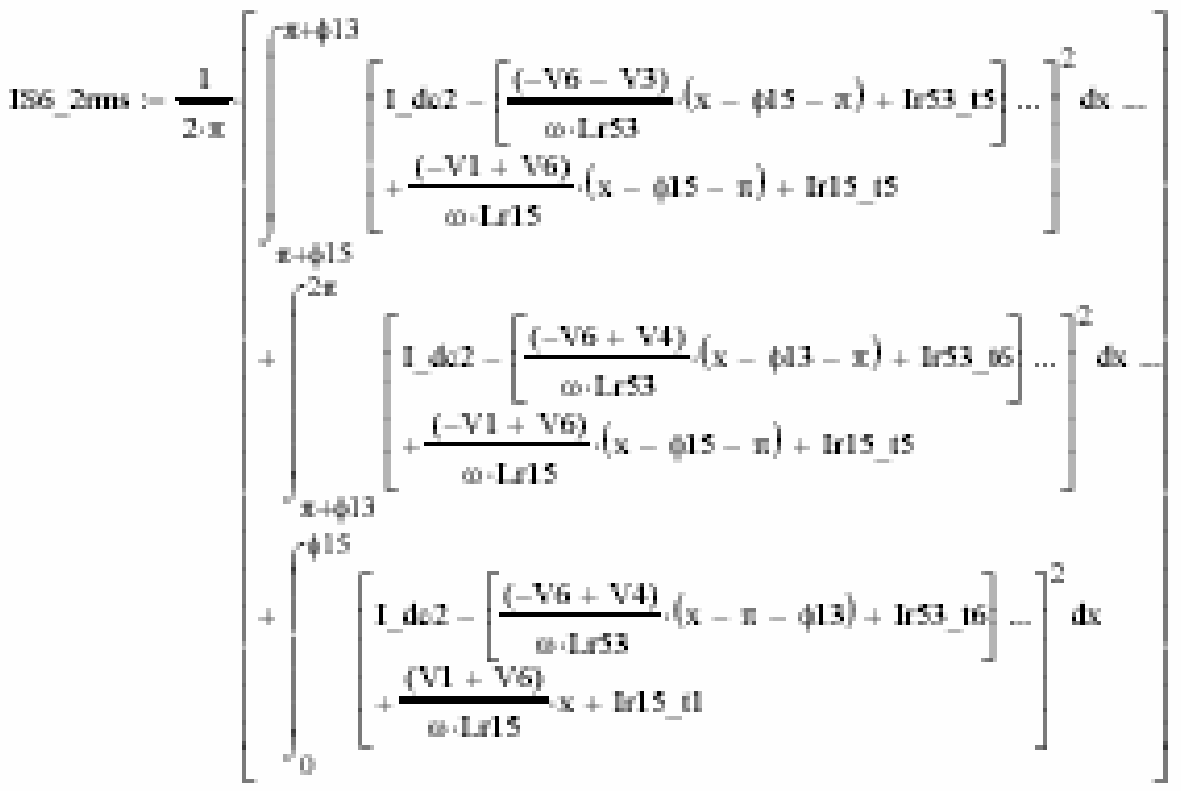

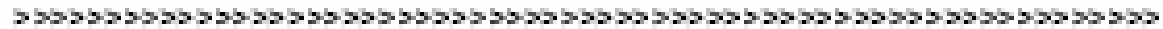

159 n.

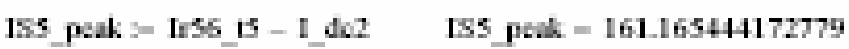

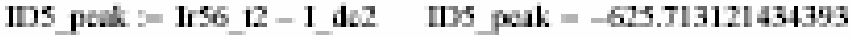

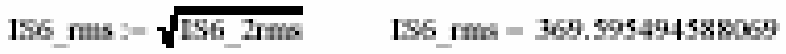

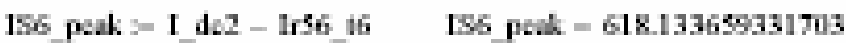

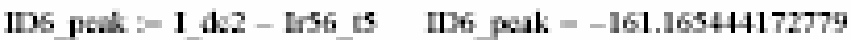


154_mis := IS3_rms IS4_peak := 153_peak: TD4_peak :- ID3_peak

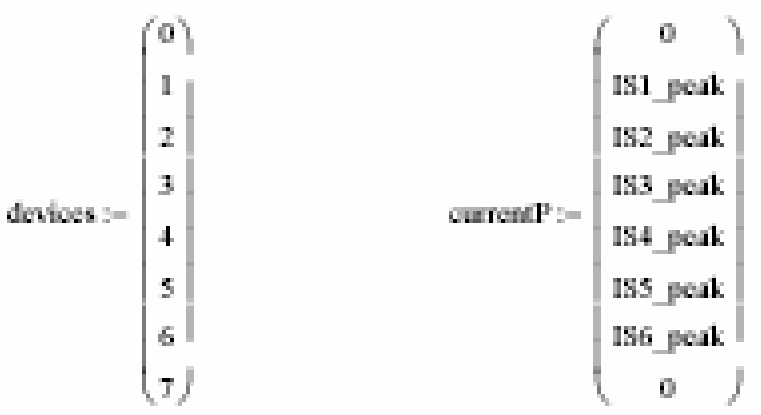

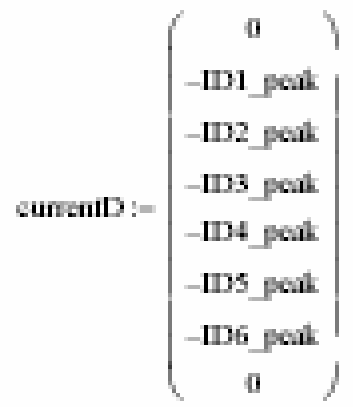

curentR : $=\left(\begin{array}{c}0 \\ 181 \text { mms } \\ 152 \text { mms } \\ 153 \text { mms } \\ 154 \text { mms } \\ 155 \text { nms } \\ 156 \text { mms } \\ 0\end{array}\right)$




\section{SUMMARY OF DESIGN REPORT}

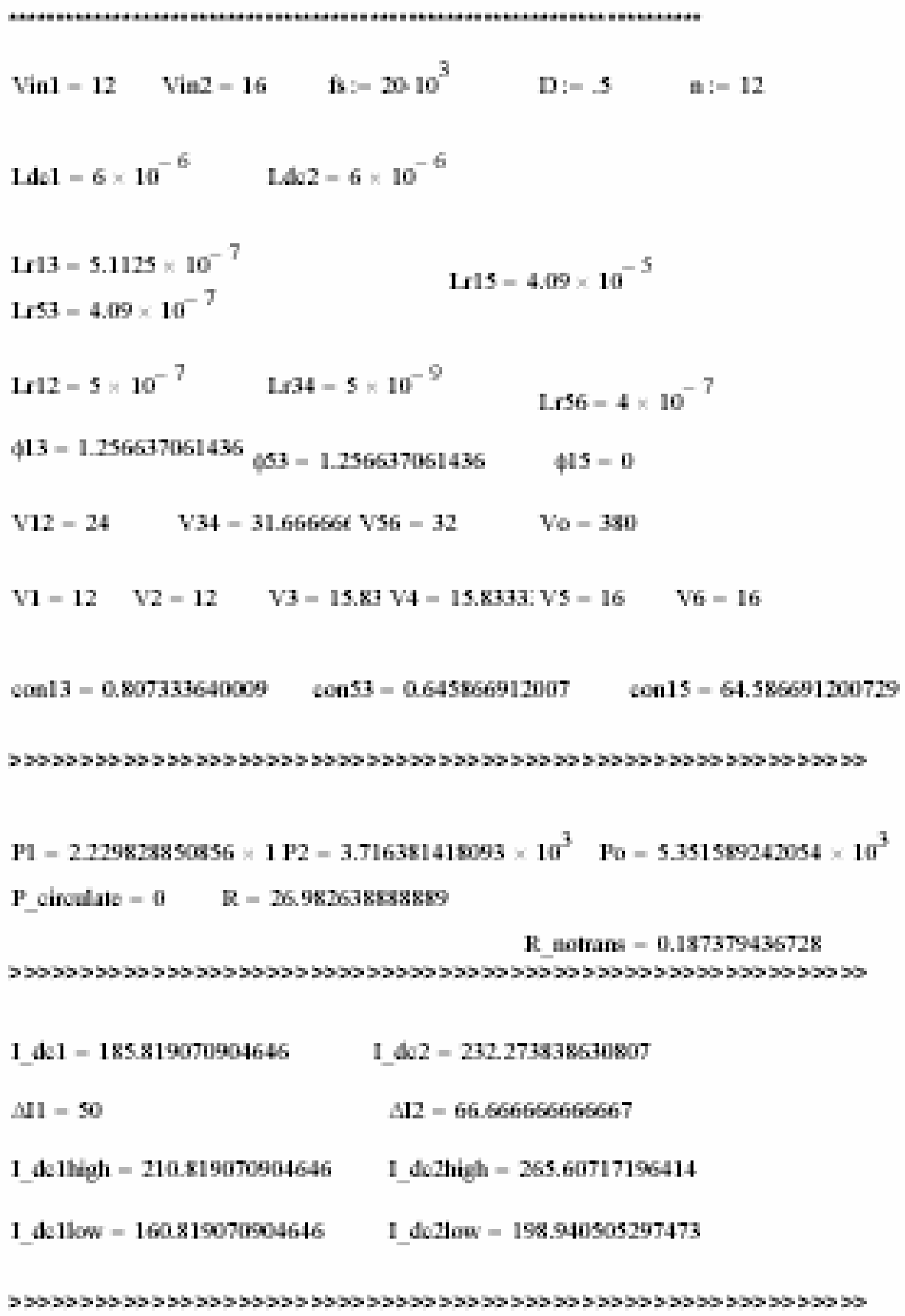




\begin{tabular}{|c|c|c|c|c|c|c|c|c|}
\hline Lo13 in & $\| \mathbf{l} 13$ & Ir13_13 & If13 14 & 4 II1 1 & Ir13 th & $(-215.97392013030$ & -215973920130350 & $32 \mathrm{E}$ \\
\hline Er15_t1 & Mrls it: & $\operatorname{lr} 15$ & 3 IrIs 14 & $4 \operatorname{Ir} 15$ & In15 th & $1.2224534 \times 531$ & 122245387531 & a24 \\
\hline Ess it & 153 & $1,53 i$ & 11331 & $4 \ln 31$ & Ins3 $\mathrm{w}$ & -32.167851605s & -3921678516055 & 3w5 \\
\hline Lf12 i1] & $\mathbb{1 1 2}$ & lil2 i & I 12 I & $4 \mathrm{In} 12 \mathrm{~s}$ & 1912 65 & $-214.7514262428 \%$ & $-21+751426242860$ & $32 \pi$ \\
\hline 11] & 156 & 156 & $\ln 5$ & $4 \ln \mathrm{N}$ & ISs_t6 & -303.430260356 & -3934302a2wosk & 1 \\
\hline 134 & 1134 & 1134 & II 34 & $4 \mathrm{I} 34 \mathrm{H}$ & Ins thi & -6s.150704046ss & -60k 1907094645 & \\
\hline
\end{tabular}

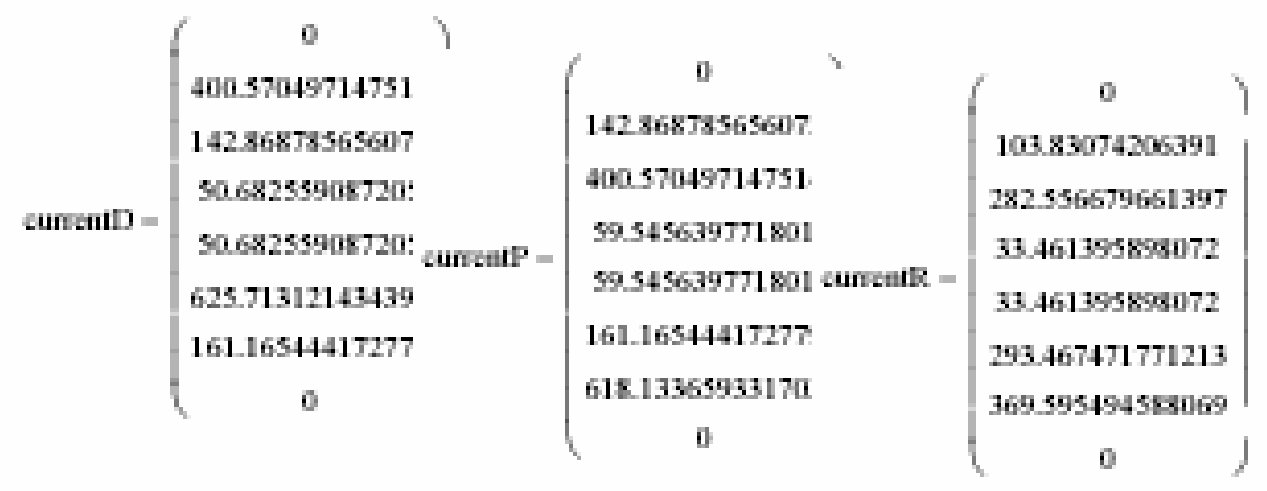

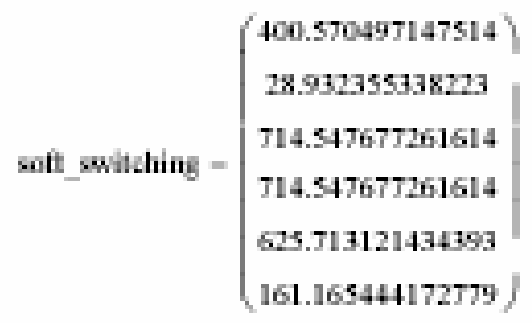

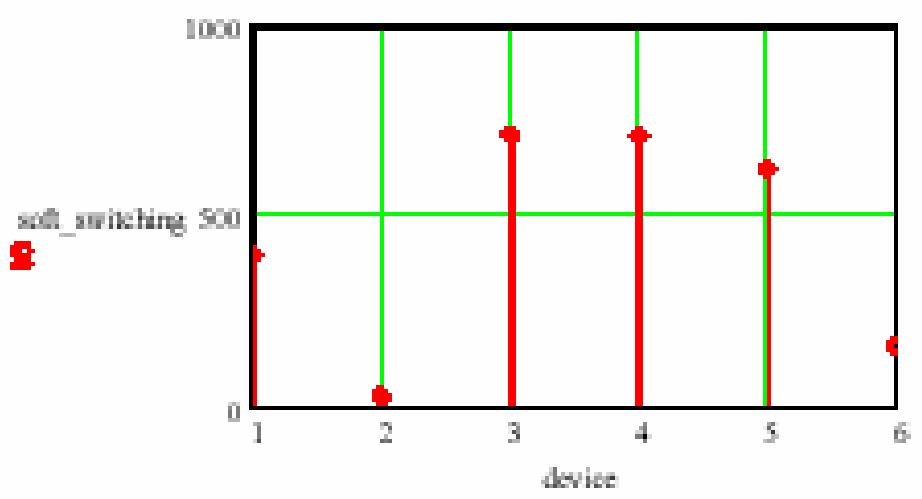



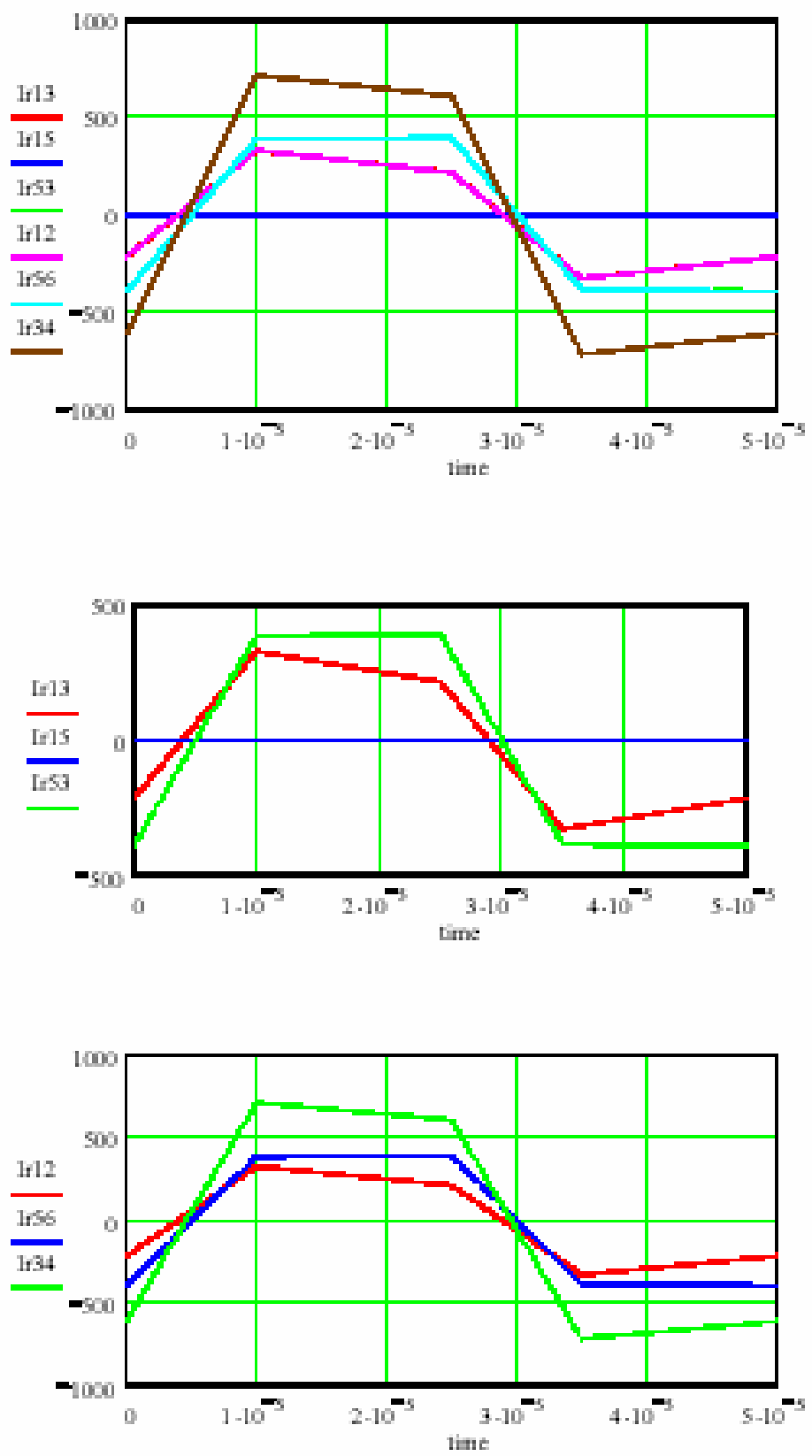

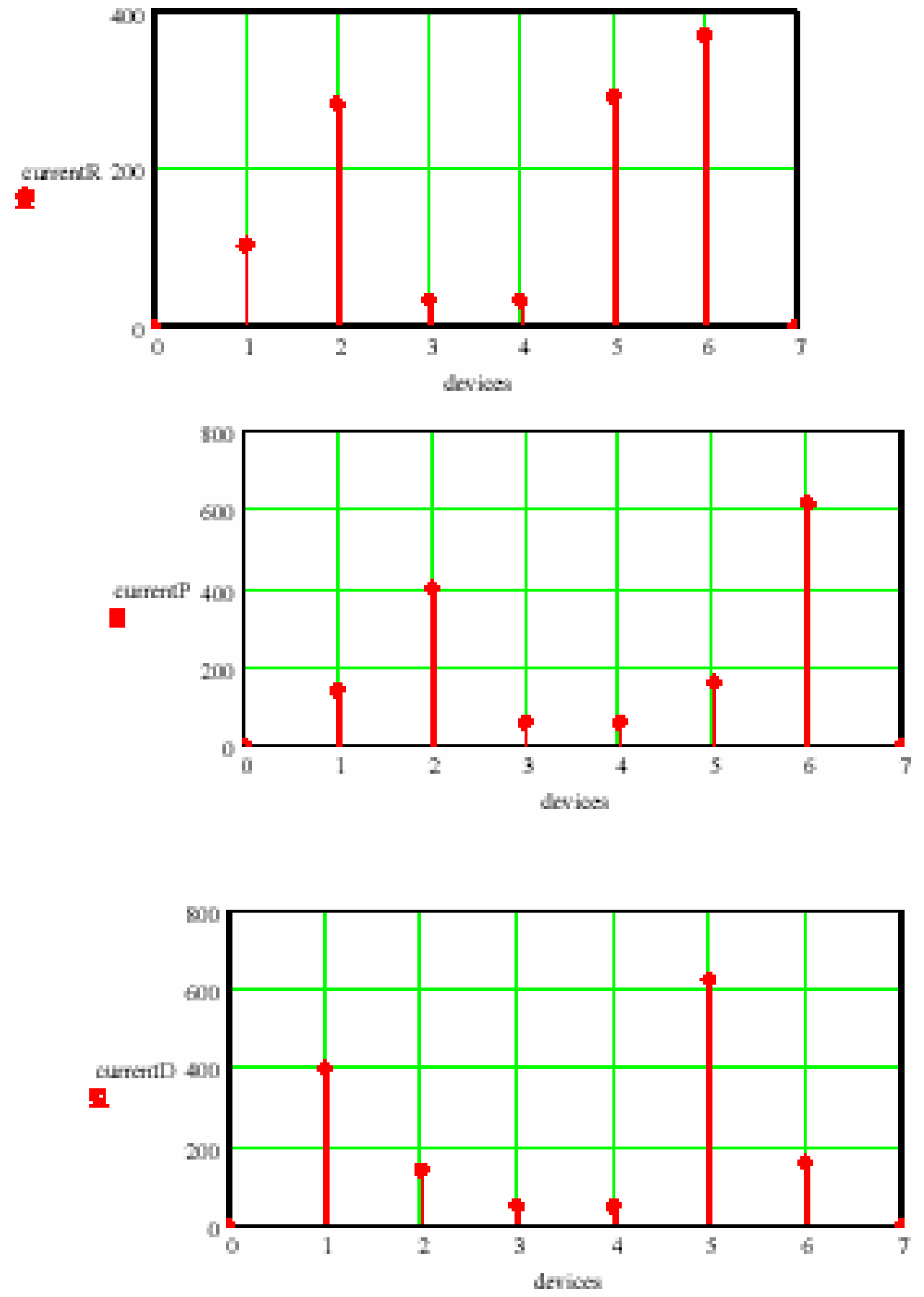


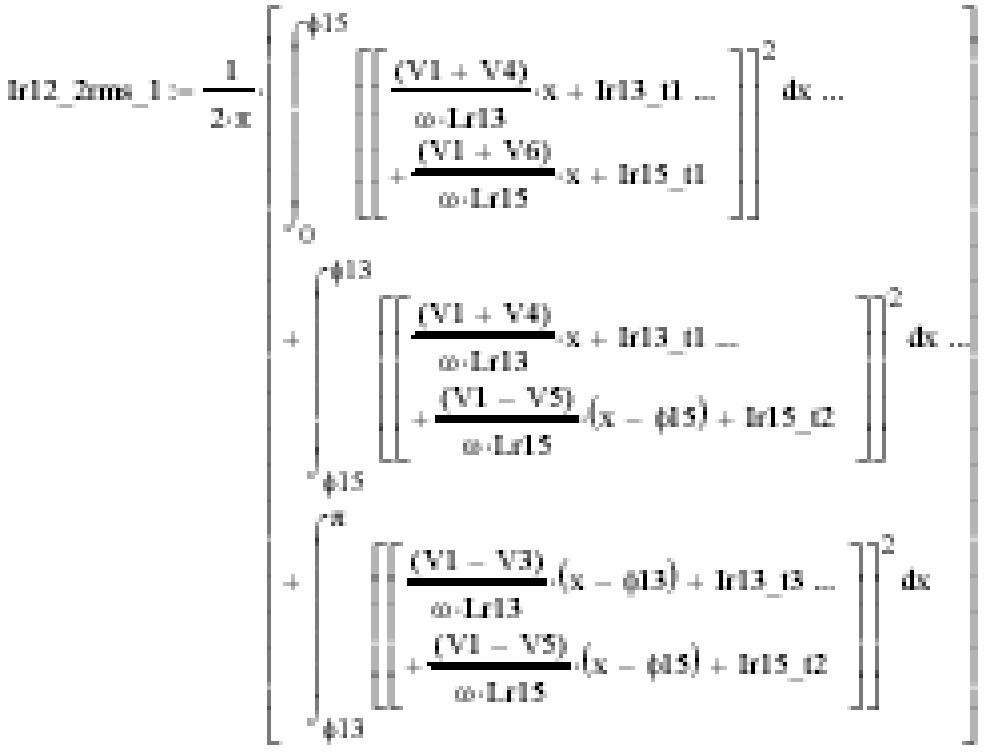

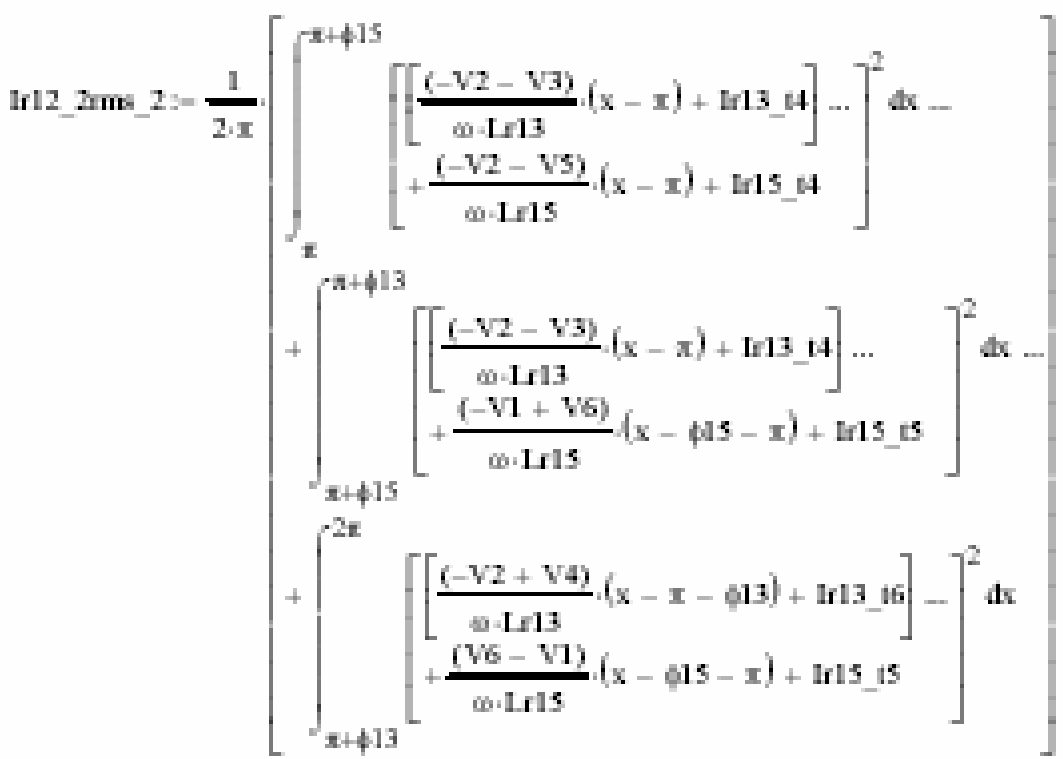

1r12_2ms :- 1r12_2ms_1 + 1r12_2ms_2 
1r12_mus :- $\sqrt{1 \mathrm{r} 12 \_2 \mathrm{~mm}}$

Lr12 $\mathrm{mms}=236.834062387466$

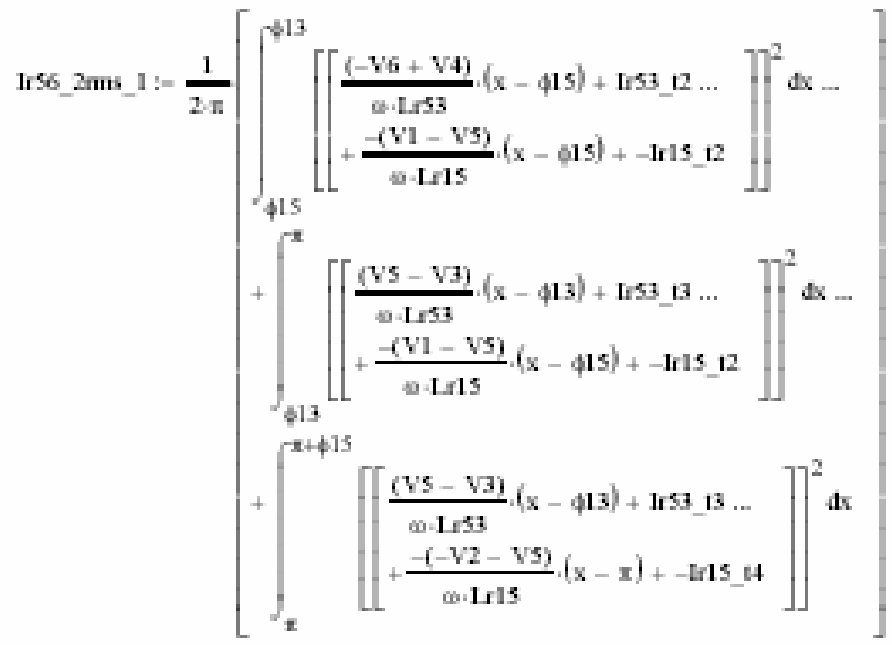

\section{Device S6}

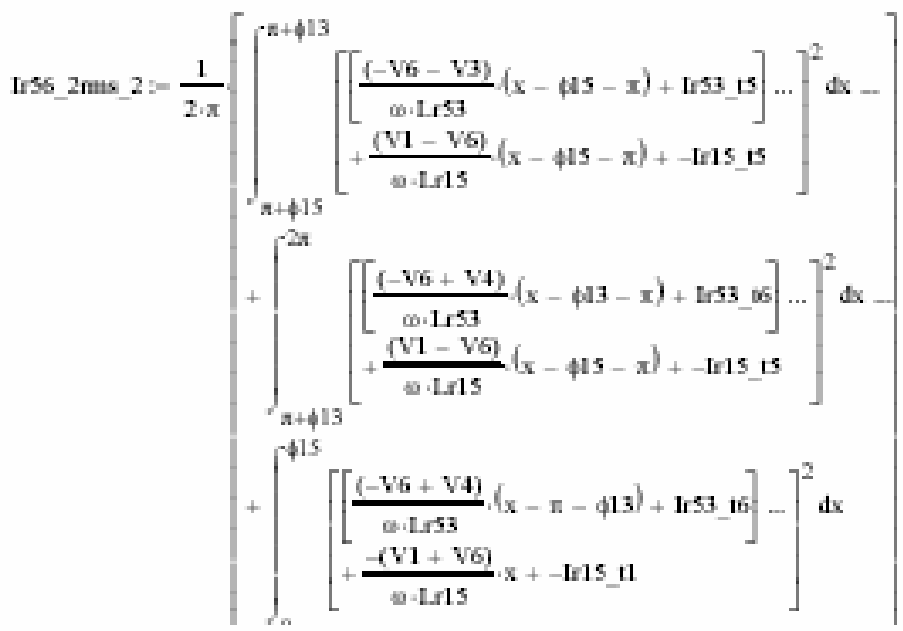

L - "

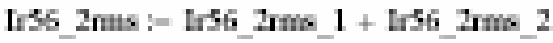

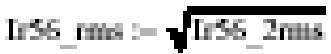

IS5 mu - 36.90452 war3 
APPENDIX B: CIRCUIT SCHEMATICS

\section{CIRCUIT BLOCK DIAGRAM}

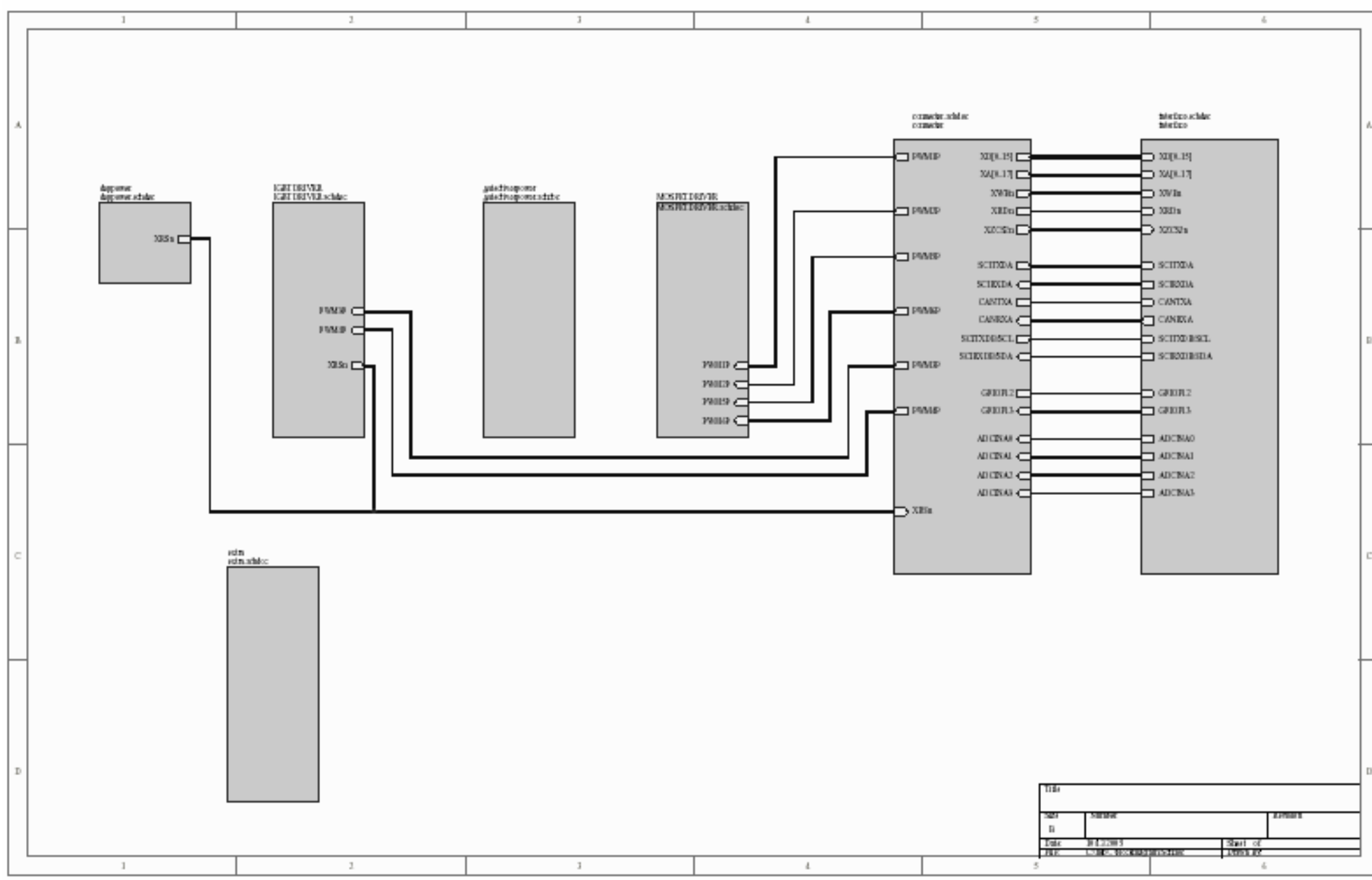




\section{CONNECTOR CIRCUIT}

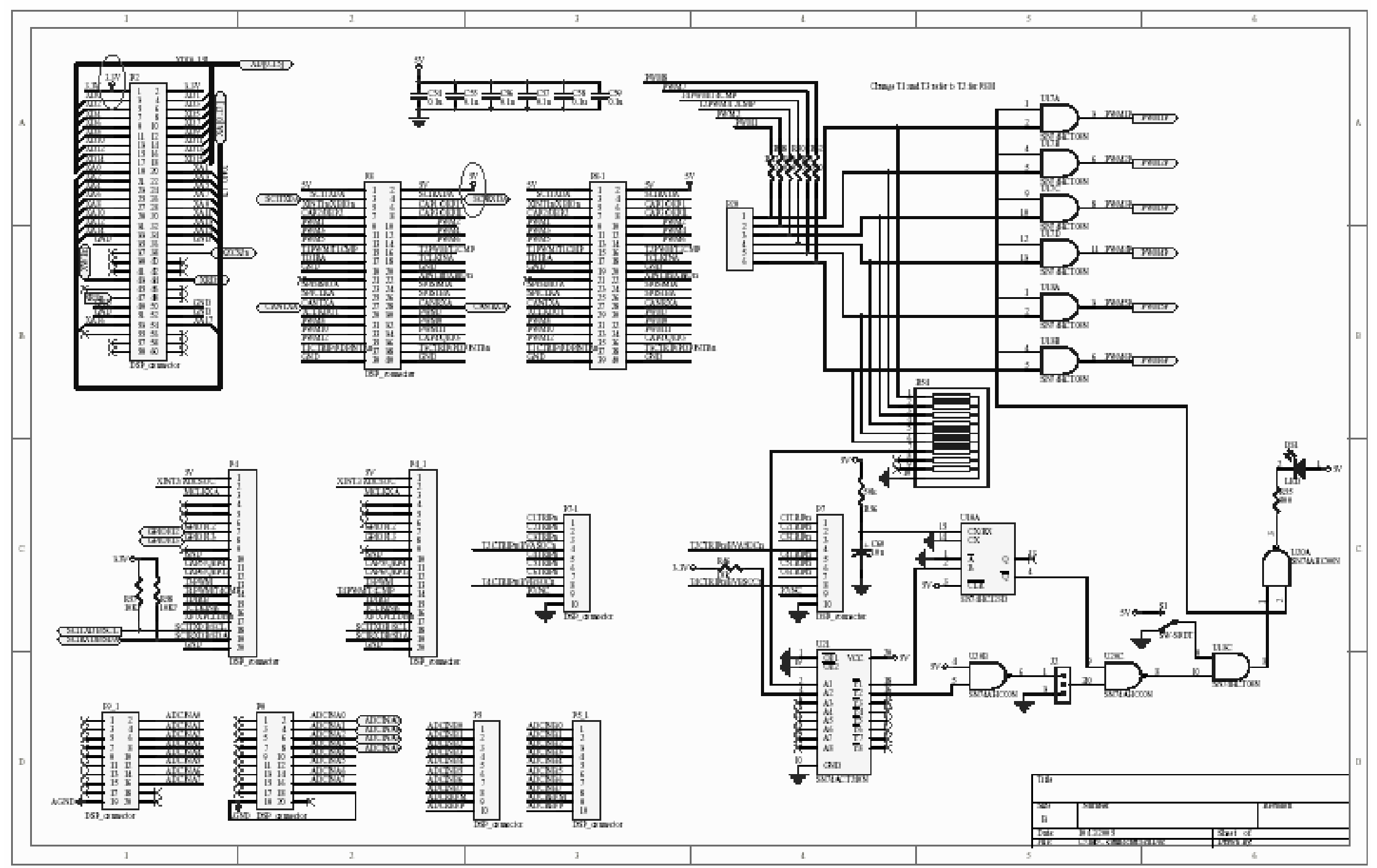




\section{AUXILIARY CONTROL POWER CIRCUIT FOR DSP}

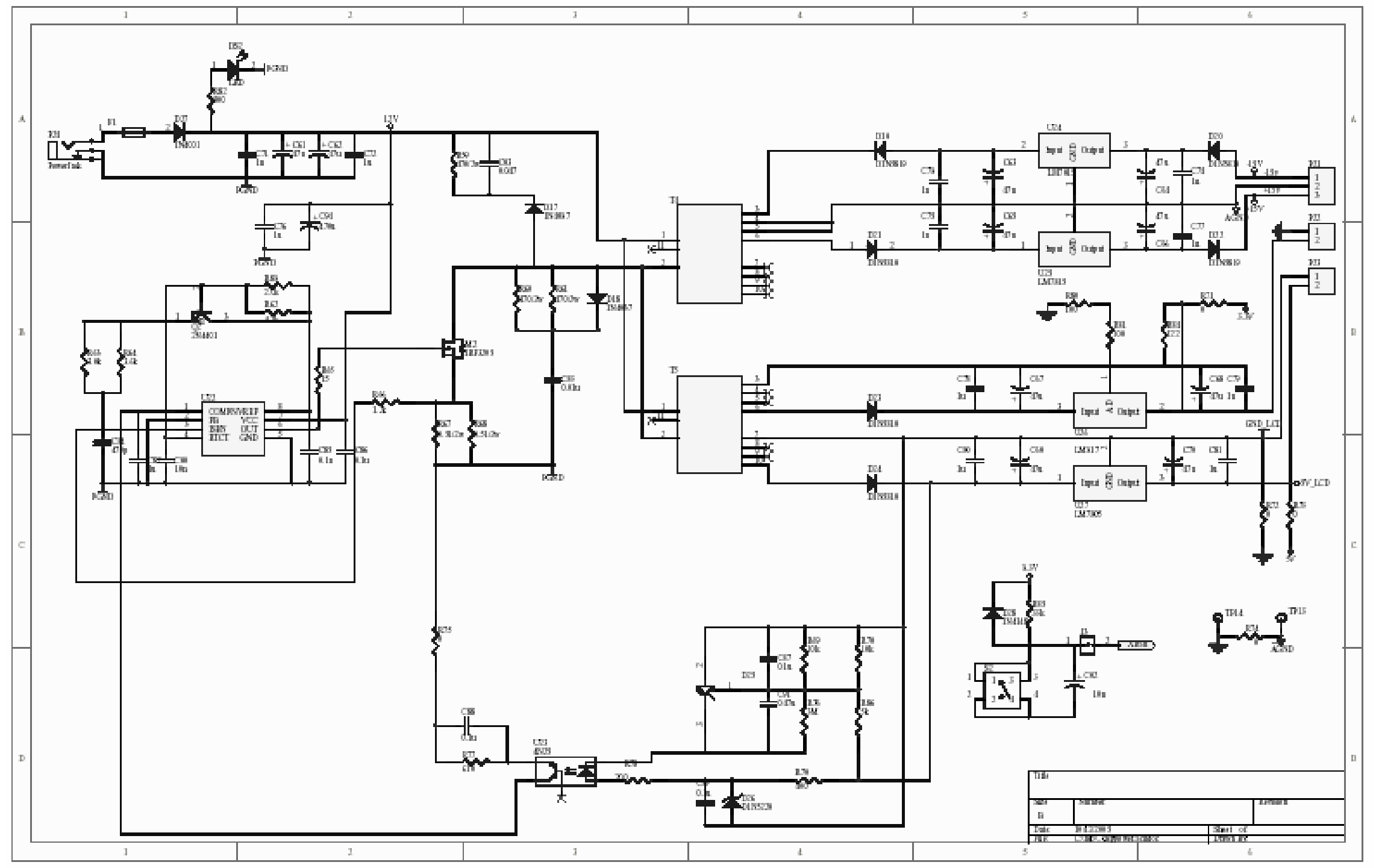


4. AUXILIARY CONTROL POWER CIRCUIT FOR GATE DRIVERS

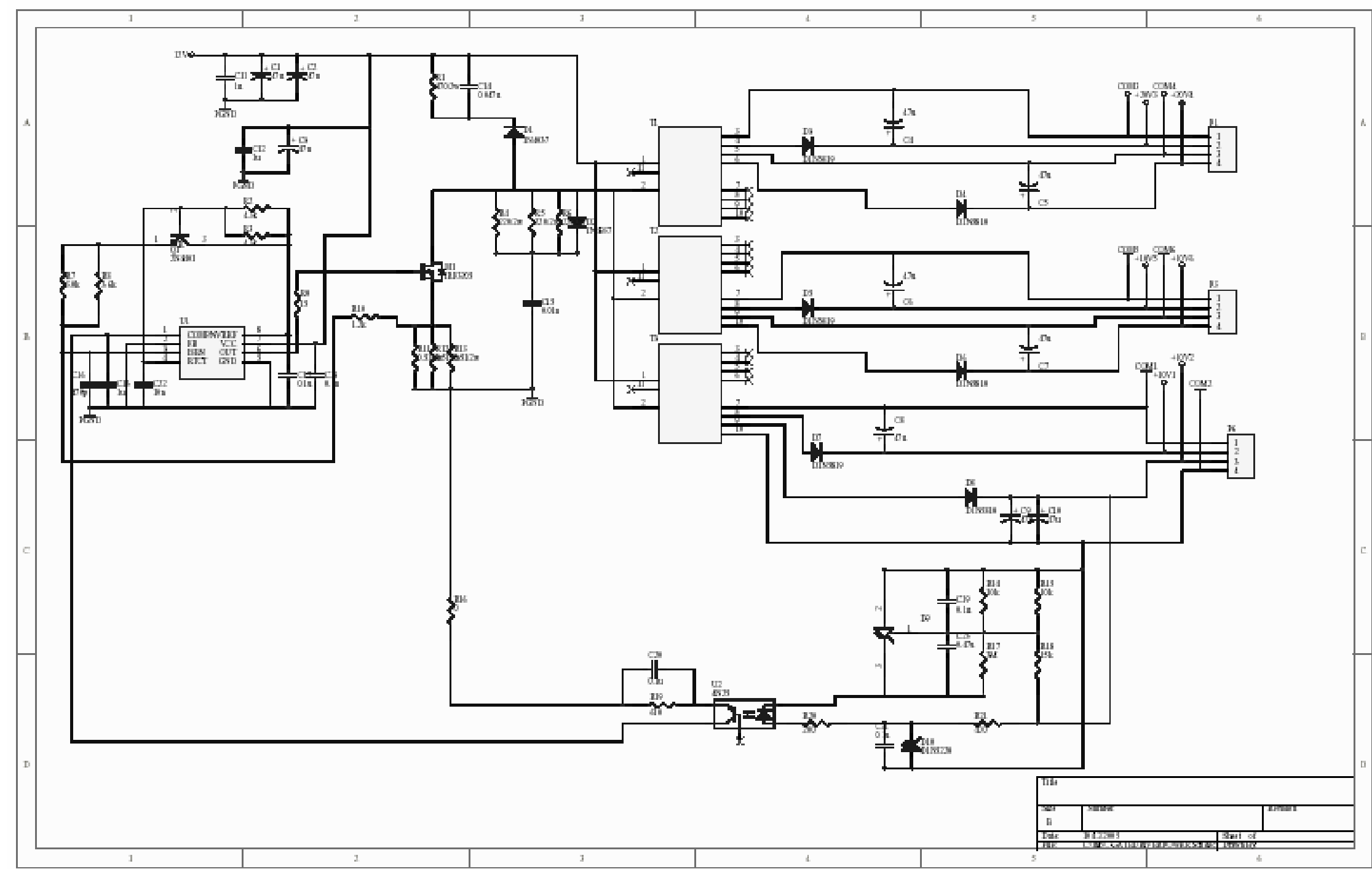


5. IGBT DRIVER

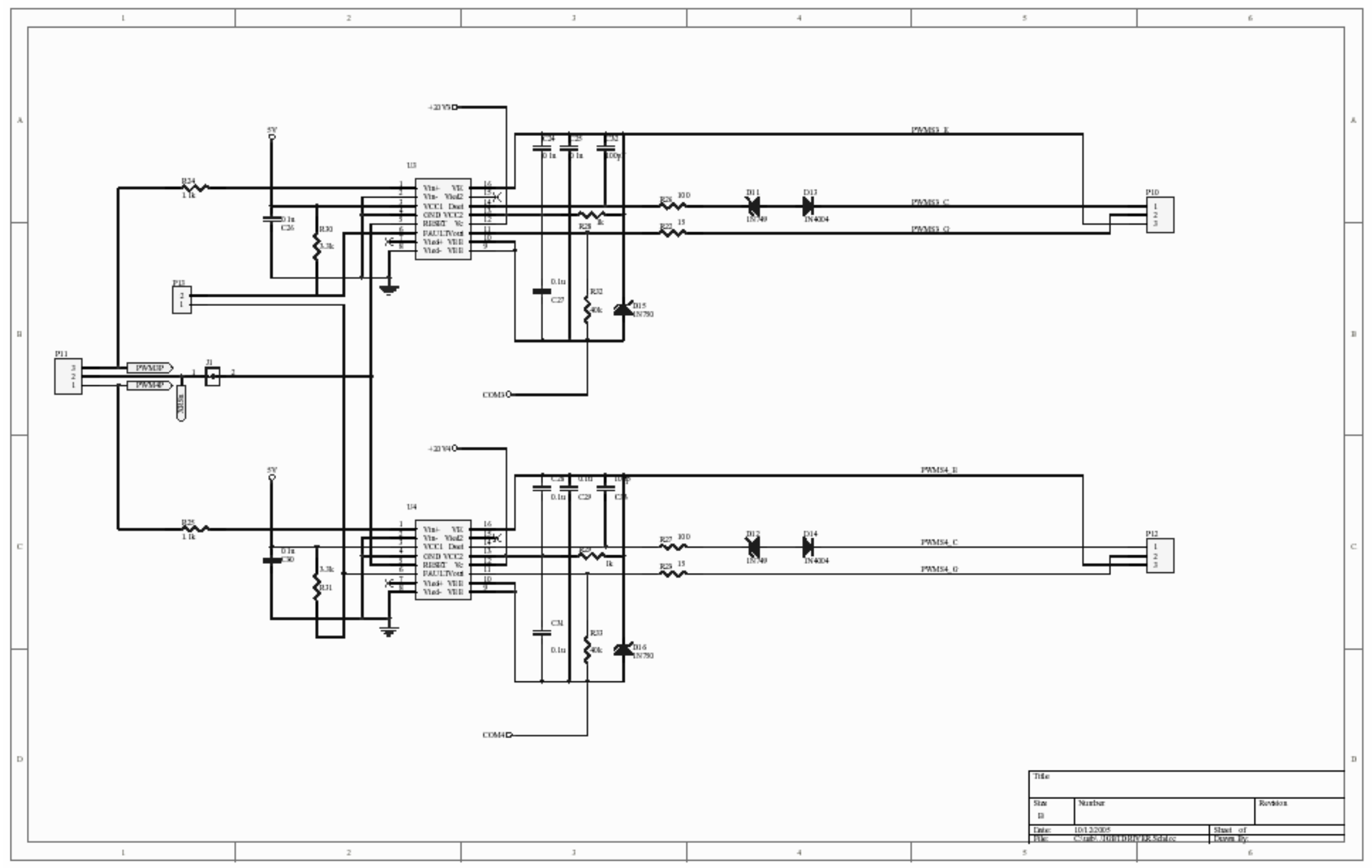


6. INTERFACE CIRCUIT

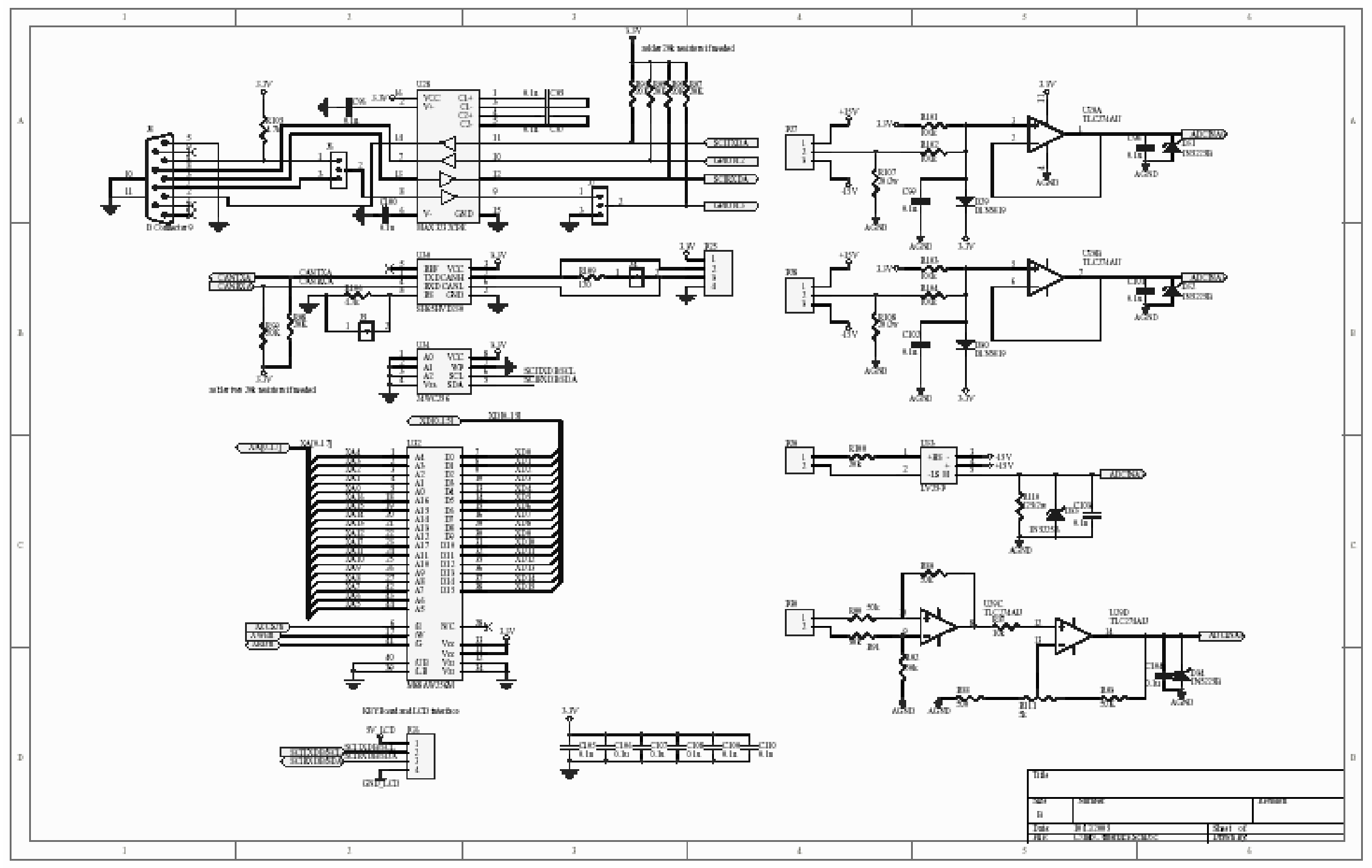




\section{MOSFET DRIVER}

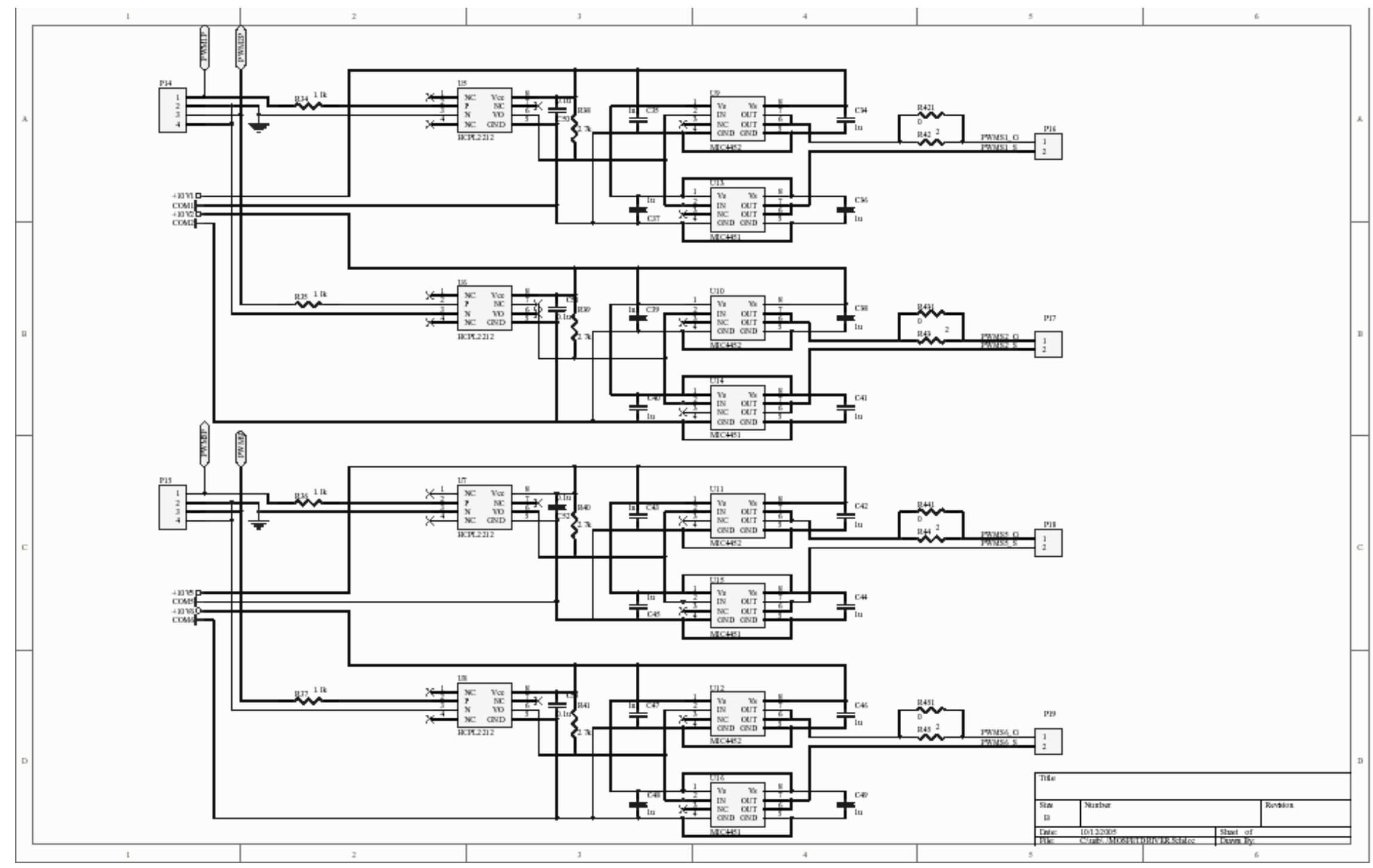




\section{APPENDIX C: PHOTO OF PROTOTYPE}

\section{PHOTO OF THE DSP AND GATE-DRIVER BOARD}

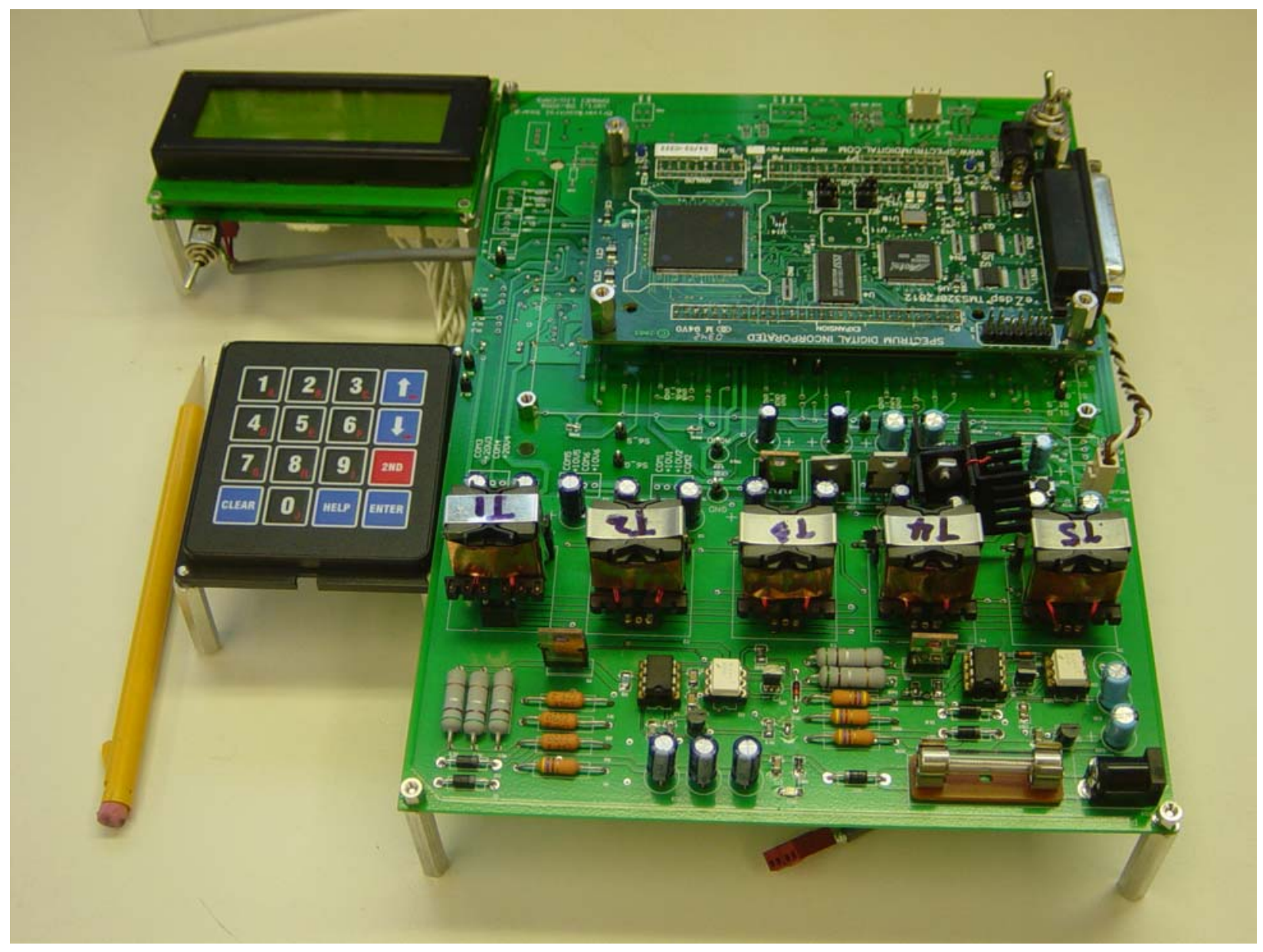


2. PHOTO OF THE PROTOTYPE

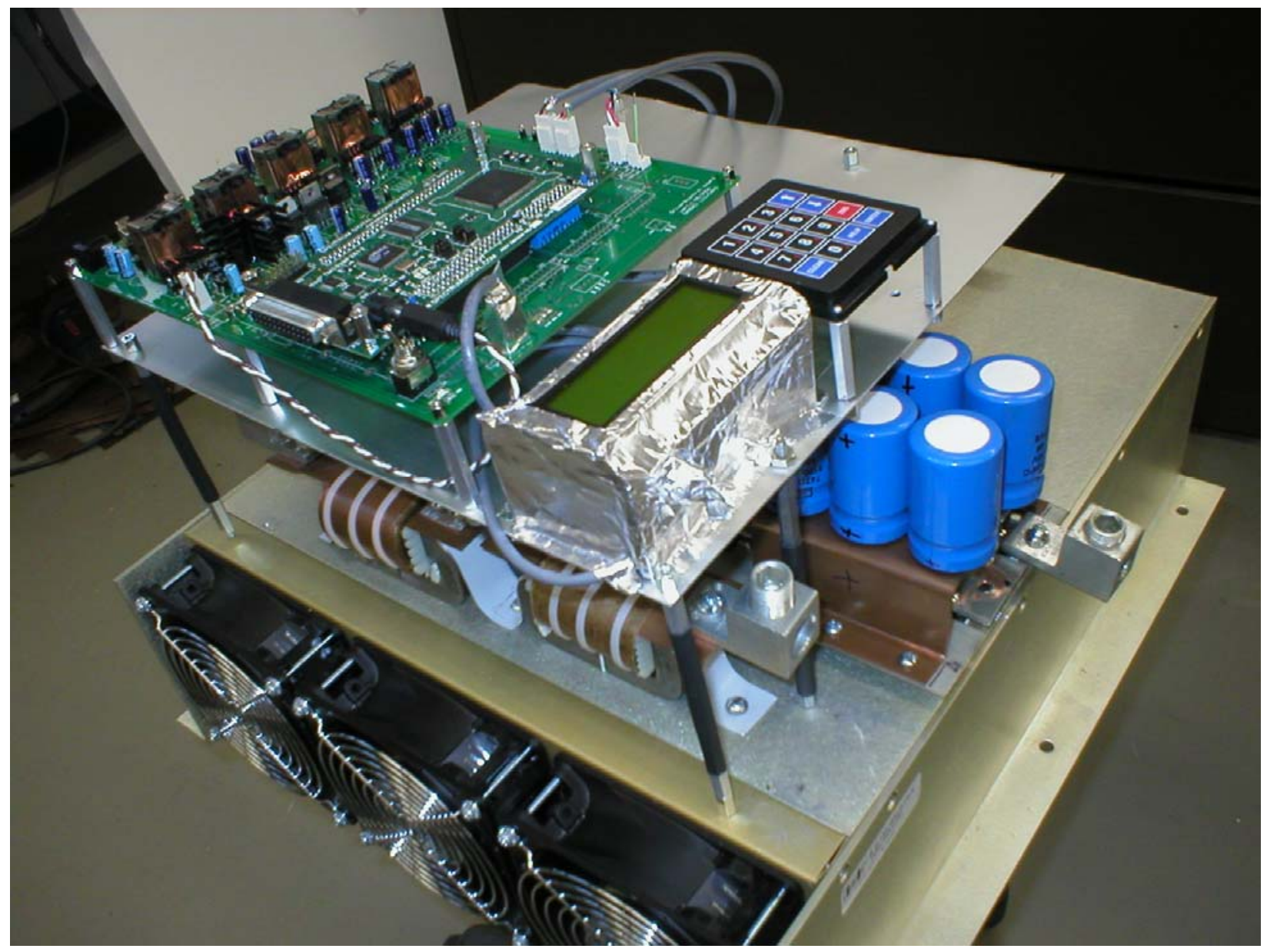




\section{PHOTO OF THE EXPERIMENTAL SETUP}

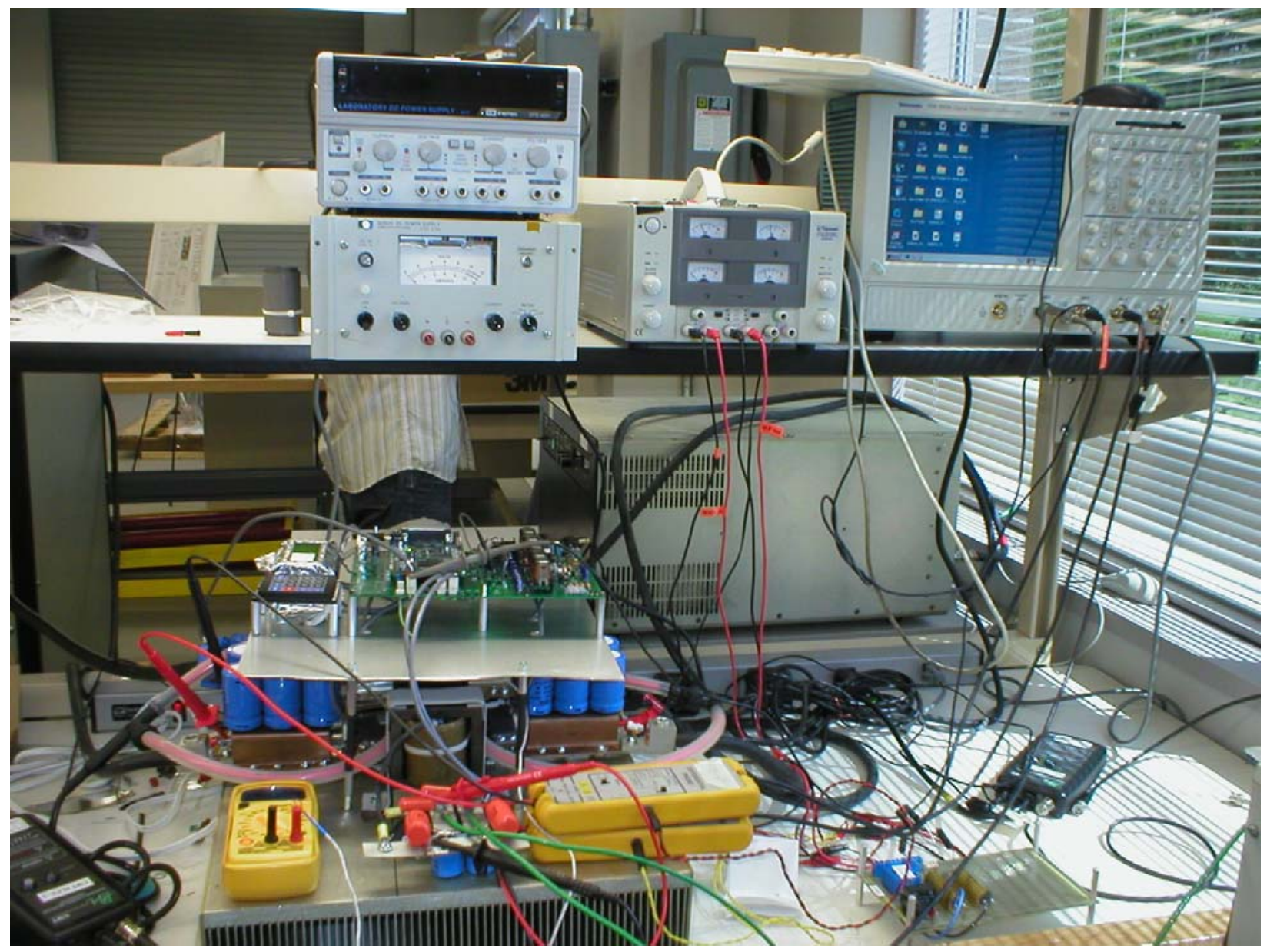




\section{DISTRIBUTION}

Internal

\author{
1. D. J. Adams \\ 2. K. P. Gambrell \\ 3. E. C. Fox \\ 4. H. Li
}

\author{
6. L. D. Marlino \\ 7. M. Olszewski \\ 7-8. Laboratory Records
}

\section{External}

9. T. Q. Duong, U.S. Department of Energy, EE-2G/Forrestal Building, 1000 Independence Avenue, S.W., Washington, D.C. 20585.

10. R. R. Fessler, BIZTEK Consulting, Inc., 820 Roslyn Place, Evanston, Illinois 60201-1724.

11. K. Fiegenschuh, Ford Motor Company, Scientific Research Laboratory, 2101 Village Road, MD-2247, Dearborn, Michigan 48121.

12. V. Garg, Ford Motor Company, 15050 Commerce Drive, North, Dearborn, Michigan 48120-1261.

13. E. Jih, Ford Motor Company, Scientific Research Laboratory, 2101 Village Road, MD1170, Rm. 2331, Dearborn, Michigan 48121.

14. A. Lee, Daimler Chrysler, CIMS 484-08-06, 800 Chrysler Drive, Auburn Hills, Michigan 48326-2757.

15. F. Liang, Ford Motor Company, Scientific Research Laboratory, 2101 Village Road, MD1170, Rm. 2331/SRL, Dearborn, Michigan 48121.

16. M. W. Lloyd, Energetics, Inc., 7164 Columbia Gateway Drive, Columbia, Maryland 21046.

17. Brenda Medellon, USCAR, brenda@uscar.org

18. M. Mehall, Ford Motor Company, Scientific Research Laboratory, 2101 Village Road, MD-2247, Rm. 3317, Dearborn, Michigan 48124-2053.

19. J. Rogers, Chemical and Environmental Sciences Laboratory, GM R\&D Center, 30500 Mound Road, Warren, Michigan 48090-9055.

20. S. A. Rogers, U.S. Department of Energy, EE-2G/Forrestal Building, 1000 Independence Avenue, S.W., Washington, D.C. 20585.

21. G. S. Smith, General Motors Advanced Technology Center, 3050 Lomita Boulevard, Torrance, California 90505.

22. E. J. Wall, U.S. Department of Energy, EE-2G/Forrestal Building, 1000 Independence Avenue, S.W., Washington, D.C. 20585.

23. B. Welchko, General Motors Advanced Technology Center, 3050 Lomita Boulevard, Torrance, California 90505.

24. P. G. Yoshida, U.S. Department of Energy, EE-2G/Forrestal Building, 1000 Independence Avenue, S.W., Washington, D.C. 20585. 